\title{
Role of Smad-interacting Protein 1 (Sip1/Zfhx1b) in the development of the cerebral cortex
}

\section{$\mathrm{PhD}$ thesis}

in partial fulfillment of the requirements

for the degree of Doctor of Philosophy (PhD)

in the Graduate Neuroscience Program

at the Georg August University Göttingen

Faculty of Biology

\author{
submitted by \\ Amaya Miquelajáuregui Graf
}

born in

Mexico City, Mexico

Göttingen, 2006 


\section{Declaration}

This thesis has been written independently and with no other sources and aids than quoted.

Amaya Miquelajáuregui Graf

Göttingen, $21^{\text {st }}$ March, 2006. 


\section{Contents}

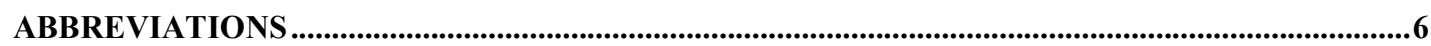

ABSTRACT

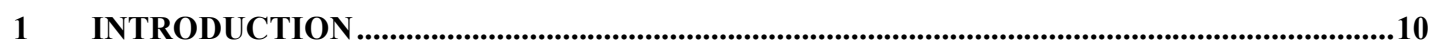

1.1 SIGNALING CENTERS IN THE DORSAL TELENCEPHALON ……...................................................... 10

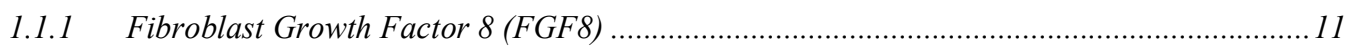

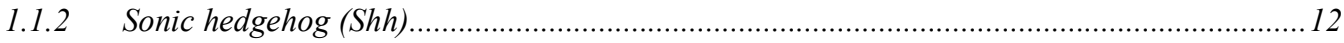

1.1.3 Bone Morphogenetic Proteins (BMPs) ……………………………………………..... 12

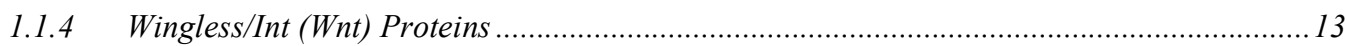

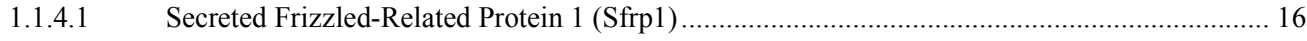

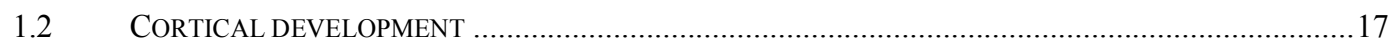

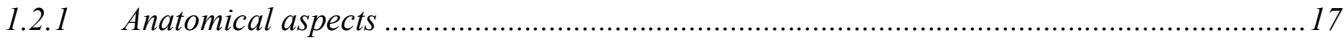

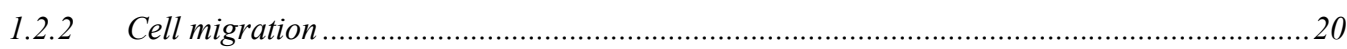

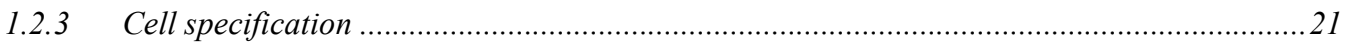

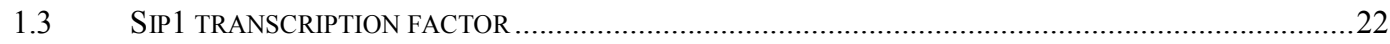

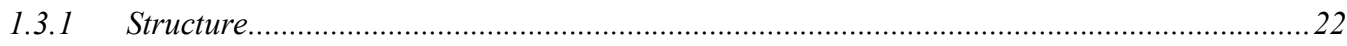

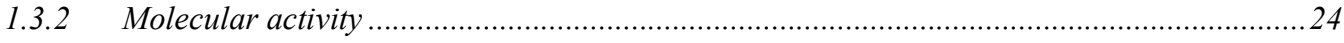

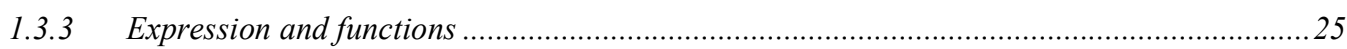

1.3.4 Mutations in humans: the Mowat-Wilson syndrome ........................................................26

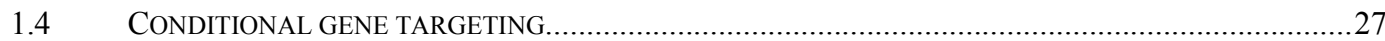

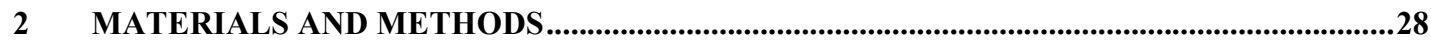

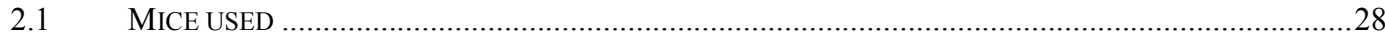

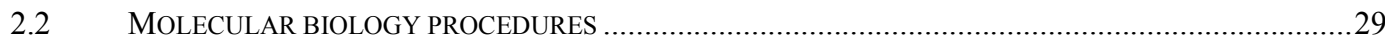

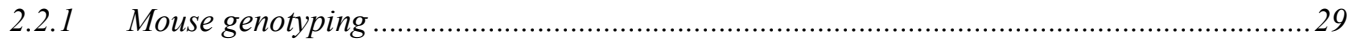

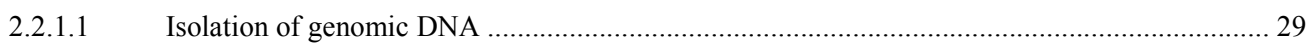

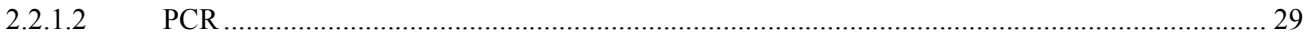

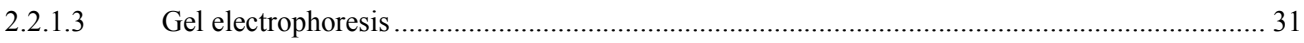

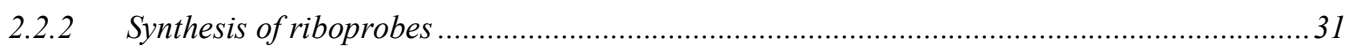

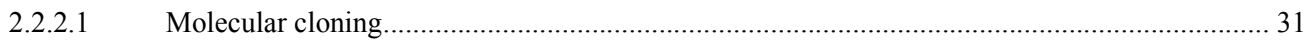

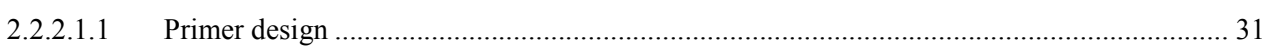

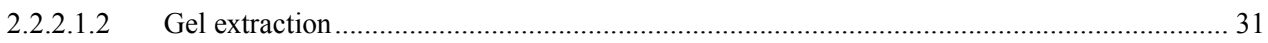

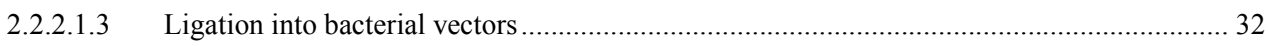

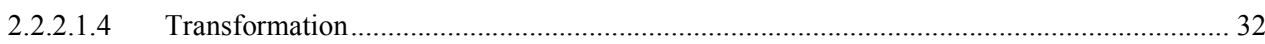

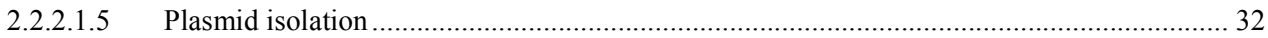

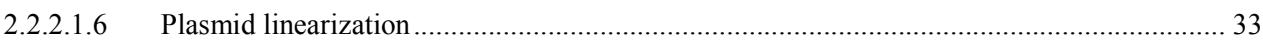

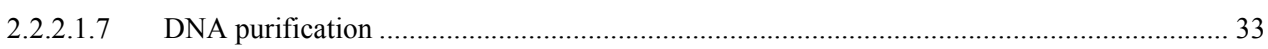

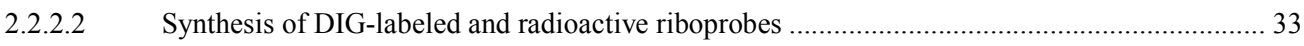

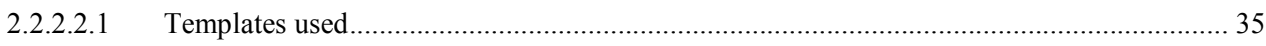




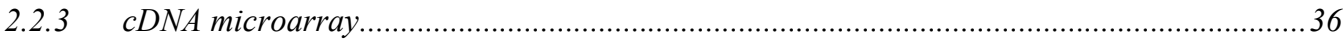

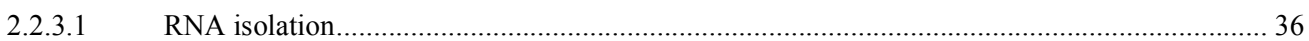

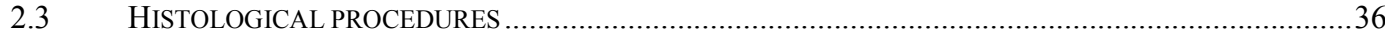

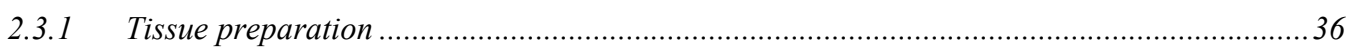

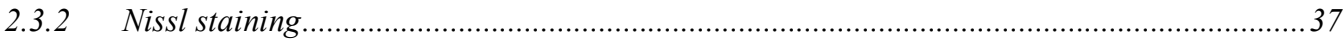

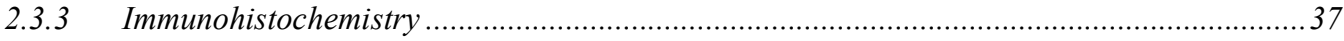

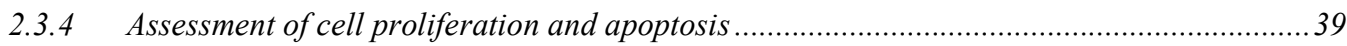

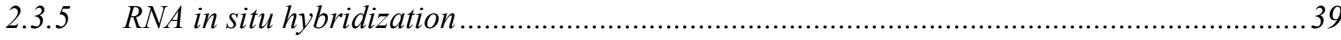

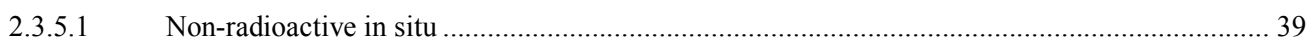

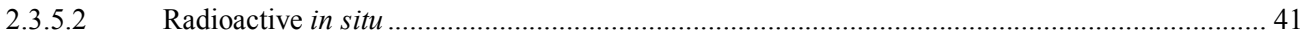

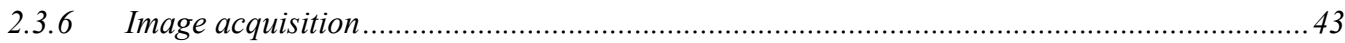

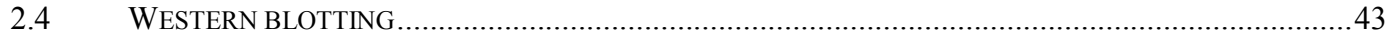

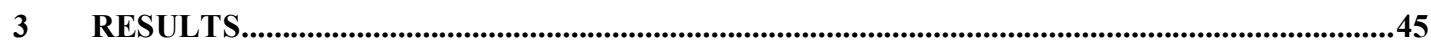

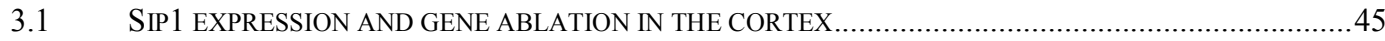

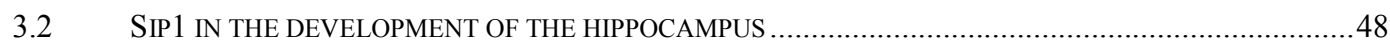

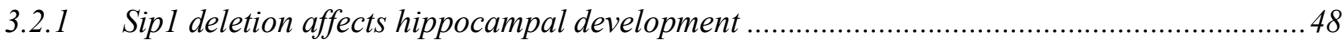

3.2.2 Sipl ablation increases cell death and impairs neural progenitor cell proliferation in the

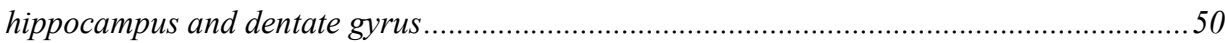

3.2.3 Neither cortical hem generation nor BMP signaling in the dorsal telencephalon is

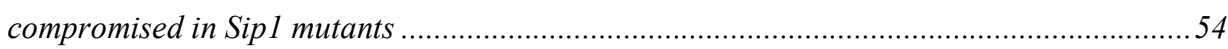

3.2.4 The Wnt negative regulator, Sfrp1, is ectopically expressed in the mutant hippocampus .....55

3.2.5 Over-expression of $\beta$-catenin in Sip1 mutant brains increases the number of dentate gyrus

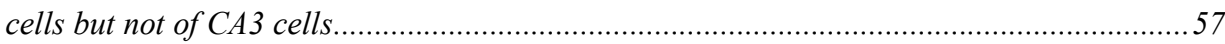

3.2.6 Canonical Wnt signaling is not significantly impaired in the Sip1 mutant hippocampal CA1CA3 fields......

3.2.7 The activity of the non-canonical Wnt effector, JNK, is inhibited in the Sip1 mutant

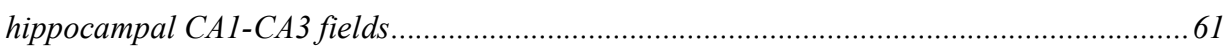

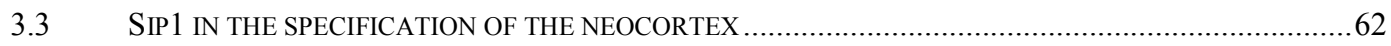

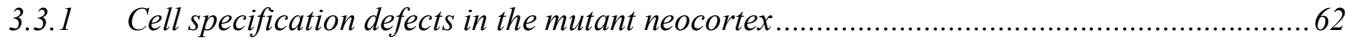

3.3.2 Cell proliferation and apoptosis in the mutant neocortex ...................................................66

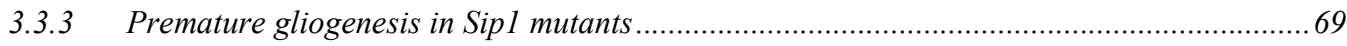

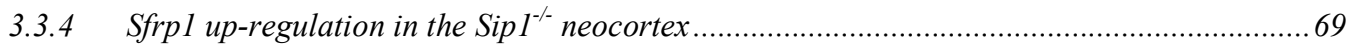

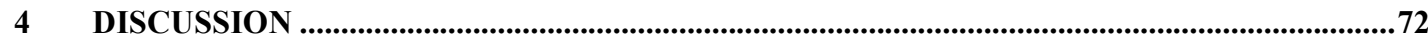

4.1 SIP1 EXPRESSION AND GENE ABLATION IN THE CORTEX...........................................................72

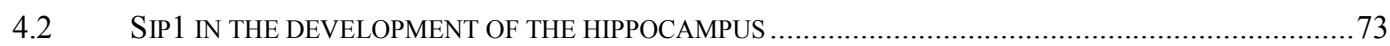

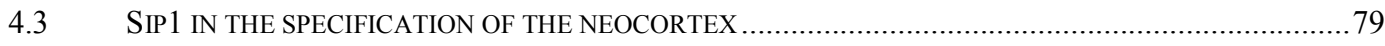

$4.4 \quad$ IMPLICATIONS TO THE MOWAT-WILSON SYNDROME ................................................................8

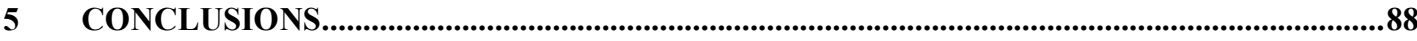




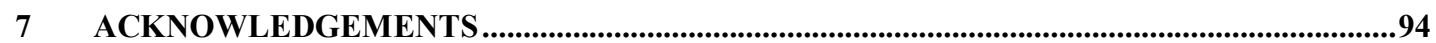

8 CURRICULUM VITAE 


\section{Abbreviations}

\begin{tabular}{|c|c|}
\hline ANR & Anterior Neural Ridge \\
\hline APC & Adenomatous Polyposis Coli tumor suppressor protein \\
\hline APS & Ammoniumpersulfate \\
\hline BCIP & 5'-bromo-4'-chloro-3'-indolylphosphate \\
\hline BG & Basal Ganglia \\
\hline BMP & Bone Morphogenetic Protein \\
\hline BrdU & 5'-Bromo-2'-deoxyuridine \\
\hline BSA & Bovine Serum Albumin \\
\hline CamKII & $\mathrm{Ca} 2+$ dependent Calmodulin Kinase II \\
\hline $\mathrm{CC}$ & Corpus Callosum \\
\hline cDNA & complementary DNA \\
\hline $\mathrm{CP}$ & Cortical Plate \\
\hline cpm & Counts per minute \\
\hline $\mathrm{CR}$ & Cajal-Retzius \\
\hline DAPI & 4',6-Diamidino-2-phenylindole \\
\hline DEPC & Diethylpyrocarbonate \\
\hline DG & Dentate Gyrus \\
\hline DIG & Digoxygenin \\
\hline Dkk & Dickkopf \\
\hline DNA & Deoxyribonucleic acid \\
\hline dNTP & Desoxynucleotidtriphosphate \\
\hline DTT & Dithiothreitol \\
\hline Dvl & Dishevelled \\
\hline ECL & Enhanced chemoluminescence \\
\hline EDTA & Ethylendiamin-N,N,N',N'-tetra acetic acid \\
\hline EMT & Epithelial-Mesenchymal Transtition \\
\hline $\mathrm{EtOH}$ & Ethanol \\
\hline FGF & Fibroblast Growth Factor \\
\hline Fzd & Frizzled \\
\hline GABA & $\gamma$-aminobutyric acid \\
\hline
\end{tabular}




\begin{tabular}{|c|c|}
\hline GFAP & Glial Fibrillary Acidic Protein \\
\hline GSK3 $\beta$ & Glycogen Synthase Kinase- $3 \beta$ \\
\hline HD & Homeodomain \\
\hline HEPES & 2-[4-(2-Hydroxyethyl)-1-piperanizo]-ethansulfonic acid \\
\hline Hip & Hippocampus \\
\hline HRP & Horseradish Peroxydase \\
\hline $\mathrm{IHC}$ & Immunohistochemistry \\
\hline $\mathrm{IZ}$ & Intermediate Zone \\
\hline JNK & c-Jun N-terminal Kinase \\
\hline KA1 & Kainate acid1 \\
\hline loxP & locus of crossover $x$ in $P 1$ \\
\hline LRP-6 & Low density lipoprotein receptor-related protein 6 \\
\hline $\mathrm{M} \& \mathrm{M}$ & Materials and Methods \\
\hline MW & Mowat-Wilson \\
\hline mRNA & messenger RNA \\
\hline $\mathrm{MZ}$ & Marginal Zone \\
\hline Ncx & Neocortex \\
\hline Ngn2 & Neurogenin2 \\
\hline NTB & 4-nitroblue tetrazoliumchloride \\
\hline PAGE & Polyacrylamide Gel Electrophoresis \\
\hline PBS & Phosphate-Buffered Saline \\
\hline PCP & Planar Cell Polarity \\
\hline PCR & Polymerase Chain Reaction \\
\hline PFA & Paraformaldehyde \\
\hline PK & Proteinase K \\
\hline PKC & Protein Kinase C \\
\hline $\mathrm{PP}$ & Preplate \\
\hline PVP & Polyvinylpyrrolidone \\
\hline RNA & Ribonucleic acid \\
\hline SBD & Smad-binding domain \\
\hline SDS & Sodium Dodecyl Sulfate \\
\hline Sfrp & Secreted Frizzled-Related Protein \\
\hline Shh & Sonic hedgehog \\
\hline Sip1 & Smad-interacting Protein 1 \\
\hline
\end{tabular}




$\begin{array}{ll}\text { Smad } & \text { Sma- and Mad- related protein } \\ \text { SSC } & \text { Sodium chloride-Sodium citrate } \\ \text { STE } & \text { Sodium chloride-Tris-EDTA } \\ \text { SVZ } & \text { Subventricular Zone } \\ \text { TAE } & \text { Tris-Acetate-EDTA } \\ \text { TAQ } & \text { Thermophilus aquaticus } \\ \text { TBS } & \text { Tris-Buffered Saline } \\ \text { TE } & \text { Tris-EDTA } \\ \text { TEMED } & \text { N,N,N',N'-tetramethyl ethylendiamine } \\ \text { TF } & \text { Transcription Factor } \\ \text { TGF- } \beta & \text { Transforming Growth Factor- } \beta \\ \text { Thal } & \text { Thalamus } \\ \text { Tris } & \text { Tris (hydroxymethyl)-amino methane } \\ \text { TujI } & \beta \text {-tubulin III } \\ \text { TUNEL } & \text { Terminal deoxynucleotidylTransferase Biotin-dUTP Nick End Labeling } \\ \text { UTP } & \text { Uridin Triphosphate } \\ \text { VZ } & \text { Ventricular Zone } \\ \text { WIF } & \text { Wnt inhibitory factor } \\ \text { Wnt } & \text { Wingless/Int }\end{array}$




\section{Abstract}

Smad-interacting protein $1(\operatorname{Sip} 1 / Z f h x 1 b)$ is a transcription factor that has been previously implicated in TGF $\beta / B M P$ signaling and in the etiology of the Mowat-Wilson syndrome. The expression of Sipl was documented during mouse corticogenesis. The cortex-specific ablation of Sip1 resulted in the lack of hippocampus and dentate gyrus and in severe cortical lamination defects. Sip1 mutant mice exhibited cell death of differentiating cells and decreased proliferation in the region of the prospective hippocampus and dentate gyrus. In Sip1 mutants, the expression of the Wnt antagonist Sfrpl was ectopically activated in the developing hippocampus and strongly up-regulated in post-mitotic cortical areas. The activity of the non-canonical Wnt effector, JNK, was inhibited in the prospective hippocampus of Sip1 mutants. The dentate gyrus defect was partially rescued by introducing in the $\mathrm{Sip}^{-/-}$background, a stabilized form of the canonical Wnt mediator $\beta$-catenin. Sip1 is therefore essential to the development of the hippocampus and dentate gyrus, and regulates both canonical and non-canonical Wnt signaling via modulating the levels of Sfrp1. In the Sip1 mutant neocortex, upper layers were expanded at the expense of the deeper layers. The cell specification defects were accompanied by ectopic proliferation, increased apoptotic cell death and premature gliogenesis. As Sfrpl was strongly up-regulated in the mutant neocortical areas, a role of Sip1 in the modulation of Wnt signaling in the neocortex is suggested. 


\section{Introduction}

\subsection{Signaling centers in the dorsal telencephalon}

There is increasing evidence supporting the hypothesis that the embryonic cortex is patterned as it is generated, without the influence of extrinsic factors such as thalamic innervation (Grove and Tole, 1999; Job and Tan, 2003; Monuki and Walsh, 2001; O'Leary and Nakagawa, 2002). In agreement with this, mouse mutants that lack thalamocortical connections develop normal cortical regions and boundaries (Ragsdale and Grove, 2001). Thus, a significant amount of patterning information already exists in the neocortex before the arrival of afferent inputs (Monuki and Walsh, 2001). This is particularly true for the hippocampus, where afferents from the septum and the entorhinal cortex do not arrive before E17.5 and E19.5, respectively (Grove and Tole, 1999).

The early cortical primordium is surrounded by organizers: discrete populations of cells that release diffusible signaling molecules such as FGF8, Shh, Wnts and BMPs (Fig. 1). These signals can influence cells over long distances and are thought to establish positional information by regulating the expression of other genes. In turn, developmental

domains in the cortex, characterized by gradients of expression of specific transcription factors such as Pax6 and Emx2, are set up by the time the cortex is generated (FukuchiShimogori and Grove, 2003). How intrinsic transcriptional regulators and signaling centers modulate cortical patterning is a matter of current investigation. 


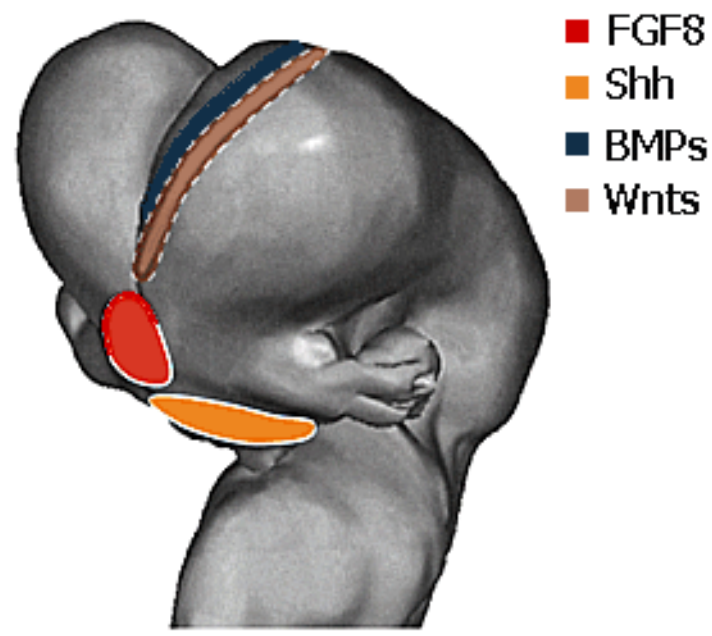

Fig.1 Signaling centers in the patterning the cerebral cortex. FGF8 is mainly released from the anterior neural ridge. Sonic hedgehog (Shh) is ventrally secreted from the prechordal mesoderm. Medially, the dorsal roof plate produces BMPs and the cortical hem are a source of Wnts. (adapted from Monuki \& Walsh, 2001)

\subsubsection{Fibroblast Growth Factor 8 (FGF8)}

The anterior neural ridge (ANR) is located in the most rostral part of the developing telencephalon and is a source of FGF8 (Fig. 1). When removed, the early cortex fails to express Foxg1 (an early marker of VZ progenitors), and the exogenous application of FGF8 is able to rescue Foxgl expression and function (Shimamura and Rubenstein, 1997). Grove and colleagues demonstrated the patterning role of FGF8 by in uteroelectroporation of different FGF8 expression constructs into either the rostral or caudal ends of the medial neocortex. The over-expression of FGF8 in the rostral end produced a caudal shift in regional markers, while caudal ectopic FGF8 expression induced their duplication (Fukuchi-Shimogori and Grove, 2003). The FGF8 signaling source in the ANR is therefore responsible for patterning the cortical primordium along the anteriorposterior axis. 


\subsubsection{Sonic hedgehog (Shh)}

In the mouse, Shh is expressed in ventral domains within neural tissue and in a group of mesodermal cells that underlie the ventral forebrain (Fig. 1). The latter is referred to as the prechordal mesoderm. The loss of Shh from the prechordal mesoderm (but not from the ventral telencephalon) in mice disrupts the induction of the midline roofplate resulting in holoprosencephaly (the failure to separate the forebrain onto two hemispheres) (Monuki and Walsh, 2001). Thus, Shh signaling from the prechordal mesoderm is necessary for midline roofplate induction.

\subsubsection{Bone Morphogenetic Proteins (BMPs)}

Another signaling center is located in the dorsal midline roof plate (Fig. 1). Selective ablation of the roof plate cells affects the growth of the entire cortex (Monuki and Walsh, 2001). The signals emanating from the roof plate as early as E8.5 include the bone morphogenetic proteins (BMPs). BMPs belong to the superfamilly of transforming growth factors $\beta$ (TGF- $\beta$ ) and transduce their signals via Smad proteins. Several BMPs are expressed in the dorsal telencephalic midline. Mice with targeted disruption of individual BMP genes show high functional redundancy, while compound mutants, such as $B m p 5 / B m p 7^{-/}$show extreme developmental defects. In addition, the cortex-specific knock-out of the gene coding for the BMPR1A receptor presented malformations of midline structures such as the choroid plexus (Hebert et al., 2002). Although the mechanisms by which roof-plate BMPs exert their function are still not known, experiments in chicken showed that the ectopic expression of BMP4 within the dorsal telencephalon is able to induce Emx2 expression (O'Leary and Nakagawa, 2002). Thus, BMP signaling in the cortex is required for the patterning of the dorso-ventral axis. 


\subsubsection{Wingless/Int (Wnt) Proteins}

The cortical hem is a transient structure located next to the dorsal midline roof. It is a main source of secreted molecules from the Wnt family (Fig. 1). Wnt signaling plays important roles in brain development such as cell fate decisions, cell polarity, embryonic patterning and axonal remodeling (Burden, 2000). Like BMPs, Wnts have been also implicated in the regulation of cortical expansion.

The secreted Wnt molecules belong to a very large glycoprotein family. In humans, 19 have been described so far (Jones and Jomary, 2002). They transduce paracrine signals through various Frizzled (Fzd) receptors and heterotrimeric G proteins. Wnt signaling occurs via, at least, three different but partially interconnected pathways (Fig. 2): the canonical/ $\beta$-catenin, the planar cell polarity/JNK and the $\mathrm{Ca} 2+/$ Protein kinase $\mathrm{C}$ pathways (Jones and Jomary, 2002; Kohn and Moon, 2005; Niehrs, 2001; Patapoutian and Reichardt, 2000).

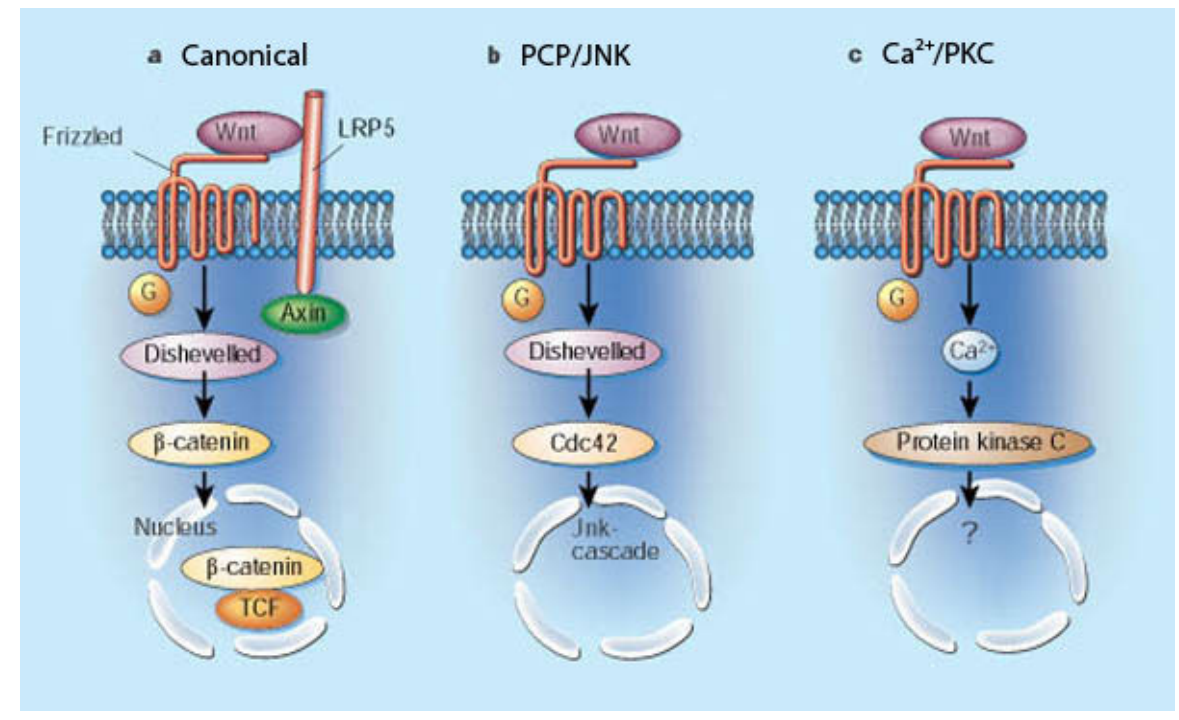

Fig.2: The three main Wnt signaling pathways. The Canonical Wnt signaling is mediated by $\beta$-catenin (a). The Planar Cell Polarity (PCP)/ c-Jun terminal kinase (JNK) (b) and the $\mathrm{Ca}^{2+}$ /Protein kinase $\mathrm{C}$ (c) are non-canonical pathways. (adapted from Niehrs, 2001) 
The canonical Wnt signaling (Fig 2a) depends on $\beta$-catenin and is the best characterized from the three known pathways. Upon binding of Wnt ligand to Fzd receptor, a cascade involving the activation of Dishevelled and the inactivation of a large molecular complex, ultimately leads to the stabilization of $\beta$-catenin via dephosphorylation. Dephosphorylated $\beta$-catenin is then able to enter the nucleus and form nuclear complexes with Tcf/Lef transcription factors to control gene expression. In the absence of Wnt signaling, cytoplasmic $\beta$-catenin is usually associated with a complex including glycogen synthase

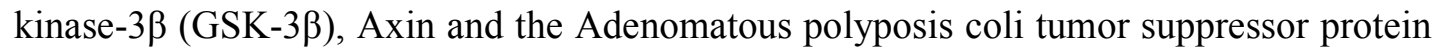
(APC). Phosphorylation of $\beta$-catenin by GSK-3 $\beta$ results in its ubiquitination and further degradation in proteosomes. Thus, the key factors in canonical Wnt signaling are the stabilization and cytoplasmic accumulation of $\beta$-catenin.

Regulation of canonical/ $\beta$-catenin Wnt signaling is achieved at multiple steps. A crosstalk between cadherin-mediated cell adhesion and canonical Wnt pathways has been proposed (Nelson and Nusse, 2004). Cadherins are linked to the cytoskeleton via $\beta$-catenin. Cadherins are able to reduce the free cytoplasmic pool of $\beta$-catenin by sequestering it at the plasma membrane. In turn, Wnt signaling can control the expression of E-cadherins via transcriptional repressors such as Slug and Snail. Significantly, Wnt signaling is attenuated in $F g f r$ knock-out mice, but signaling can be rescued by lowering the levels of E-cadherin. Therefore, by regulating the levels of free $\beta$-catenin in the cytoplasm, the threshold for Wnt-activation may be dynamically modulated (Nelson and Nusse, 2004).

In the dorsal telencephalon, the expression of several members of the canonical Wnt pathway has been found to be confined to the midline. The loss of the hem-specific $W n t 3 a$ decreases the proliferation of progenitors in the hippocampal neuroepithelium, the region immediately adjacent to the cortical hem (Gleeson and Walsh, 2000). Similar 
defects appear in mice that have reduced function in downstream mediators of canonical Wnt signaling pathway, ranging from the receptor LRP6 (Zhou et al., 2004); Lef1/Tcf transcription factors (Galceran et al., 2000) and $\beta$-catenin (Machon et al., 2003) to frizzled-9 (Zhao et al., 2005). Additionally, deletion of the transcription factor Emx2, known as a target gene of canonical Wnt signaling in the cortex (Theil et al., 2002), leads to a severe reduction in the hippocampus proper and almost a total lack of dentate gyrus (Pellegrini et al., 1996; Tole et al., 2000). Therefore, canonical Wnt signaling in the cortical hem is required for the expansion of the cortical progenitors responsible for the correct development of the hippocampus.

Non-canonical Wnt pathways are, by definition, independent of $\beta$-catenin. The existence of the planar cell polarity (PCP) was discovered in Drosophila and a vertebrate version of the PCP pathway was found to be responsible for the polarization of migrating cells during gastrulation (Niehrs, 2001) (Fig 2b). Upon Wnt binding to Frizzled receptors and in the absence of LRPs, Dishevelled is phosphorylated and activated. Dishevelled activates the c-Jun $\mathrm{NH}_{2}$-terminal kinase (JNK) cascade through small GTP-binding proteins from the Cdc42/Rho family. Downstream components of the PCP/JNK Wnt pathway include other kinases (e.g. MKK7) and the transcription factor c-Jun. In Drosophila, JNK signaling is required for the morphogenetic process of dorsal closure (Niehrs, 2001; Weston and Davis, 2002).

In the mouse brain, the function of the PCP/JNK Wnt pathway is just starting to be elucidated. Jnk1 and Jnk2 compound mutant mice exhibit increased apoptosis in the forebrain (Kuan et al., 1999). Recently, Salinas and colleagues demonstrated that Wnt signaling through Dishevelled, Rac and JNK controls dendritic development in cultured hippocampal cells (Rosso et al., 2005). Interestingly, neural cell morphology and 
migration in the developing neocortex has been shown to be regulated by JNK in a cellautonomous way (Hirai et al., 2002).

The $\mathrm{Ca}^{2+}$ /Protein kinase $\mathrm{C}$ (PKC) Wnt pathway is, like the $\mathrm{PCP} / \mathrm{JNK}$, dependent on Dishevelled and independent of $\beta$-catenin and LRPs (Fig 2c). Some Wnt signals are able to raise the levels of intracellular $\mathrm{Ca}^{2+}$ via phosphatidylinositol metabolism. This leads to the activation of PKC and $\mathrm{Ca}^{2+}$-dependent calmodulin kinase II (CamKII). The $\mathrm{Ca} 2+$ /PKC Wnt pathway was believed to be part of the PCP pathway until crucial experiments in Xenopus embryos were performed. The effects of Fzd7 inactivation on ectodermal cell sorting could be rescued by injection of $\mathrm{PKC}$, but not by components of the canonical or the PCP/JNK pathways (Niehrs, 2001). The $\mathrm{Ca}^{2+} / \mathrm{PKC}$ pathway opens new ways of action of Wnt molecules that might be also present in mammals.

There is a vast number of extracellular molecules known to regulate Wnt action. Wnt antagonists have been divided in two functional classes: the Dickkopf (Dkk) class and the Sfrp class, the latter including Cerberus and WIF. While Dkk proteins regulate the canonical Wnt pathway via LRP5/6, Sfrps are able to bind both to Wnt ligands and Fzd receptors (Kawano and Kypta, 2003). Thus, Sfrps may inhibit both canonical and noncanonical pathways. Each inhibitor might be specific for a particular Wnt or pathway, but given the complexity and intercross between pathways it has been difficult to build a precise classification scheme (Wang and Malbon, 2004).

\subsubsection{Secreted Frizzled-Related Protein 1 (Sfrp1)}

The first Wnt negative regulators to be described belong to the family of Secreted Frizzled-Related Proteins (Sfrps). These are molecules with a strong homology with the extracellular Frizzled cysteine-rich domain (CRD), which has been strongly implicated in the recognition and binding of Wnt ligands (Jones and Jomary, 2002). In spite of their 
similarities, Sfrps and Fzds are encoded by different genes. Sfrps also contain a Netrindomain highly homologous to the axonal guidance protein, netrin.

Sfrp inhibition of Wnt signaling may operate through at least two mechanisms: by competition with Fzd for Wnt ligands, or in a dominant-negative fashion by direct formation of non-signaling complexes with Fzds themselves (Kawano and Kypta, 2003).

Many of the Sfrp genes have been found to be expressed in the developing nervous system. The regional expression pattern of Sfrps is usually complementary -and sometimes overlapping- to that of certain Wnts (Jones and Jomary, 2002; Kim et al., 2001). Sfrpl expression in the dorsal telencephalon has been detected in the mouse neocortical neuroepithelium from E10.5 (Kim et al., 2001) until adulthood (Shimogori et al., 2004). A time-course analysis of Sfrpl expression revealed that, in the hippocampal formation, Sfrpl starts to be expressed only after birth (Augustine et al., 2001).

The Sfrpl gene is located in chromosome 8 both in human and mouse. The Sfrp1 mouse knock-out is viable but shows reduced osteoblast apoptosis, an important process during bone remodeling (Bodine et al., 2004). Sfrp1 has been also linked to tumor suppression by attenuation of Wnt signaling in vitro (Suzuki et al., 2004).

\subsection{Cortical development}

\subsubsection{Anatomical aspects}

The cerebral cortex comprises the hippocampus in its most medial part and, more laterally, the neocortex proper. The mammalian cortex is entirely derived from the embryonic ectoderm. After gastrulation, the neural plate is induced by the ectoderm and, around E8.5, the neural tube is formed (Trainor et al., 2000). The anterior part of the 
neural tube is then subdivided into two halves, the future telencephalic hemispheres. This subdivision depends on the dorsal midline roof plate, where the proliferation rate is slower than in the rest of the neuroepithelium (Monuki and Walsh, 2001).

With some important exceptions, most of the cortical neurons are generated by radial glia progenitors in the neuroepithelium or ventricular zone (VZ) (Malatesta et al., 2000). As they are generated, young neurons migrate away from the $\mathrm{VZ}$ into the cortical plate $(\mathrm{CP})$ in an inside-first, outside-last manner. Three main events take place during cortical development: 1) proliferation in the ventricular zone; 2) translocation of neuronal precursors into the intermediate zone (IZ) and 3) settling and final differentiation of neurons in the cortical plate (Bayer and Altman, 1991).

The glutamatergic projection neurons and the GABAergic interneurons forming the mature neocortex are organized in six layers that are aligned parallel to the pial surface and numbered from the cortical surface inwards. They have been generally characterized by differences in their cytoarchitecture. Thus, the polymorphic forms dominate layer 6; big pyramidal neurons characterize layer 5; layer 4 is mainly composed of granule cells while layers 3 and 2 are mostly composed of small pyramidal neurons. The layer 1 or marginal zone is filled by afferents to the cortex and contains the transient population of Cajal-Rezius cells (Bayer and Altman, 1991; Caviness et al., 2000).

The earliest formed neurons make the innermost cortical layer, while neurons formed later make successive outer layers. Exceptions to this rule are the earliest-born neurons that form the preplate (PP), a transitory structure that contributes to the organization of layers and later becomes part of layer 1 (Bayer and Altman, 1991) The time-course of cortical development from an anatomical perspective has been analyzed in detail by Bayer \& Altman (1991) in the rat neocortex. In order to extrapolate this time-course it 
should be considered that mouse development is roughly two days ahead that of the rat.

Thus, in the mouse embryonic (E) day:

E10.5 Telencephalic vesicles appear

E11.5-12.5 Accelerated expansion of the VZ. The (PP) appears

E13.5 Cortical plate appears dividing VZ from PP

E14.5 Cortical plate expansion (15\% of total volume). The SVZ and IZ appear between the $\mathrm{CP}$ and $\mathrm{VZ}$

E16.5 Considerable growth of SVZ/IZ (56\%) and CP (30\%). The relative thickness of VZ declines $(6 \%)$

E17.5 IZ is slightly expanded while SVZ is reduced

E18.5 CP thickness further increased; layer 6 distinguishable by its lower cell density. The VZ/SVZ are greatly diminished ( $\mathrm{VZ}=1 \%$ of total volume)

The hippocampal formation is the most medial part of the cortex and consists of the hippocampus proper or Ammon's horn, the dentate gyrus and the subiculum. Early in cortical development, the hippocampal primordium forms a continuum with the neocortex and is undistinguishable from it in terms of cytoarchitecture. Around E14.5 in the mouse, the developing hippocampus starts to blend along its longitudinal axis. The characteristic Ammon's horn is subdivided into CA1-CA3 fields and the V-shaped dentate gyrus starts to form. As in the neocortex, progenitors in the hippocampal VZ generate neurons that migrate into the $\mathrm{CP}$ in an inside-out manner. The hippocampal cortical plate, however, does not become a multi-laminar cortex but remains as a cell-dense pyramidal layer (Super et al., 1998). In turn, the dentate gyrus is mainly formed of granular cells and provides the primary afferent pathway to the hippocampus. The generation of dentate gyrus cells is initially carried out by progenitors of the hippocampal VZ and by a transient sub-population of progenitors that migrate into the dentate anlage itself and produce 
dentate cells until early post-natal weeks. Moreover, a third population of 'displaced' progenitors settled along the granule cell layer continues to generate dentate gyrus cells throughout life (Pleasure et al., 2000).

\subsubsection{Cell migration}

To reach the cortical plate, young neurons migrate radially out from the ventricular zone and bypass the older neurons in their way to their correct position. Time-lapse experiments have shown that radial migration occurs either by somal translocation or by cellular locomotion (Noctor et al., 2004). Both events require the physical interaction with radial glia processes that lie spanning the neocortex from the ventricular to the pial surfaces. Radial glia do not only serve as a scaffold for newly generated neurons, but are also thought to be the main progenitors of neurons and glia in the neocortex (Malatesta et al., 2000).

Mutations in a growing number of genes related to radial migration produce laminar malformations in the cortex (e.g. lissencephalies). Probably the best known mouse model for lamination is the spontaneous Reeler mutant. During cortical development, reelin protein is normally expressed by Cajal-Retzius cells in layer 1. Reeler mutants lack reelin and present inverted lamination (Gleeson and Walsh, 2000).

Tangential migration is another way of cell translocation into the cortical plate. Most of the GABAergic interneurons in the neocortex are generated elsewhere, namely in the ganglionic eminences (Monuki and Walsh, 2001). Interneurons migrate into the neocortex by means of tangential migration, although inward and outward radial migration has been also detected (Hevner et al., 2004). Most oligodendrocyte precursors also migrate tangentially into the neocortex. However, oligodendrocytes are also generated postnatally, 
like astrocytes, from precursors within the cortex itself (Gorski et al., 2002; He et al., 2005).

\subsubsection{Cell specification}

The identity of a cortical neuron is specified by its time of birth and before it begins to migrate. The birthday of a neuron is defined as the time when its progenitor cell underwent its last mitotic division. Neurons born at early stages of cortical development migrate to layers closest to their site of birth, whereas those born later end up in more superficial layers. Therefore, the specification of neurons in the neocortex and their migration to particular layers are correlated with the time when the neuron is born ( $\mathrm{He}$ et al., 2005; Hirabayashi and Gotoh, 2005).

Neurogenesis in the mammalian neocortex occurs through a combination of modes of cell division. These include symmetrical progenitor 'self-renewing' cell divisions; assymetrical cell divisions that give rise to one daughter neuron; and symmetrical 'terminal' divisions that generate two daughter neurons (Noctor et al., 2004). Thus, whether the plane of cell division is parallel (symmetrical) or at right angles (asymmetrical) to the neuroepithelium strongly determines the neuronal fate.

Birth-dating experiments have shown the time frames at which neurons in specific layers are generated in the mouse neocortex. Neurons forming deep layers 5 and 6 are mainly born at E12.5-13.5; the peak of production of upper layers 2-4 occurs at E14.5. Neurons born between E15.5-E17.5 migrate slowly to integrate into upper layers (Hevner et al., 2004).

Molecular markers offer a more precise tool than birth-dating to identify specified neurons throughout cortical development. In spite of the particular cytoarchitectural features of each layer, neuronal sub-types within each layer may arise at different time 
points. The identification of neuronal sub-types is particularly useful in the analysis of mutant phenotypes in the neocortex. In this respect, a growing array of molecular markers for the neocortex has been recently compiled (He et al., 2005; Hevner et al., 2003).

In the hippocampus, cell specification is also intrinsic to its cortical primordium. Explants harvested as early as E10.5 start expressing hippocampal-specific markers such as $K A 1$, SCIP/Oct6 and Steel after two days in culture (Tole and Grove, 2001).

\subsection{Sip1 transcription factor}

\subsubsection{Structure}

Smad-interacting protein 1 (Sip1/Zfhxlb, GeneBank: NM_015753) is a member of the emerging family of two-handed zinc finger transcription factors, which also includes $\delta$-EF1 (Remacle et al., 1999). In vertebrates, this family is characterized by a homedomain-like domain flanked by two terminal clusters of highly conserved zinc fingers. The N-terminal cluster contains three $\mathrm{CCHH}$ and one $\mathrm{CCHC}$-type fingers while the C-terminal cluster contains three zinc fingers of the CCHH type (Fig. 3). Almost half of the total coding sequence for the $\sim 140 \mathrm{kDa}$ protein is encoded by exon 7 . This unusually

long exon of $2 \mathrm{~Kb}$ contains the coding sequence for the fourth $\mathrm{N}$-terminal zinc finger, a homeodomain-like (HD) sequence and a Smad-binding domain (SBD) (Maruhashi et al., 2005). 


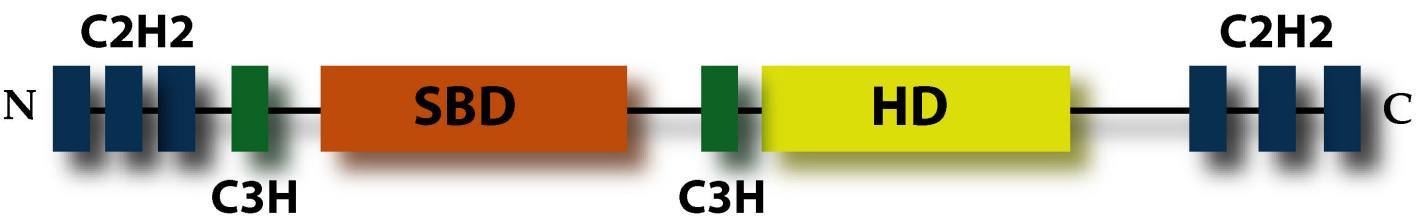

Fig. 3 Schematic representation of Sip1. Two terminal zinc-finger clusters formed by $\mathrm{C} 2 \mathrm{H} 2$ and $\mathrm{C} 3 \mathrm{H}$ types flank the Homeodomain-like (HD) and the Smad-binding domain (SBD).

Sip1 has sequence similarities with the vertebrate $\delta$-EF-1, Drosophila Zfh-1 and Xenopus XSIP1 transcription factors, particularly in respect to the zinc finger clusters $(\sim 90 \%)$. More variable (30-40\%) are the central regions, including the SBD, HD and a consensus sequence for the binding of the corepressor CtBP (Postigo, 2003). Importantly, unlike Sip1 and $\delta$-EF-1, Drosophila Zfh-1 does not contain a domain for binding Smads (SBD). Moreover, the homedomains of Sip 1 and $\delta$-EF-1 (but not that of Zfh-1) do not possess the two key consensus aminoacids that are required for the binding of the homeodomain to DNA (Gehring et al., 1994). This suggest that the homeodomain-like sequence of Sip1 is not able to directly bind to DNA (Remacle et al., 1999).

More recently, sequence analysis predicted in C.elegans a homologue of mouse Sip1/ס-EF-1 and Drosophila Zfh-1. The C.elegans ZAG-1 transcription factor contains a highly conserved homedomain, a CtBP binding domain and terminal zinc fingers sequences (Clark and Chiu, 2003). 


\subsubsection{Molecular activity}

SIP1 recognizes spaced CACCT sequences (E-box) in its target DNA and binds to them as a monomer (Comijn et al., 2001; van Grunsven et al., 2003). Previous studies have shown that Sip1 is able to regulate the expression of target genes such as Xenopus Xbra and human E-cadherin and a4-integrin (Postigo, 2003; Remacle et al., 1999). The integrity of both zinc-finger terminal clusters in Sip1 has been shown to be necessary for DNA binding (Remacle et al., 1999). In epithelial cells Sip1 is able to down-regulate E-cadherin expression (Comijn et al., 2001; Vandewalle et al., 2005). SIP1 is also able to repress the transcription of Xbra both in vitro and in vivo (Eisaki et al., 2000; Remacle et al., 1999).

Although SIP1 is also able to interact with the co-repressor CtBP, it was demonstrated that SIP1-mediated repression of E-cadherin is independent of binding to CtBP (Van Grunsven 2003). Recently, SIP1 sumoylation has been shown to attenuate the Sip1 transcriptional repression on E-cadherin (Long et al., 2005).

Importantly, SIP1 also interacts with the MH2 domain of R-Smads $(1,2,5)$, implicating it as a regulator of TGF $\beta / \mathrm{BMP}$ signaling (Verschueren et al., 1999). The Bone Morphogenetic Proteins (BMPs) belong to the superfamily of Transforming Growth Factor $\beta$ (TGF- $\beta$ ). Binding of these factors to the transmembrane Ser/Thr kinase receptors type I and II directly activates members of the Smad family of signal transducers (Attisano and Wrana, 2000).

The Smad family consists of 8 intracellular effector molecules classified as receptorregulated Smads (R-Smads), common-partner Smads (Co-Smads) and inhibitory Smads (I-Smads). In vertebrates, R-Smads include the BMP-regulated Smad1, Smad5 and Smad8 and the activin-regulated Smad2 and Smad3. R-Smads recruit Co-Smad 4 and are 
antagonized by I-Smads (Smad6 and Smad7). In the absence of signaling, Smads are kept in a latent conformation through an intramolecular interaction between the MH1 and MH2 domains (Remacle et al., 1999). Upon activation, R-Smads bind the Co-Smad4 and translocate as a complex into the nucleus, where they can bind to short Smad-binding elements in the promoters of responsive genes. Given the low affinity of this binding, Smads need the cooperation with transcription factors that modulate their transcriptional activity (Wrana, 2000).

\subsubsection{Expression and functions}

In the developing mouse, the highest levels of Sipl expression are found in the central nervous system, but also in other tissues such as liver, gut, eye, skeletal muscle, thymus and lower limbs (Bassez et al., 2004). Sipl mRNA expression has been detected as early as E8.5 in the mouse neural plate and paraxial mesoderm (Maruhashi et al., 2005). The targeted disruption of Sip1 causes early developmental defects. Whereas heterozygous Sip1 mutant mice develop normally, Sipl-deficient embryos show multiple defects at E8.5 and die at E9.5 (Van de Putte et al., 2003). The neural plate of Sip1-deficient mice shows reduced transcript levels of the neural ectoderm marker Sox2 and persistence of Ecadherin in the neural ectoderm, where it normally should be down-regulated and in fact replaced by $\mathrm{N}$-cadherin. In addition, these mice display a migration arrest of vagal neural crest cells.

In Xenopus embryos, XSIP1 has been found to participate in the specification of the neuroectoderm. The over-expression of XSIP1 results in an enlargement of neural anterior tissue probably due to the activin-dependent activation of anterior neural markers (Eisaki et al., 2000), and in the transcriptional repression of the endogenous mesodermal marker Xbra (Remacle et al., 1999). 
SIP1 is homogeneously expressed by day 33 in the human neural tube. (Espinosa-Parrilla et al., 2002). Like in the mouse, SIP1 is also expressed ubiquitously in peripheral tissues. At later stages, SIP1 expression is found in the cerebral cortex, basal ganglia, thalamus hypothalamus and cerebellum (Bassez et al., 2004).

SIP1 has been also linked to tumorogenesis. It is expressed in epithelial tumor cell lines and in intestinal gastric carcinomas, where its expression inversely correlates with that of E-cadherin (Comijn et al., 2001; Vandewalle et al., 2005). E-cadherin is a cell-cell adhesion molecule involved in the epithelial-mesenchymal transition (EMT), a process that allows cells to dissociate from epithelial tissue and become more motile. The EMT is required for the development of neural crest cells and is a landmark of pathological situations such as cancer and wound healing (Vandewalle et al., 2005).

\subsubsection{Mutations in humans: the Mowat-Wilson syndrome}

Mutations in SIP1 were identified in patients with a syndromic form of Hirschsprung disease (Cacheux et al., 2001; Wakamatsu et al., 2001), that was then defined as the Mowat-Wilson syndrome (Amiel and Lyonnet, 2001; Wilson et al., 2003). Patients with heterozygous mutations in SIP1 display, with variable penetrance, mental retardation, microcephaly, agenesis of the corpus callosum, epilepsy and poor hippocampal formation. They also exhibit other congenital defects such as Hirschsprung disease, a failure to form enteric ganglia in the hindgut due to a delamination arrest of neural crest cells (Zweier et al., 2005).

All SIP1 mutations identified so far are de novo non-sense or frameshift mutations, indicating that they lead to happloinsufficiency (Wilson et al., 2003). In this respect, a $\sim 50 \%$ reduction of SIP1 protein levels would be sufficient for the syndrome to occur. 


\subsection{Conditional gene targeting}

The generation of transgenic mice owes to the development of embryonic stem (ES) cell technologies in the early 1980's that allowed the colonization of germ line upon blastocyst injection (reviewed in Müller, 1999). Conventional gene targeting has been widely used to inactivate or modify genes in all tissues throughout the whole lifespan. Limitations to this method arise when one attempts to study the function of a gene in a time- and tissue-dependent manner, and when the deletion of a ubiquitously-expressed gene leads to a lethal phenotype.

Conditional gene targeting allows for a more precise control in gene inactivation than conventional methods. This approach involves the use of the site-specific recombinase Cre from phage $\mathrm{P} 1$ that recognizes and binds to a 34-bp long sequence called loxP (locus of crossover $x$ in $P 1$ ) (Müller U., 1999). Transgenic mice that express Cre recombinase under the control of a tissue-specific promoter are first crossed to target mice that harbor loxP sites flanking the genomic region to be deleted or modified. Mice carrying the 'floxed' alleles are in turn engineered by homologous recombination in embryonic stem cells. The crossing of these mouse lines produce offspring bearing Cre and one/two floxed target genes. Thus, mutant mice undergo gene deletion only in the tissues expressing Cre recombinase, without compromising the function of the gene in the rest of the organism or at earlier developmental stages. 


\section{Materials and Methods}

\subsection{Mice used}

Mouse strains harboring the floxed alleles of Sipl and $\beta$-catenin, as well as Emx $1^{\text {IRESCre }}$ have been described (Higashi et al. 2002; Harada et al. 1999, Gorski et al. 2002; Harada et al. 1999; respectively). Sip $1^{\text {flox }}$ mice have the exon7 of Sip1 flanked by loxP sequences, $\mathrm{a} \sim 2 \mathrm{~kb}$ region coding for almost half of the protein (see Introduction). The $\beta$-catenin ${ }^{\text {flox }}$ mouse line contains loxP sites neighboring exon3, the coding sequence for the inactivation site upon $\beta$-catenin phosphorylation. The Cre line used to delete the regions flanked by loxP sites had Cre recombinase expression driven by the Emx1 ${ }^{\text {IRES }}$ promoter. Emxl-transcription factor is expressed in the dorsal telencephalon from E9.5 in neuronal progenitors and the activity of Emx $1^{\text {IRESCre }}$ has been shown to recapitulate Emxl expression (Gorski et al. 2002). Mice were kept on a mixed CD1/C57B6 background. All animal manipulations were carried out in accordance with the German law and were approved by the Bezirksregierung Braunschweig.

Heterozygous mice were intercrossed to obtain the following genotypes:

Sip1 mutant $\left(\operatorname{Sip} 1^{\text {flox/flox }} / \mathrm{Emx} 1^{\text {IRESCre }}\right)$

Double mutant $\left(\operatorname{Sip} 1^{\text {flox/flox }} / \mathrm{Emx} 1^{\text {IRESCre }} / \beta-\right.$ cat $\left.^{\text {exo3/wt }}\right)$

Control mice (Sip $1^{\text {flox/wt } / E m x} 1^{\text {IRESCre }}$ or wild-type) 


\subsection{Molecular biology procedures}

\subsubsection{Mouse genotyping}

\subsubsection{Isolation of genomic DNA}

Tissue (from tail, cortex or midbrain) was incubated in $0,5 \mathrm{ml}$ PK-lysis buffer $(100 \mathrm{mM}$ Tris- $\mathrm{HCl} \mathrm{pH} 8.5,5 \mathrm{mM}$ EDTA, 200mM NaCl, 0.2\% SDS, $100 \mu \mathrm{g} / \mathrm{ml}$ Proteinase K), shaking overnight at $55^{\circ} \mathrm{C}$. After a $10 \mathrm{~min}$. centrifugation at $13000 \mathrm{rpm}$, the DNA in the supernatant was precipitated by the addition of isopropanol to a final $50 \%$ concentration. Genomic DNA was then collected by centrifugation, washed twice in $70 \%$ ethanol and resuspended in water at $40^{\circ} \mathrm{C}$ for $1 \mathrm{~h}$.

\subsubsection{PCR}

Polymerase chain reaction was performed for the amplification of specific DNA fragments for cloning and genotyping.

A PCR reaction, normally carried out in a $20 \mu \mathrm{l}$-volume, contained:

$\begin{array}{ll}\text { 10x Buffer (Genecraft) } & 2 \mu \mathrm{l} \\ 10 \mathrm{mM} \text { dNTPs (Invitrogen) } & 0,4 \mu \mathrm{l}(20 \mathrm{pmol} / \mathrm{ml}) \\ \text { Primer 1/Primer 2 (IBA) } & 0.8 \mu \mathrm{l}(40 \mathrm{pmol} / \mathrm{ml}) \text { each } \\ \text { TAQ polymerase (Genecraft) } & 0.4 \mu \mathrm{l}(0.5 \text { units }) \\ \text { Template DNA } & 1 \mu \mathrm{l} \\ \mathrm{dH}_{2} \mathrm{O} & 13 \mu \mathrm{l}\end{array}$


Each mouse was characterized for the presence of specific transgenes by using its genomic DNA as a template and the following specifications:

Cre genotyping: A region coding for Cre recombinase ( $500 \mathrm{bp})$ was amplified by PCR $\left(94^{\circ} \mathrm{C} 10 \mathrm{sec} ; 55^{\circ} \mathrm{C} 30 \mathrm{sec} ; 72^{\circ} \mathrm{C}, 40 \mathrm{sec} ; 30\right.$ cycles) with the primers:

\section{CREforward 5'-TCGATGCAACGAGTGATGAG-3' \\ CREreverse 5'-TTCGGCTATACGTAACAGGG-3'}

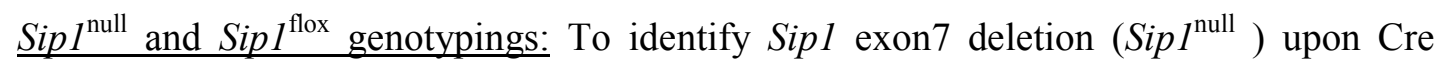
recombination, primers outside the flanking region were used to amplify a $\sim 2 \mathrm{~kb}$ fragment $\left(94^{\circ} \mathrm{C} 30 \mathrm{sec} ; 59^{\circ} \mathrm{C} 1 \mathrm{~min} ; 72^{\circ} \mathrm{C}, 1 \mathrm{~min} 40 \mathrm{sec} ; 34\right.$ cycles $)$, as shown in Fig. 6.

SIP1 ${ }^{\text {null }}$ forward 5'-GAGCAGGTAACCGCAAGTTCAAGTG-3'

SIP $1^{\text {null }}$ reverse 5'-ATCGGAGTCTGTCATGTCATCTAGG-3'

A PCR genotyping for Sip $1^{\text {flox }}$ was used in order to distinguish between floxed ( $\left.600 \mathrm{bp}\right)$ and WT ( $450 \mathrm{bp})$ Sip 1 alleles $\left(94^{\circ} \mathrm{C} 10 \mathrm{sec} ; 59^{\circ} \mathrm{C} 20 \mathrm{sec} ; 72^{\circ} \mathrm{C}, 40 \mathrm{sec} ; 31\right.$ cycles):

SIP1 ${ }^{\text {flox }}$ forward 5'-TGGACAGGAACTTGCATATGCT-3'

SIP1 ${ }^{\text {flox }}$ reverse 5'-GTGGACTCTACATTCTAGATGC-3'

$\beta$-cat ${ }^{\text {exo3 }}$ genotyping: $\beta$-catenin ${ }^{\text {flox }}$ mice were genotyped for floxed $(\sim 600 \mathrm{bp})$ and wildtype ( $\sim 560 \mathrm{bp})$ exon 3 by PCR $\left(94^{\circ} \mathrm{C} 6 \mathrm{sec} ; 62^{\circ} \mathrm{C} 20 \mathrm{sec} ; 72^{\circ} \mathrm{C}, 45 \mathrm{sec} ; 38 \mathrm{cycles}\right)$ :

CAT $^{\text {flox }}$ forward 5'-AGAATCACGGTGACCTGGGTTAAA-3'

$\mathrm{CAT}^{\text {flox }}$ reverse 5'-CATTCATAAAGGACTTGGGAGT-3', 


\subsubsection{Gel electrophoresis}

DNA fragments amplified by PCR were separated by agarose gel electrophoresis at $\sim 5 \mathrm{~V} / \mathrm{cm}$ (chamber length). The 1-2\% agarose (Gibco) gels were prepared in TAE buffer (40mM Tris-acetate, $1 \mathrm{mM}$ EDTA, $\mathrm{pH} 8$ ) containing $0.5 \mu \mathrm{g} / \mathrm{ml}$ ethidium bromide (Fluka), which allowed for the proper visualization of DNA under ultraviolet light. OrangeG (Sigma) was used as loading buffer and $100 \mathrm{bp}$ and $1 \mathrm{~kb}$-DNA markers (Invitrogen) were used at a concentration of $50 \mathrm{ng} / \mu \mathrm{l}$.

\subsubsection{Synthesis of riboprobes}

\subsubsection{Molecular cloning}

\subsection{Primer design}

In order to amplify a unique sequence of interest, primers were designed according to the following rules: 1)Size ranging from 22-24 bases; 2)40-60\% of GC content; 3)No GGG/CCC; 4)Three terminal 5' and 3'bases not complementary; 5)Six last 3'bases contain 3G/C; 6)Second last 3'base not G/C; 7)Best if last 3'base is G/C.

The annealing temperature for a set of primers is the lowest of both, calculated with the formula: $2(\mathrm{~A}+\mathrm{T})+4(\mathrm{G}+\mathrm{C})+5$. The fragment is then amplified by PCR using a cDNA library (from E15.5 WT mouse) and separated by gel electrophoresis as described above.

\subsection{Gel extraction}

The separated DNA fragment of the expected size was cut out from the gel under the u.v. light and extracted from agarose using the QIAEX II DNA purification kit (Qiagen). 


\subsection{Ligation into bacterial vectors}

Ligation of insert into plasmid was performed using T4 DNA Ligase (Roche) with a 1:3 ratio of plasmid:insert for $1 \mathrm{~h}$ at room temperature or at $4^{\circ} \mathrm{C}$ overnight. A total volume of 10 $\mu 1$. contained: $5 \mu 12 x$ Ligation Buffer, $1 \mu 1$ Ligase, $1 \mu 1$ plasmid and $3 \mu 1$ PCR product.

\subsection{Transformation}

Chemically competent bacteria (DH5 $\alpha-E$. coli) were used for the amplification of plasmids carrying the cDNA fragment of interest. For this, a $50 \mu 1$ aliquot of bacteria was first defrosted on ice and incubated on ice for $30 \mathrm{~min}$ with $1 \mu 1$ of the ligated plasmid. Cells were transformed by heat shock $\left(42^{\circ} \mathrm{C} ., 1 \mathrm{~min}\right)$ and placed on ice for $5 \mathrm{~min}$. They are then incubated in LB medium for $1 \mathrm{~h}$ with slight agitation and finally plated onto selective LBagar plates containing appropriate antibiotics (e.g. ampicillin $100 \mathrm{mg} / \mathrm{ml}$ ). Plates were incubated at $37^{\circ} \mathrm{C}$. overnight for the growth of individual colonies.

\subsection{Plasmid isolation}

Small-scale preparation of plasmid DNA (Miniprep): $5 \mathrm{ml}$ of LB medium containing the appropriate antibiotics were inoculated with a single E. Coli colony and incubated for 10$16 \mathrm{~h}$ at $37^{\circ} \mathrm{C}, 220 \mathrm{rpm}$. The bacterial pellet was obtained by centrifugation (10min, 3000rpm,). Plasmid isolation was performed with the aid of Macherey-Nagel NucleoSpin ${ }^{\mathrm{TM}}$ Plasmid Kit, according to the manufacturer's specifications.

Large-scale preparation of plasmid DNA (Midiprep): For the preparation of large-scale bacterial cultures, $5 \mathrm{ml}$ of LB medium containing appropriate antibiotics were inoculated with a single colony and incubated for $6-8 \mathrm{~h}$ at $37^{\circ} \mathrm{C}, 220 \mathrm{rpm}$. A $200 \mu \mathrm{l}$-aliquot from this culture was then used to inoculate $100 \mathrm{ml}$ of LB medium with appropriate antibiotics. The culture was let grow overnight at $37{ }^{\circ} \mathrm{C}, 220 \mathrm{rpm}$. The pellet was then recovered by 
centrifugation and the plasmid was isolated according to the Wizard Plus Midipreps DNA purification system (Promega).

\subsection{Plasmid linearization}

The purified plasmid was linearized using a specific restriction enzyme, according to the orientation of the fragment and the characteristics of the vector. The plasmid DNA was diluted in $\mathrm{H}_{2} \mathrm{O}$ to a concentration of $50 \mathrm{ng} / \mu \mathrm{l}$ and the following components were added: $1: 10$ of $10 \mathrm{x}$ Buffer, $1-5 \mu \mathrm{l} / \mathrm{ml}$ of enzyme and 1:100 of $100 \mathrm{x}$ BSA (when required). Reactions were normally incubated at $37^{\circ} \mathrm{C}$ for few hours-overnight until complete restriction, as verified by gel electrophoresis.

\subsection{DNA purification}

In order to purify DNA from proteins, an equal volume of Tris-saturated phenolchloroform/isoamyethanol $\mathrm{pH} 8$ (Invitrogen) was added to the completed restriction mixture. The mixture was then vortexed and centrifuged (10min, 13000rpm). The upper phase is transferred to a new tube and equal volume of chloroform is added. It was again vortexed, centrifuged and the upper phase transferred to a new tube with 0.1 volume of $3 \mathrm{M}$ sodium acetate $(\mathrm{pH} 5.5)$. After vortexing, DNA was precipitated with 3 volumes of $100 \%$ ethanol for $1 \mathrm{~h}$ at $-20^{\circ} \mathrm{C}$, washed twice in cold $70 \%$ ethanol and resuspended in $\mathrm{H}_{2} \mathrm{O}$ at a final concentration of $0.1-1 \mu \mathrm{g} / \mu \mathrm{l}$.

\subsubsection{Synthesis of DIG-labeled and radioactive riboprobes}

In vitro transcription of the linearised cDNA was carried out for both radioactive and nonradioactive in situ hybridization, incubating for $2 \mathrm{~h}$ at $37^{\circ} \mathrm{C}$ the following reagents: 


$\begin{array}{lll} & \text { Radioactive } & \text { Non-radioactive } \\ \text { Linearized DNA }(>0.25 \mu \mathrm{g} / \mathrm{ml}) & 0.5-3 \mu \mathrm{l}(0.5-1 \mu \mathrm{g}) & 0.5-3 \mu \mathrm{l}(0.5-1 \mu \mathrm{g}) \\ \text { Transcription Buffer 10x (Boehringer) } & 2 \mu \mathrm{l} & 2 \mu \\ \text {-U dNTPs (Boehringer) } & 2 \mu \mathrm{l}(1 \mathrm{mM} \text { each) } & 2 \mu \mathrm{l}(1 \mathrm{mM} \text { each) } \\ \text { RNase inhibitor (Promega) } & 0.5 \mu \mathrm{l}(1 \mathrm{U} / \mu \mathrm{l}) & 0.5 \mu \mathrm{l}(1 \mathrm{U} / \mu \mathrm{l}) \\ \text { T3/T7/SP6 RNA polymerase (Promega) } & 1 \mu \mathrm{l}(0.5 \mathrm{U} / \mu \mathrm{l}) & 1 \mu \mathrm{l}(0.5 \mathrm{U} / \mu \mathrm{l}) \\ {[\alpha]_{35} \text { S-UTP (Amersham) }} & 4 \mu \mathrm{l}(10 \mathrm{mCi} / \mathrm{ml}) & - \\ \text { Digoxygenin11 (DIG)-UTP (Boehringer) } & - & 0.5 \mu \mathrm{l}(1 \mathrm{mM}) \\ \text { Dithiothreitol (DTT, Promega) } & - & 2 \mu \mathrm{l}(10 \mathrm{mM}) \\ \text { DEPC-H }{ }_{2} \mathrm{O} & \text { up to } 20 \mu \mathrm{l} & \text { up to } 20 \mu \mathrm{l}\end{array}$

For DIG-labeled probes, the cDNA template was digested with $0.1 \mathrm{U} / \mu \mathrm{l}$ RNase freeDNase (Promega) for $15 \mathrm{~min}$ at $37^{\circ} \mathrm{C}$. The RNA was precipitated by adding $4 \mathrm{MLiCl}(1 / 10$ of the original volume) and $100 \%$ ethanol $(2.5 \mathrm{x}$ volumes). Precipitated RNA was dissolved in $50 \mu \mathrm{l}$ of DEPC-treated water and kept at $-80^{\circ} \mathrm{C}$. Quality and amount of the transcribed probe was examined by electrophoresis in $1 \%$ agarose gel.

For $[\alpha]_{35}$ S-labeled probes, the reaction was stopped by the addition of $40 \mu$ of Sodium chloride-Tris-EDTA (STE) buffer. Non-incorporated nucleotides (dNTPs) were removed by gel filtration with MicroSpin G-50 colums (Amersham), according to the manufacturer's instructions. A scintillation counter (Beckmann) was used to measure the quality of the radioactive probe $\left(1-2 \times 10^{6} \mathrm{cpm} / \mu \mathrm{l}\right)$. The probes were kept at $-20{ }^{\circ} \mathrm{C}$ and used the same/next day. 


\subsection{Templates used}

Riboprobes baring a sequence complementary to the mRNA of interest (antisense) were synthesized using the following cDNA templates:

\begin{tabular}{|c|c|c|c|c|c|}
\hline cDNA & Size (bp) & Vector & Enzyme & Pol & Provider \\
\hline Axin 2 & 387 & pSVSport1 & SalI & $\mathrm{T} 7$ & R.Grosschedl \\
\hline Cux2 & 530 & pGEM-T & SpeI & $\mathrm{T} 7$ & Lab stock \\
\hline$E m x 2(E P 1.3)$ & 359 & & BssHI & $\mathrm{T} 7$ & A.Mallamaci \\
\hline Er81 & 300 & pGEM-Teasy & SacII & SP6 & Lab stock \\
\hline$K A 1$ & 331 & pGEM-T & SpeI/NdeI & $\mathrm{T} 7$ & Lab stock \\
\hline Msxl & 516 & pGEM-T & ApaI & SP6 & Lab stock \\
\hline Oct6/SCIP & 170 & BluescriptKS & BamHI & $\mathrm{T} 3$ & P.Gruss \\
\hline Prox 1 & 300 & & SacI & $\mathrm{T} 3$ & P.Gruss \\
\hline $\operatorname{Ror} \beta$ & 400 & & SalI & $\mathrm{T} 3$ & Lab stock \\
\hline Sip1(ex4-7) & 700 & pGEM-Teasy & SpeI & $\mathrm{T} 7$ & Lab stock \\
\hline Sip1(ex7) & & & SacI & $\mathrm{T} 7$ & D.Huylebroeck \\
\hline Sfrp1 & 400 & pT773D-PacI & SfiI & $\mathrm{T} 3$ & RZPDgi.7305480 \\
\hline SvetI & 900 & pBluescript & XhoI & $\mathrm{T} 7$ & P.Gruss \\
\hline Wnt $3 A$ & 800 & pBluescriptSK & NotI & $\mathrm{T} 7$ & A.Mallamaci \\
\hline Wnt5A & 1000 & pBluescriptSK & PstI & $\mathrm{T} 3$ & A.Mallamaci \\
\hline
\end{tabular}




\subsection{3 cDNA microarray}

\subsubsection{RNA isolation}

Hippocampi of E15.5 mice were removed and kept until mouse genotyping in RNAlater (Sigma) at $-20^{\circ} \mathrm{C}$. Total RNA from Sip1 mutant and control tissue was individually isolated with TRIzol (Invitrogen) using DEPC (Sigma) water (1ml/l) and filtered tips. Samples were further processed for microarray analysis in the GBC, Braunshweig.

\subsection{Histological procedures}

\subsubsection{Tissue preparation}

The day of vaginal plug was considered embryonic day (E) 0.5. Pregnant females were sacrificed by cervical dislocation. Brains were fixed either by immersion (embryonic and perinatal brains) into or perfused (adult brains) by freshly prepared $4 \%$ paraformaldehyde (PFA, Sigma) in PBS (pH 8) overnight at $4^{\circ} \mathrm{C}$ and then washed, dehydrated, and embedded in wax according to standard procedures. Sections $(10 \mu \mathrm{m}$ thick) were mounted on Marienfeld Histobond slides and dried overnight at $37^{\circ} \mathrm{C}$. Alternatively, upon $4 \%$ paraformaldehyde-PBS fixation, brains were cryoprotected by $30 \%$ sucrose-PBS, included in OCT (TissueTeck) and cut at $10 \mu \mathrm{m}$ with a cryostat. Cryosections, mounted on Menzel-Gläser SuperFrost Plus slides, were dried for $20 \mathrm{~min}$. and kept at $-80^{\circ} \mathrm{C}$ until used.

Paraffin sections were subsequently dewaxed by histoclear (xylene substitute), rehydrated in descending ethanol series, and processed for Nissl staining, immunohistochemistry or in situ hybridization. 


\subsubsection{Nissl staining}

After rehydration, paraffin sections were washed in $\mathrm{H}_{2} \mathrm{O}$ for 5 min., incubated in $50 \%$ (w/v) potassium sulfite solution for $15 \mathrm{~min}$. and washed again. Sections were stained for $20 \mathrm{~min}$. in cresylviolet solution (1.5\% cresylviolet in acetate buffer) and cleared in two washes of acetate buffer $\left(10 \mathrm{mM}\right.$ sodium acetate, $10 \mathrm{mM}$ acetic acid in $\mathrm{H}_{2} \mathrm{O}$ ) for $2 \mathrm{~min}$ (or until desired coloration was achieved). Sections were finally rinsed in $\mathrm{H}_{2} \mathrm{O}$, dehydrated in a series of ethanol dilutions $(70 \%, 80 \%, 100 \%, 100 \% ; 2 \mathrm{~min}$. each) and immersed in histoclear for 10min. Nissl-stained sections were mounted using Eukitt mounting media (E. Kindler $\mathrm{GmbH}$ ).

\subsubsection{Immunohistochemistry}

For immunohistochemistry on paraffin sections and after dehydrating the sections, two unmasking steps were usually carried out by 3 min.-boiling and chilling in Unmasking solution (Vector). Both paraffin and frozen sections were washed in PBS, blocked for $1 \mathrm{~h}$ in BSA-blocking solution (1\%BSA (Sigma) / 0.5\%Tween-20 in PBS) and incubated with primary antibodies overnight at $4{ }^{\circ} \mathrm{C}$ in the same solution. Sections were then washed and incubated for $1 \mathrm{~h}$ with secondary antibodies that were either biotinylated, HRP- or fluorophor-conjugated. For biotynilated antibodies, extravidin conjugated with HRP (Upstate 1:50) was used. In the case of HRP-secondary antibodies, the blocking of endogenous peroxydase was performed $\left(50 \% \mathrm{MeOH} / 3 \% \mathrm{H}_{2} \mathrm{O}_{2} /\right.$ PBS for $30 \mathrm{~min}$ at RT) prior to the incubation in BSA-blocking solution. The HRP detection was carried out by the $\mathrm{ABC}$ method with diaminobenzidine (Vector). Sections were mounted either in Mowiol (Calbiochem) or in Prolong Gold Antifade with DAPI (Molecular Probes). The following antibodies were used: 


\begin{tabular}{|c|c|c|c|c|}
\hline Antigen & Source & Class & Provider & Conc. \\
\hline$\beta$-Cat & Mouse & Monoclonal & BD Biosciences 610153 & $1: 100$ \\
\hline BrdU & Mouse & Monoclonal & Chemicon MAB3424 & $1: 100$ \\
\hline BrdU & Rat & Monoclonal & Abcam ab6326 & $1: 100$ \\
\hline Brn2 & Goat & Polyclonal & Santa Cruz SC6029 & $1: 500$ \\
\hline GABA & Rabbit & Polyclonal & Sigma A2052 & $1: 200$ \\
\hline GFAP-Cy3 & Mouse & Monoclonal & Sigma C9205 & $1: 200$ \\
\hline Nestin & Mouse & Monoclonal & Chemicon MAB353 & $1: 100$ \\
\hline Reelin & Mouse & Monoclonal & Calbiochem 553731 & $1: 500$ \\
\hline Satb2 & Rabbit & Polyclonal & Lab stock & $1: 200$ \\
\hline Sip1 & Rabbit & Polyclonal & Lab stock & $1: 500$ \\
\hline Tbr1 & Rabbit & Polyclonal & M. Sheng's Lab & $1: 200$ \\
\hline TujI & Mouse & Monoclonal & Sigma T8660 & $1: 300$ \\
\hline $\begin{array}{l}\text { Alexa Flour } 488 \text { anti- } \\
\text { mouse IgG }(\mathrm{H}+\mathrm{L})\end{array}$ & Goat & Polyclonal & Molecular Probes & $1: 1000$ \\
\hline $\begin{array}{l}\text { Alexa Flour } 568 \text { anti- } \\
\text { rat } \operatorname{IgG}(\mathrm{H}+\mathrm{L})\end{array}$ & Goat & Polyclonal & Molecular Probes & $1: 1000$ \\
\hline $\begin{array}{l}\text { Alexa Flour } 594 \text { anti- } \\
\text { rabbit IgG }(\mathrm{H}+\mathrm{L})\end{array}$ & Goat & Polyclonal & Molecular Probes & $1: 1000$ \\
\hline anti-mouse IgG-Cy3 & Rabbit & Polyclonal & $\begin{array}{l}\text { Jackson } \\
\text { ImmunoResearch }\end{array}$ & $1: 2000$ \\
\hline anti-rabbit IgG-Cy5 & Goat & Polyclonal & $\begin{array}{l}\text { Jackson } \\
\text { ImmunoResearch }\end{array}$ & $1: 2000$ \\
\hline $\begin{array}{l}\text { anti-mouse IgG } \\
(\mathrm{G}+\mathrm{M})-\mathrm{HRP}\end{array}$ & Goat & Ployclonal & Chemicon & $1: 500$ \\
\hline Anti-rat IgG-HRP & Rabbit & Polyclonal & Sigma A5795 & $1: 500$ \\
\hline $\begin{array}{l}\text { Anti-mouse IgG- } \\
\text { Biotin }\end{array}$ & Goat & Ployclonal & Sigma B8895 & $1: 300$ \\
\hline Anti-goat IgG-Biotin & Rabbit & Ployclonal & Sigma B8895 & $1: 300$ \\
\hline
\end{tabular}




\subsubsection{Assessment of cell proliferation and apoptosis}

Mitotically active cells (S-phase) incorporate in the newly synthesized DNA, the thymidine analogue 5'-Bromo-2'-deoxyuridine (BrdU, Sigma) (Hevner et al., 2003). Pregnant females received a peritoneal injection of $100 \mathrm{mg} / \mathrm{kg}$ body weight BrdU (Sigma) and were sacrificed $1.5 \mathrm{~h}$ later. Paraffin sections were prepared as described above. After antigen retrieval, sections were treated with $2 \mathrm{~N} \mathrm{HCl}$ for $20 \mathrm{~min}$. at $37^{\circ} \mathrm{C}$, neutralized with $0.1 \mathrm{M} \mathrm{Na} \mathrm{Na}_{2} \mathrm{~B}_{4} \mathrm{O}_{7} \mathrm{pH} 8.5$ twice for 5min., washed with PBS and processed for immunohistochemistry. For counting BrdU-labeled cells, six sections at the same coronal level were chosen for each animal. Three independent pairs of littermates were quantified and the data was statistically analyzed by Student's $t$-test.

Apoptotic cell death was assessed by TUNEL assay on paraffin sections using the Apoptag Fluorescein Direct In situ Apoptosis Detection Kit (Chemicon), according to the manufacturer's instructions.

\subsubsection{RNA in situ hybridization}

\subsubsection{Non-radioactive in situ}

Frozen sections were defrost and incubated in PBS-DEPC water for $5 \mathrm{~min}$ at RT. They were rinsed in $0.1 \mathrm{M}$ TEA pH8 for $5 \mathrm{~min}$., incubated for $10 \mathrm{~min}$ in acetylation buffer (0.05M acetic anhydride/ 0.1M TEA) and rinsed twice in PBS-DEPC water (5min./each). They were then prehybridized for 2-4h in filtered Hybridization buffer containing: 
$50 \% \quad$ Formamide (Fulka)

$25 \% \quad 20 x \mathrm{SSC}\left(3 \mathrm{M} \mathrm{NaCl} / 0.3 \mathrm{M} \mathrm{NaCitrate/} \mathrm{DEPC} \mathrm{H}_{2} \mathrm{O} ; \mathrm{pH}\right.$ )

$20 \%$ Blocking reagent 10\% (Boehringer)

$0.02 \% \operatorname{SDS} 20 \%$

$0.1 \%$ Sarcosyl 10\%

DEPC- $\mathrm{H}_{2} \mathrm{O}$

Slides were hybridized for $16 \mathrm{~h}$ at $65^{\circ} \mathrm{C}$ in $150 \mu \mathrm{l}$ Hybridization buffer containing $~ 200 \mathrm{ng}$ of cRNA probe. After washing in 2xSSC, slides were incubated with RNase A $(50 \mu \mathrm{g} / \mathrm{ml}$ in $10 \mathrm{mM}$ TrisCl; $1 \mathrm{mM}$ EDTA, $500 \mathrm{mM} \mathrm{NaCl}$; $\mathrm{pH} 8.0$ ) for $30 \mathrm{~min}$ at $37^{\circ} \mathrm{C}$, and washed at $68^{\circ} \mathrm{C}$ and then at RT in $0.2 x S S C$. For immunological detection, slides were preequilibrated in buffer $1(0.1 \mathrm{M}$ maleic acid, $0.15 \mathrm{M} \mathrm{NaCl}, \mathrm{pH} 7.5)$, blocked for $1 \mathrm{~h}$ in buffer 2 (buffer 1 containing $1 \mathrm{x}$ blocking agent), and overlayed with anti-DIG-AP antibody (Boehringer) diluted 1:2000 in buffer 2. Slides were washed twice for 30min in buffer 1 and 5min in buffer $3(100 \mathrm{mM}$ Tris- $\mathrm{HCl}, 100 \mathrm{mM} \mathrm{NaCl}, 50 \mathrm{mM} \mathrm{MgCl} 2, \mathrm{pH} 9.5)$. For signal detection, slides were incubated in color substrate solution containing $45 \mu$ of 4-nitroblue tetrazoliumchloride (NTB; $75 \mathrm{mg} / \mathrm{ml}$ in $70 \%$ dimethylformamide; Roth) and $35 \mu \mathrm{l}$ of 5 -bromo-4-chloro-3-indolyl-phosphate, (BCIP; $50 \mathrm{mg} / \mathrm{ml}$ in $100 \%$ dimethylformamide; Roth), per 10ml of buffer 3. The slides were kept in darkness at RT and the signal was monitored in the following $6-48 \mathrm{~h}$. The reaction was stopped by immersion in TE buffer (10 mM Tris, $1 \mathrm{mM}$ EDTA, $\mathrm{pH}$ 8). Mounting of slides was done using Mowiol (Calbiochem). 


\subsubsection{Radioactive in situ}

Paraffin sections were dewaxed in Histoclear (twice for 10min), rehydrated in a series of ethanol dilutions $(100 \%, 100 \%, 95 \%, 90 \%, 80 \%, 70 \%, 50 \%, 30 \%, 2 \mathrm{~min} / \mathrm{each})$ and rinsed in saline $\left(0.86 \% \mathrm{NaCl}\right.$ in DEPC- $\left.\mathrm{H}_{2} \mathrm{O}\right)$ and PBS-DEPC. They were then fixed for $15 \mathrm{~min}$ in 4\% PFA/PBS-DEPC and washed twice in PBS-DEPC for 5min. The sections were immersed for 5min. in Proteinase K solution (50mM Tris-HCl; 5mM EDTA; $20 \mu \mathrm{g} / \mathrm{ml}$ Proteinase K) and rinsed in PBS-DEPC. Sections were placed in freshly prepared acetylation buffer $\left(0.1 \mathrm{M}\right.$ Triethanolamine; $0.05 \mathrm{M}$ acetic anhydride in $\left.\mathrm{DEPC}-\mathrm{H}_{2} \mathrm{O}\right)$ twice for 15min, washed in PBS-DEPC and dehydrated in the ethanol series.

The radioactive RNA probe was diluted to $10^{5} \mathrm{cpm} / \mu$ in Hybridization Buffer:

50\% Deionized Formamide (Fulka)

10\% Hybridization Salt stock (0.2\% Polyvinilpyrrolidon; 0.2\% Ficoll; $0.1 \mathrm{M}$ $\mathrm{NaH}_{2} \mathrm{PO}_{4} ; 50 \mathrm{mM}$ EDTA pH6.8; $3 \mathrm{M} \mathrm{NaCl} ; 0.1 \mathrm{M}$ Tris-HCl pH8 in DEPC$\left.\mathrm{H}_{2} \mathrm{O}\right)$

$10 \% \quad 1 \mathrm{M}$ DTT (Sigma/Promega)

20\% Dextran sulfate 50\% (Amersham)

$500 \mu \mathrm{g} / \mathrm{ml} \quad$ tRNA (Sigma)

$200 \mu \mathrm{g} / \mathrm{ml} \quad \alpha$ SPthio-ATP (Roche)

Diluted probes were denatured at $80^{\circ} \mathrm{C}$ for $2 \mathrm{~min}$ and placed immediately on ice for $5 \mathrm{~min}$. Around $12-18 \mu$ l of the diluted probe was applied to each section and covered with $15 \times 20 \mathrm{~mm}$ coverslips, previously siliconized with SurfaSil ${ }^{\mathrm{TM}}$, according to the manufacturer's instructions. Sections were hybridized overnight at $55^{\circ} \mathrm{C}$ in a humid chamber containing $50 \%$ formamide in $2 \mathrm{xSSC}$. 
Sections were transferred to $2 \mathrm{xSSC}$ at $55^{\circ} \mathrm{C}$ and coverslips were removed by gentle agitation $(<15 \mathrm{~min}$.). Sections were then washed in $50 \%$ Formamide $/ 2 \times \mathrm{SSC}$ at $75 \%$ then at $65^{\circ} \mathrm{C}$ (both in a shaking waterbath). A new wash in the same solution was carried out for $30 \mathrm{~min}-2 \mathrm{~h}$ at $37^{\circ} \mathrm{C}$ with slight agitation. The sections were then incubated twice in NTE buffer $(0.5 \mathrm{M} \mathrm{NaCl} ; 10 \mathrm{mM}$ Tris-HCl; $5 \mathrm{mM}$ EDTA pH8) for 5 and $15 \mathrm{~min}$. The unbound RNA was digested with $20 \mu \mathrm{g} / \mathrm{ml}$ RNase A (Boehringer) in NTE buffer at $37^{\circ} \mathrm{C}$ for $30 \mathrm{~min}$. Sections were then incubated at $37^{\circ} \mathrm{C}$ in NTE buffer (shaking for $15 \mathrm{~min}$ ) to wash out the RNase. They were washed in preheated $50 \%$ Formamide $/ 2 \mathrm{xSSC}$ at $65 \%$ then at $37^{\circ} \mathrm{C}$. The salt concentration was decreased by washing first in $2 \mathrm{xSSC}$ then in $0.1 \mathrm{xSSC}$, 15min./each. Sections were finally dehydrated in the ethanol series and let dry. A preview of the signal was obtained by exposing the sections to Biomax X-ray films (Kodak) overnight.

Autoradiography with the hybridized sections was performed in complete darkness by embedding the slides in NTB-2 emulsion (Kodak) pre-warmed at $42^{\circ} \mathrm{C}$. Sections were let dry and exposed overnight at RT then at $4{ }^{\circ} \mathrm{C}$ for few days $(5-10$, depending on the strength of the signal). After exposition, the emulsion was developed in total darkness by dipping into $16 \%(\mathrm{w} / \mathrm{v})$ Kodak D-19 developer solution for $4 \mathrm{~min}$. at $15^{\circ} \mathrm{C}$.; washed in $1 \%$ $(\mathrm{v} / \mathrm{v})$ acetic acid for $1 \mathrm{~min}$. and fixed in $30 \%(\mathrm{w} / \mathrm{v})$ sodium thiosulfate (Sigma) for $3 \mathrm{~min}$. The slides were finally washed several times in water and counterstained in a solution containing $4 \%$ of Giemsa stock ( $0.85 \%$ Giemsa; $50 \%$ Glycerol; $50 \%$ Methanol) and 2\% 0.2M Sodium phosphate buffer ( $\mathrm{pH} 6$ ). The excess of stain was washed out in running tap water. Sections were air-dried and mounted with Eukitt. 


\subsubsection{Image acquisition}

Bright and dark field images were obtained with a light microscope (Olympus). For fluorescence images, a Leica inverted microscope equipped with a TCS-SP2 confocal scanhead was used. Confocal pictures of $1-2 \mu \mathrm{m}$ thickness were acquired by sequential 4line averaging. Fluorophors were excited with an Argon laser $(488 \mathrm{~nm})$ or with diode lasers (561 and 405nm). Pictures were analyzed with the Leica software and further merged and refined with Adobe Photoshop.

\subsection{Western blotting}

Tissue from the medial telencephalon of E15.5 embryos was extracted, dissociated in Triton X-100 buffer (25mM HEPES pH7.2; 150mM NaCl; 1mM EDTA; 2mM DTT; $0.5 \%$ Triton $\mathrm{X}-100$ and proteinase inhibitors) and centrifuged at $1000 \mathrm{~g}$ for $15 \mathrm{~min}$. The supernatant was dissolved 1:2 in Protein loading buffer (125mM Tris-HCl pH6.8; 15\% Glycerol; 3\% SDS; 5\% $\beta$-mercaptoethanol; $0.05 \%$ bromophenol blue). The proteins ( 40 $120 \mathrm{kDa}$ ) were resolved by SDS-Polyacrylamide Gel Electrophoresis (SDS-PAGE) on a $10 \%$ polyacrilamide gel consisting of an initial $1-2 \mathrm{~cm}$-stucking gel $(0.125 \mathrm{M}$ Tris- $\mathrm{HCl}$ pH6.8; 0.1\% SDS; 0.1\% APS; 0.1\% TEMED; 3.2\% acrylamide) and a 4-6cm-resolving gel (0.375M Tris-HCl pH8.8; 0.1\% SDS; 0.05\% APS; 0.05\% TEMED; $10 \%$ acrylamide). The running buffer contained 25mM Tris-base; $192 \mathrm{mM}$ glycine and $0.1 \%$ Sodium Dodecyl Sulfate (SDS, Fluka). The Page-Ruler ${ }^{\mathrm{TM}}$ Protein Ladder (Fermentas) was run in parallel to estimate the molecular weight of proteins.

The proteins were then transferred by electroblotting from the gel onto a nitrocellulose membrane $(0.2 \mu \mathrm{m}$ pore diameter, Millipore) by a standard semy-dry procedure. The transference was performed under constant current $\left(2.5 \mathrm{mAmp} / \mathrm{cm}^{2}\right)$ for 
45min. Membranes were blocked for $1 \mathrm{~h}$ in a solution containing 5\% Milk in TBS-T $(0.05 \%$ Tween-20; $10 \mathrm{mM}$ Tris- $\mathrm{HCl} \mathrm{pH} 8 ; 0.9 \% \mathrm{NaCl})$, probed with primary antibodies overnight at $4{ }^{\circ} \mathrm{C}$ and washed in the same solution (4 times, 5min/each). Secondary HRPconjugated antibodies were incubated in 5\% Milk-TBS-T for 2 hours at RT, washed in the same solution, then in TBS-T and TBS. Proteins were detected by chemiluminiscence using the ECL kit (Amersham) according to the manufacturer's instructions and by exposure to X-Omat ${ }^{\mathrm{TM}}$ Blue Films. The following antibodies were used:

$\begin{array}{lllll}\text { Antigen } & \text { Source } & \text { Class } & \text { Provider } & \text { Conc. } \\ \text { Active } \beta \text {-Cat } & \text { Mouse } & \text { Monoclonal } & \text { Upstate 05-665 } & 1: 250 \\ \beta \text {-Cat } & \text { Mouse } & \text { Monoclonal } & \text { BD Biosciences 610153 } & 1: 500 \\ \text { GAPDH } & \text { Mouse } & \text { Monoclonal } & \text { Chemicon MAB374 } & 1: 300 \\ \text { Active JNK } & \text { Mouse } & \text { Monoclonal } & \text { Santa Cruz SC6254 } & 1: 500 \\ \text { TujI } & \text { Mouse } & \text { Monoclonal } & \text { Sigma T8660 } & 1: 300 \\ \begin{array}{l}\text { anti-mouse IgG } \\ (\mathrm{G}+\mathrm{M})-H R P\end{array} & \text { Goat } & \text { Ployclonal } & \text { Chemicon } & 1: 5000\end{array}$




\section{Results}

\subsection{Sip1 expression and gene ablation in the cortex}

In the developing mouse brain, Sipl mRNA is predominantly expressed in the telencephalon, basal ganglia and thalamus (Fig. 4). By the time the cortex starts to form (E12.5), the developing telencephalon showed strong Sip1 in situ hybridization signals in the preplate, the region where young post-mitotic neurons are located (Fig. 4a,b). Sip1 expression in the neocortex and prospective hippocampus was also observed at later embryonic stages. At E16.5 (Fig. 4c,e) and E18.5 (Fig. 4g,i) stronger Sip1 in situ hybridization signals were detected in post-mitotic (IZ, CP) than in mitotically active areas (VZ, SVZ).

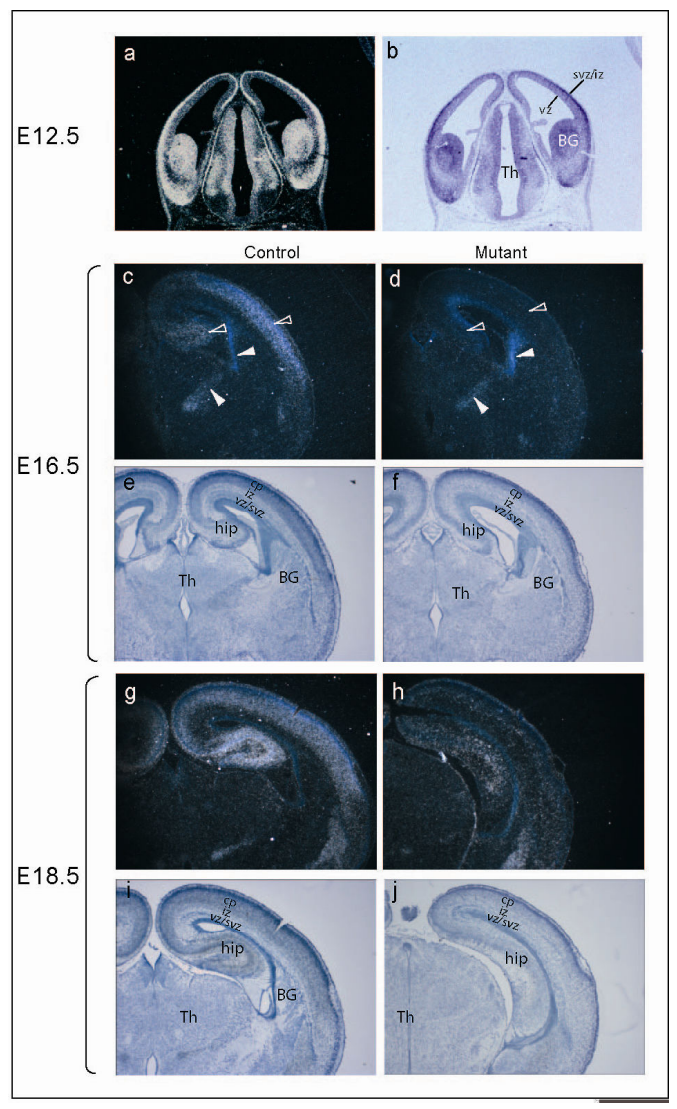

Fig.4: Sip1 mRNA is expressed in the developing mouse brain and is specifically deleted in the cortex of Sip1 mutant mice. Empty arrows indicate cortical domains; filled arrows point to non-cortical expression domains. 
Moreover, the wild-type expression of Sip1 protein in the developing telencephalon of at E16.5 (Fig. 5a) correctly recapitulates that of the mRNA signal at the same stage (Fig 4c,e).
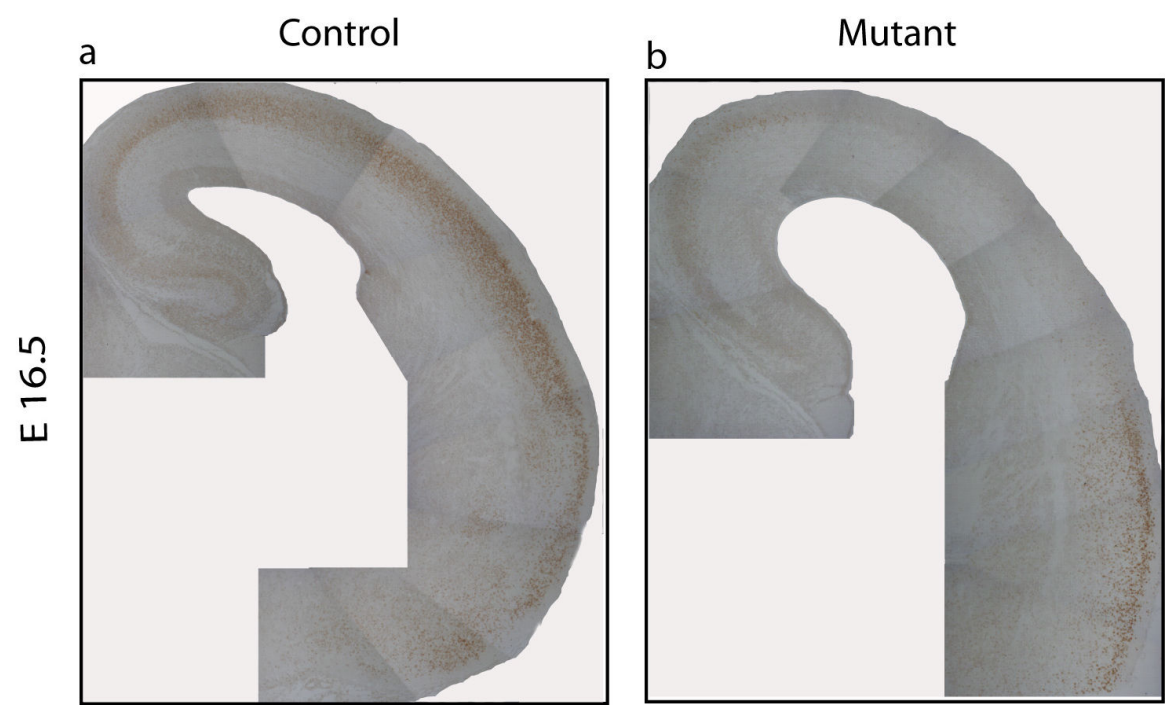

Fig.5: Immunohistochemistry analysis of Sip1expression in the cortex

In order to inactivate Sip1 function specifically in the cortex, we created Sip1 mutants by crossing Siplexo $7^{\text {flox }}$ with Emx $1^{\text {IRESCre }}$ mouse lines (see M\&M for details). The tissuespecific gene deletion was first confirmed by PCR (Fig. 6). A $\sim 2 \mathrm{~kb}$ PCR fragment could be amplified from genomic DNA only when the floxed exon7 of Sip1 is excised by Cre recombinase (Fig. 6b, boxes represent exons and triangles the loxP sequences). Using several samples of genomic DNA from E15.5 cortices (lanes 1-13), a PCR product was obtained only when either one (+/-) or two (-/-) Siplexo $7^{\text {flox }}$ alleles were present together with Cre (Fig. 6a). Concordantly, Siplexo7 deletion did not occur in corresponding tissue from midbrain and tail, where Cre is not synthesized (data not shown). 

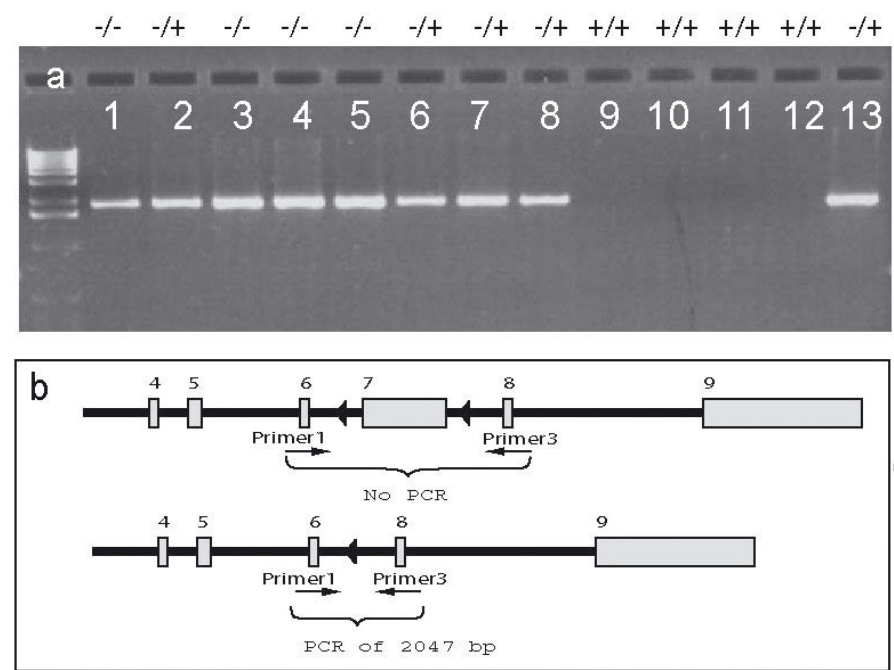

Fig. 6: Verification of specific Sip1 exon 7-deletion in the mutant cortex by PCR

To further confirm Sip1 ablation in the dorsal telencephalon, we carried out radioactive in situ hybridization with an exon7-specific RNA probe at E16.5 and E18.5. In Sip1 mutants (Fig. 4d,h), expression of wild type (Fig. 4c,g) Sipl mRNA was abolished in the developing Ncx and Hip (empty arrowheads) but remained unchanged in other regions such as BG and Th (filled arrowheads). At E18.5, however, we detected some Sip1 signal scattered throughout the mutant cortex with a relatively higher intensity in the hippocampus (Fig. 4h). Similarly, at the protein level, Sip1 expression was abolished in the mutant cortex although very few $\operatorname{Sip}^{+}$nuclei were still observed laterally, in the piriform cortex (Fig. 5b). 


\subsection{Sip1 in the development of the hippocampus}

\subsubsection{Sip1 deletion affects hippocampal development}

Sip1 mutants were born with the expected Mendelian frequency. Mutants were generally smaller than control littermates and survived until early adulthood (3-4 weeks-old), age at which the differences in weight were almost two-fold (Fig. 7). Analysis of Nissl-stained sections of adult Sip1 mutant brains showed a remarkable phenotype in which both the hippocampus and corpus callosum were consistently missing (Fig. 8).

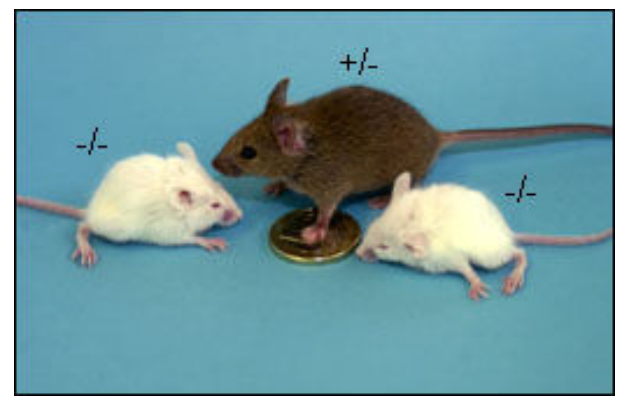

Fig. 7: Adult Sip1 mutant (-/-) and control littermates (+/-)

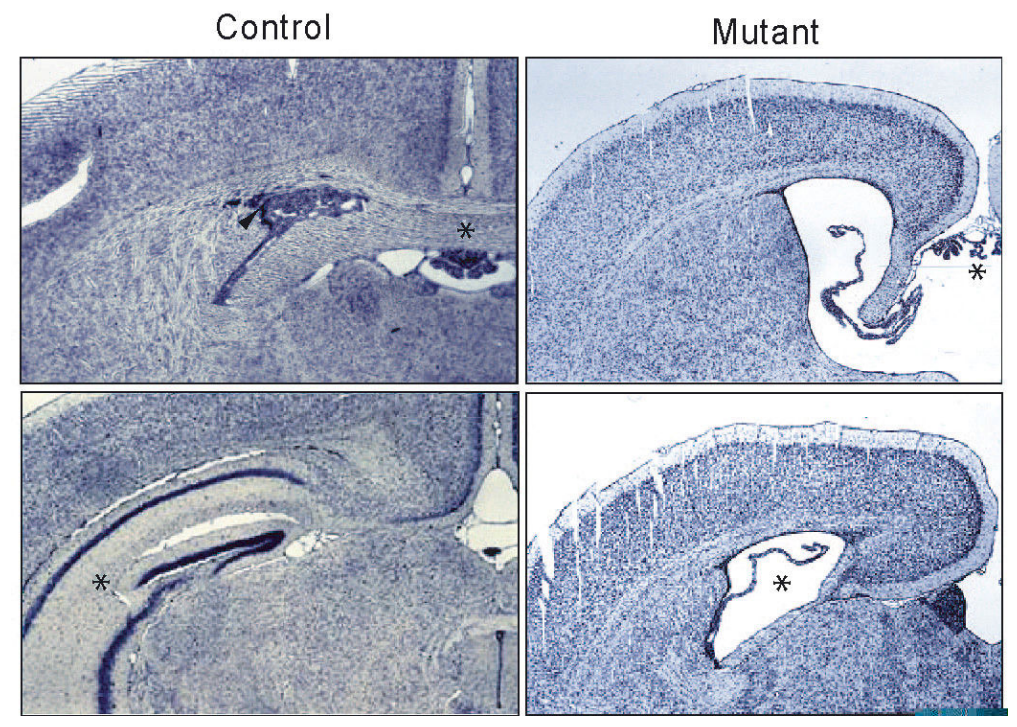

Fig. 8: Adult Sip1 mutants lack hippocampus and corpus callosum 
The morphological onset of the phenotype was detected at E15.5 (Fig. 9, left panel) as at this stage the developing mutant hippocampus appeared smaller than in control mice. Later at P2, the absence of corpus callosum in Sip1 mutants was clear, and the difference in hippocampal size between mutant and control littermates was more pronounced, in particular that of the DG (Fig. 9, middle panel). Perinatally, all hippocampal fields were reduced in size but not completely absent in Sipl mutants (Fig. 9j,1). This was confirmed by in situ hybridization (Fig. 9, right panel) with the CA3 and CA1 markers: KA1 (Wisden and Seeburg, 1993) and SCIP/Oct6 (Frantz et al., 1994), respectively. The dentate gyrus was almost absent (Fig. 91,r), although there were very few cells caudally expressing the earliest molecular marker known for the DG, Proxl (Oliver et al., 1993).
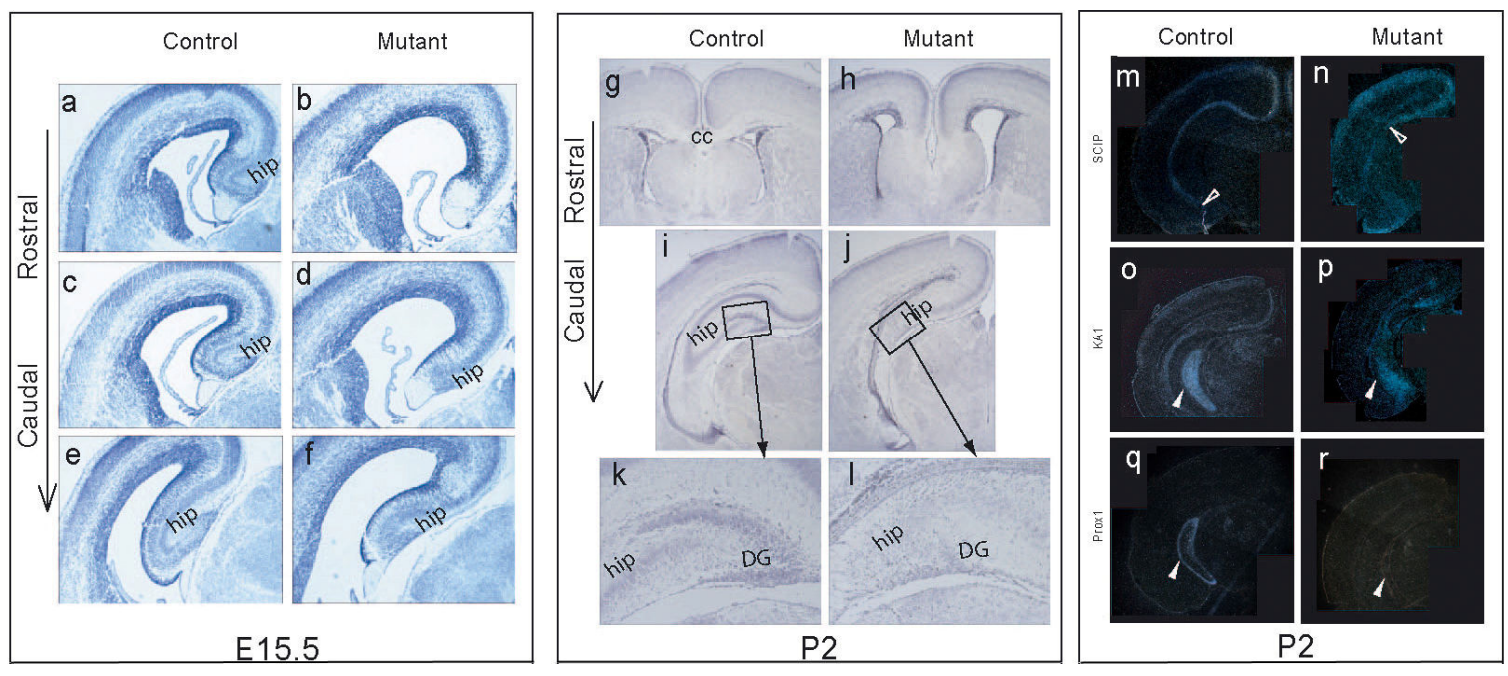

Fig. 9: Hippocampal development is severely compromised in Sip1 mutants. Morphological comparisons of Nissl-stained coronal sections of E15.5 (left panel) and P2 (middle panel). The right panel shows the expression of hippocampal markers (empty arrowheads demarcate the medial border of SCIP expression in CA1; filled arrowheads indicate the cortical domains of expression of KA1 and Prox 1 in CA3 and DG regions respectively). 


\subsubsection{Sip1 ablation increases cell death and impairs neural progenitor cell proliferation in the hippocampus and dentate gyrus}

The reduction of the overall size of the hippocampal formation could be due to an increased cell death rate, to a decrease in proliferation and/or to premature neuronal differentiation in the developing hippocampus. In the latter, a larger number of differentiated cells would be produced at the expense of the proliferating pool. For this, the presence of the neuron-specific class III beta-tubulin $(\mathrm{TuJ} 1$, a marker of differentiating neurons) and nestin (a marker of neuronal progenitors) was investigated at the onset of the phenotype (Fig. 10).

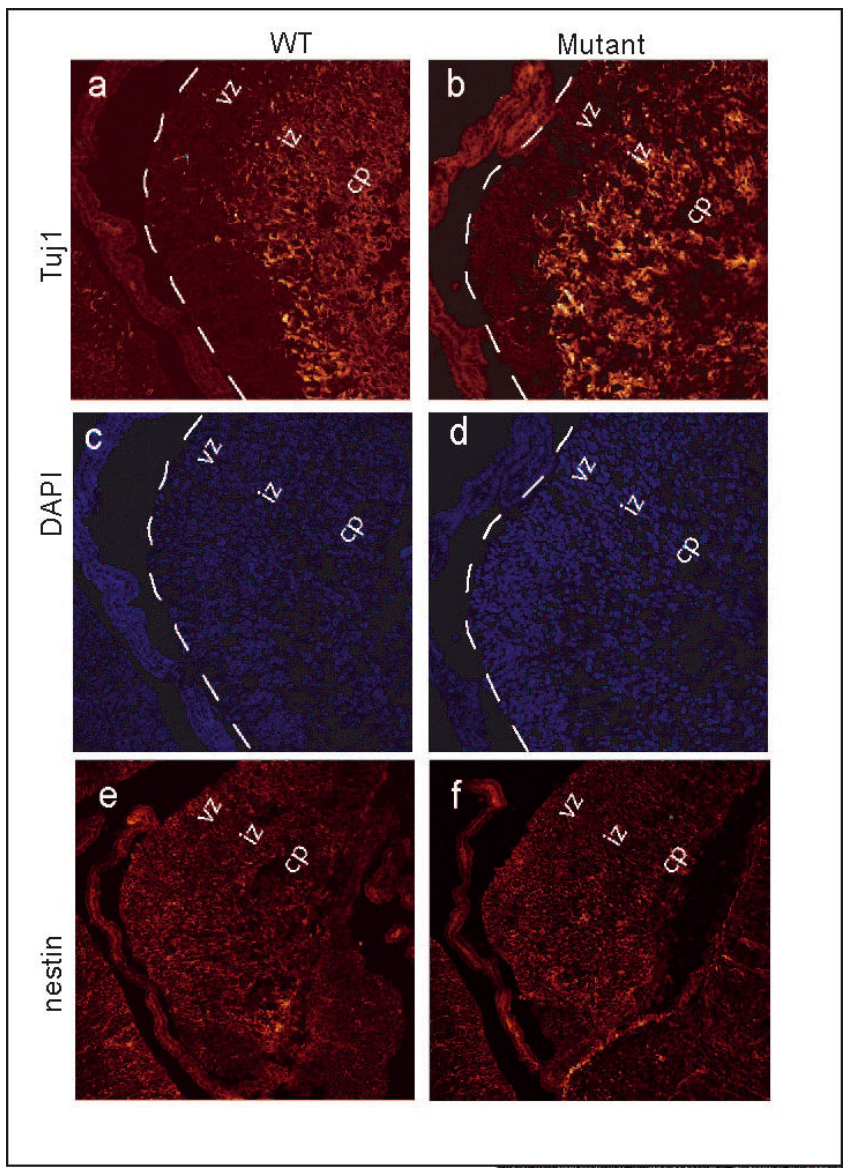

Fig. 10: Neuronal differentiation is not altered in the developing hippocampus of Sip1 mutants at E15.5. Dashed lines delineate the border with the ventricle. 
Immunohistochemistry against TuJ1 shows the confinement of early-differentiated neurons to the CP and IZ of the developing hippocampus in both control (Fig. 10a) and mutant (Fig. 10b) brains. In the same sections, density of $\mathrm{DAPI}^{+}$cell nuclei did not seem to be altered (Fig. 10c,d). Neuronal precursors labeled with Nestin antibody were present in the mutant hippocampal anlage (Fig. 10f) in a similar pattern as in control brains (Fig. 10e). These data suggest that the cause of cellular depletion in the mutant hippocampus is other than premature differentiation of precursors into neurons. To answer the question of whether Sip1 is required for the normal proliferation of progenitors in the prospective hippocampus, we monitored the incorporation of bromodeoxyuridine (BrdU) into the nuclei of cycling cells (see M\&M for details). At the onset of the morphological onset of the phenotype (E14.5-15.5), the number of $\mathrm{BrdU}^{+}$ cells was significantly reduced in both the VZ of the hippocampus and in the proliferating dentate gyrus (Fig 11).

The number of proliferating $\mathrm{BrdU}^{+}$cells at E15.5 (Fig 11c,d) was quantified in the ventricular zone of the developing hippocampus (small dashed box) and within the secondary proliferative population of the dentate gyrus (SPP, big dashed box) of 3 independent pairs of mutant and control brains in a number of corresponding sections (mutant, $\mathrm{n}=29$; control, $\mathrm{n}=27$ ). Results were normalized to the area and expressed in $\mathrm{um}^{2}$. Statistical analysis was performed using the Student's $t$-test. A substantial decrease $(P$ $<0.0001$ ) of about $20 \%$ and $75 \%$ in proliferation rate was detected within the proliferating hippocampus and dentate gyrus of Sip1 mutants (Fig. 12). 


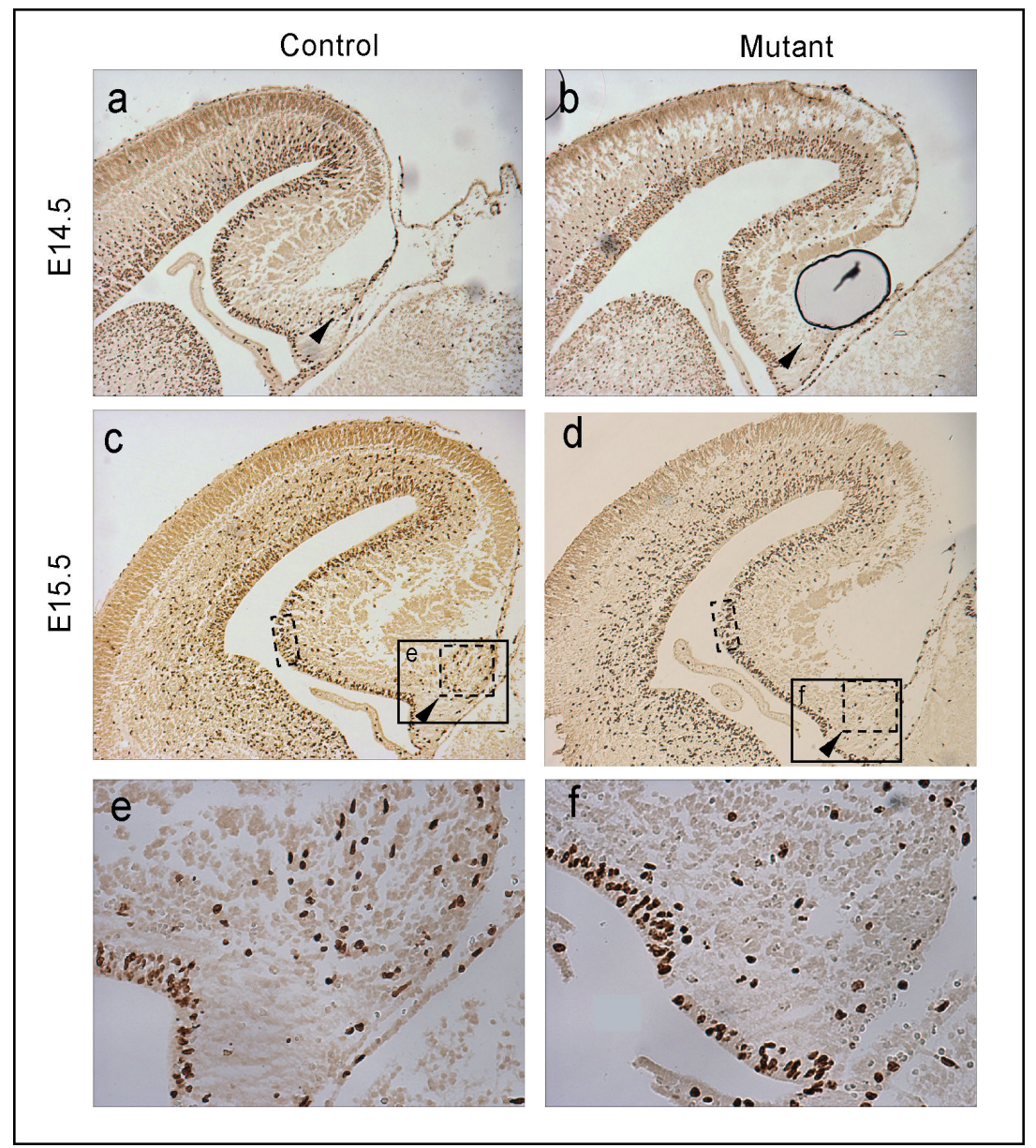

Fig. 11: Decreased proliferation in the Sip1 mutant hippocampus and dentate gyrus. Cells that incorporated the thymidine analogue BrdU after a 1,5h-pulse were detected by immunohistochemistry on coronal sections of E14.5 (a,b) and E15.5 (c,d) brains. Note the reduced number of $\mathrm{BrdU}^{+}$cells of the second proliferative population (black arrows in a-d and high magnification of boxes $(e, f)$ from $c, d)$ when mutant $(b, d)$ are compared with control brains $(\mathrm{a}, \mathrm{c})$.

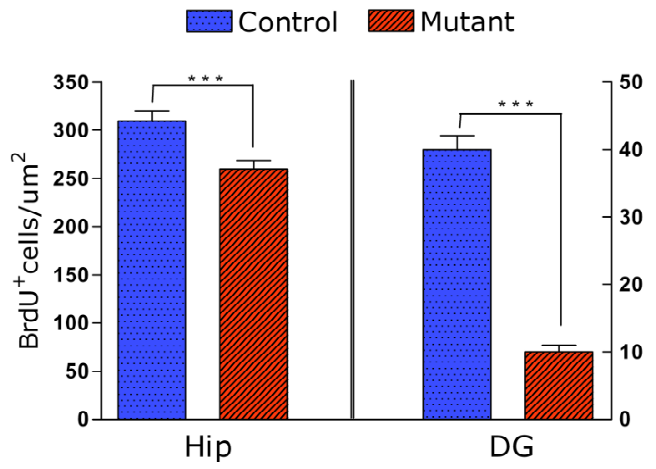

Fig. 12: Proliferation is significantly reduced in the hippocampus $(\sim 20 \%)$ and dentate gyrus $(\sim 75 \%)$ of E15.5 Sip1 mutant mice. $(* * * P<0.0001)$ 
A direct TUNEL assay was performed in order to investigate whether the cells in the hippocampus would respond to Sip1 deficiency by activating apoptotic cell death. Before the morphological onset of the mutant phenotype at E14.5, apoptotic cell death was not detected in either mutant or control brains (data not shown). Starting from E16.5, however, a substantial increase in the number of TUNEL-positive cells was observed in the mutant hippocampi (Fig. 13a,b). At this stage, cells undergoing apoptosis were located in the $\mathrm{CP}$ of the developing hippocampus, a region composed mainly of postmigratory neurons, but not in the hippocampal ventricular and intermediate zones or in the neocortex. Later, at P0, the majority of dying cells was detected in the intermediate zone and ventral part of the $\mathrm{CP}$ of the hippocampus (Fig. 13c,d). Thus, using three different approaches, it can be concluded that increased apoptotic cell death and decreased proliferation, but not premature differentiation, may account for the total loss of the hippocampus and dentate gyrus in adult Sip1 mutant mice.

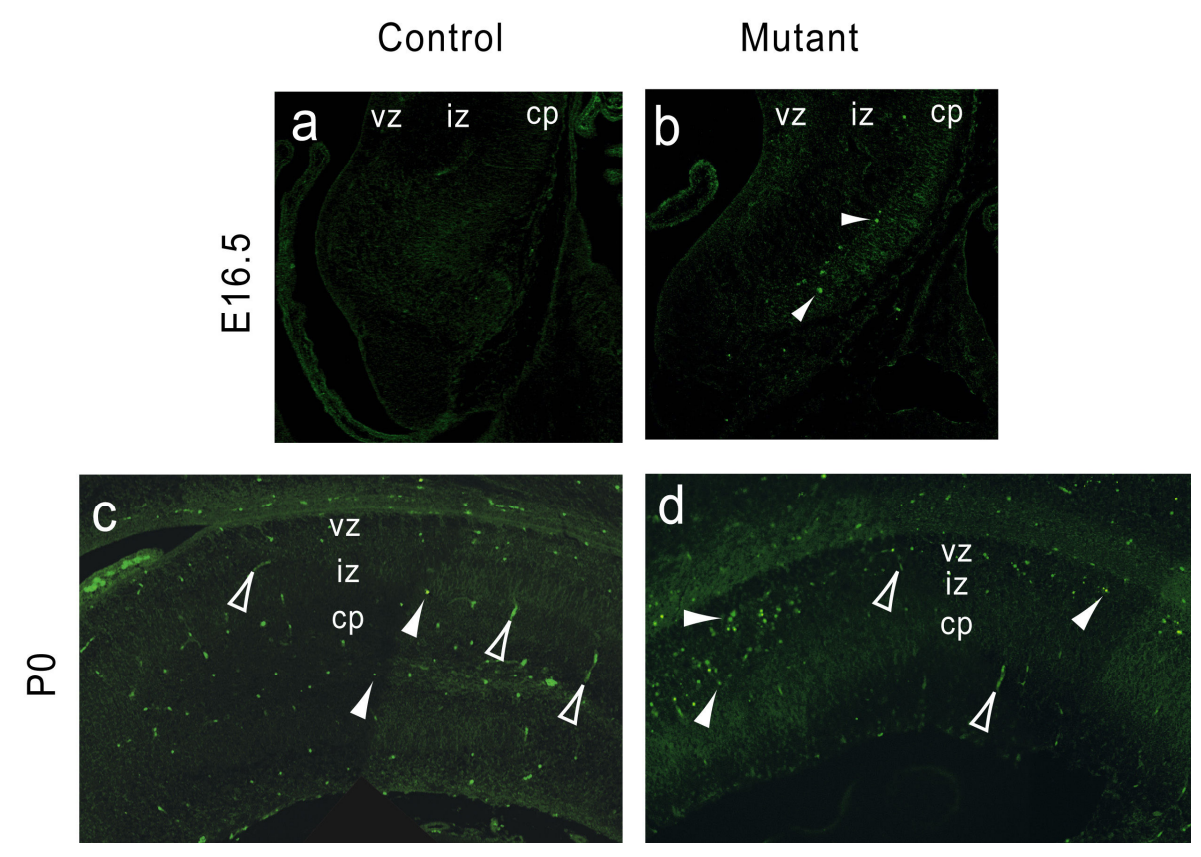

Fig. 13: Apoptotic cell death in the Sip1 mutant hippocampus. (Filled arrows point to apoptotic cells. Empty arrows indicate unspecific staining of blood vessels) 


\subsubsection{Neither cortical hem generation nor BMP signaling in the dorsal telencephalon is compromised in Sip1 mutants}

The cortical hem is a signaling center located between the presumptive hippocampus and choroid plexus (Grove et al., 1998). This center is the source of fine-tuned Wnt and BMP signaling, and is essential for the normal development of the hippocampus (see Introduction). In order to investigate whether the cortical hem is compromised in Sip1 mutant brains, the expression of hem-specific markers was verified (Fig. 14). The expression of Wnt $3 a$ and $W n t 5 a$ RNA (Fig. 14a-d), both markers of cortical hem, was not affected in Sip1 mutant embryos.

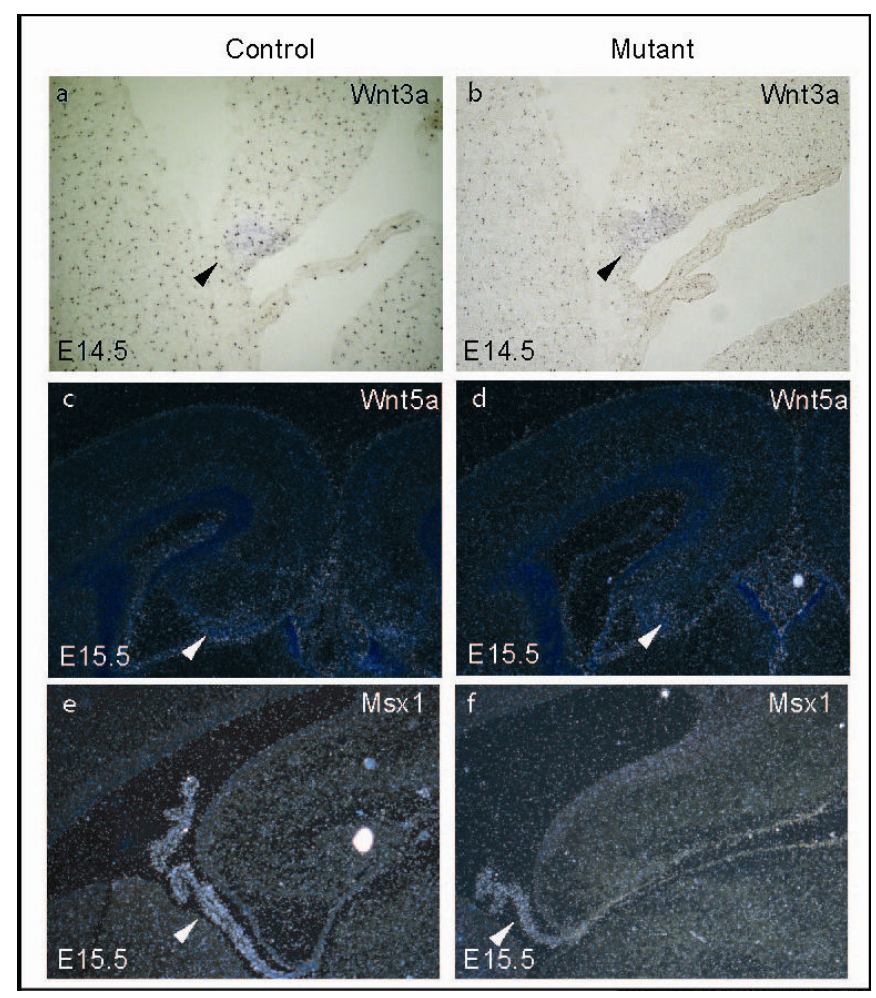

Fig. 14: Markers for Cortical hem and BMP signaling in the cortical midline. Neither the generation of the cortical hem (Wnt3a+ and Wnt5a+) nor BMP signaling in the midline of the dorsal telencephalon $(M s \times l+)$ is compromised in Sip1 mutants. (Arrowheads point to domains of expression). 
Because Sip1 has been shown to interact with SMADs (Remacle et al., 1999), Sip1 deletion could in principle interfere with BMP signaling in the dorsal telencephalon. One of the few targets of SMAD-dependent BMP signaling is the transcription factor Msxl. Recently, Herbert et al. (2002) showed that Msxl is expressed in the dorsal midline of the telencephalon. This expression pattern was confirmed in E15.5 wild-type brains and was not found to be compromised in Sip1 mutants (Fig 14e,f).

Thus, both the cortical hem and the BMP signaling in the dorsal telencephalic midline do not seem to be affected in Sip1 mutants at the stages analyzed.

\subsubsection{The Wnt negative regulator, $S$ frp1, is ectopically expressed in the mutant hippocampus}

In order to identify putative Sip1 targets, total RNA from E15.5 hippocampus was isolated and submitted to cDNA microarray. The expression of many genes was found to be either up or down-regulated in the mutant. Because Sip1 is mainly known to act as transcriptional repressor (Remacle et al., 1999), special attention was given to those genes whose expression was up-regulated in the mutant. The soluble Frizzled-Related Protein 1 (sFRP1) gene was found to be 5 times up-regulated in the mutant hippocampus. To confirm this result, in situ hybridization was performed using a specific riboprobe against Sfrpl at different stages of cortical development (Fig. 15). 


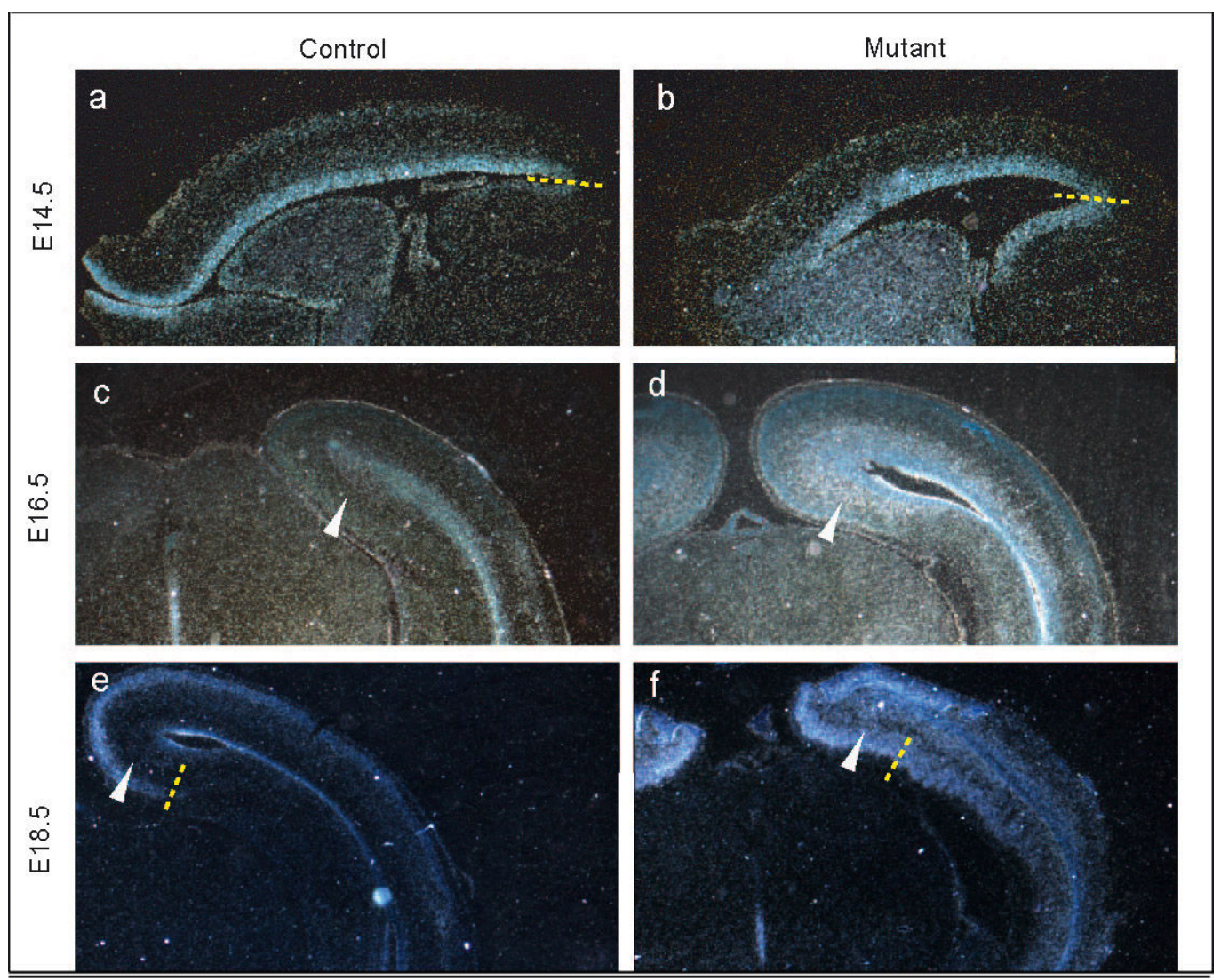

Fig. 15: Secreted frizzled-related protein 1 (Sfrp1) mRNA is up-regulated and ectopically expressed in Sip1 mutants. (Dashed lines demarcate the normal medial border of Sfrp1 expression. Arrows represent ectopic expression domains)

As shown on E14.5 sagittal sections, Sfrpl expression has a very distinct rostro-caudal gradient: transcripts in the dorsal telencephalon were normally confined to the VZ of the neocortex but were excluded from the hippocampal anlage at the onset of hippocampal development (Fig. 15a). In Sip1 mutants, however, Sfrpl is not only found in the neocortical VZ but was also ectopically expressed in the hippocampal VZ (Fig. 15b). Additionally, by E16.5 (Fig. 15c,d) and E18.5 (Fig. 15e,f) Sfrpl was strongly upregulated in the mutant in both the proliferating and post-mitotic areas of the cortex, as shown on coronal sections hybridized with a radioactive Sfrp1 riboprobe. 


\subsubsection{Over-expression of $\boldsymbol{\beta}$-catenin in Sip1 mutant brains increases the number of dentate gyrus cells but not of $\mathrm{CA3}$ cells}

The ectopic expression of the Wnt antagonist, Sfrp1, in the prospective hippocampus of Sip1 mutants and the resemblance of the mutant phenotype with mutants from other Wnt signaling members (see Introduction for details), suggested the involvement of Sip1 in the regulation of the Wnt pathway in hippocampal development. As discussed earlier, Wnt signaling occurs via canonical and non-canonical pathways (Niehrs, 2001). In the first one, the main cytoplasmic target of liganded Wnt receptor activation is $\beta$-catenin. Upon stimulation, the phosphorylation of $\beta$-catenin is inhibited, leading to its stabilization and accumulation in the nucleus, where it exerts its function as a regulator of gene expression (Nelson and Nusse, 2004). Non-canonical pathways, on the other hand, do not act via $\beta$ catenin stabilization.

It is known that Sfrp proteins are able to suppress both canonical and non-canonical Wnt pathways (Jones and Jomary, 2002). In order to address the question whether the canonical Wnt pathway was affected in Sip1 mutants, a genetic approach was used. The aim of this rescue experiment was to overcome the possible Sfrp1-inhibition of Wnt signaling by over-expressing $\beta$-catenin in the same cells where Sip1 is deleted. This was achieved by crossing Sip $1^{\text {flox/wt } / E m x} 1^{\text {IRESCre }}$ mice with a $\beta$-catenin ${ }^{\text {exo3 }}$ mouse line where the exon 3 of the $\beta$-catenin gene is flanked by loxP sites. This exon encodes all amino acids essential for the phosphorylation of $\beta$-catenin, and its subsequent degradation. Deletion of exon 3 by Cre results in the generation of a truncated but stabilized form of $\beta$ catenin that retains its transcriptional activity (Harada et al., 1999). 


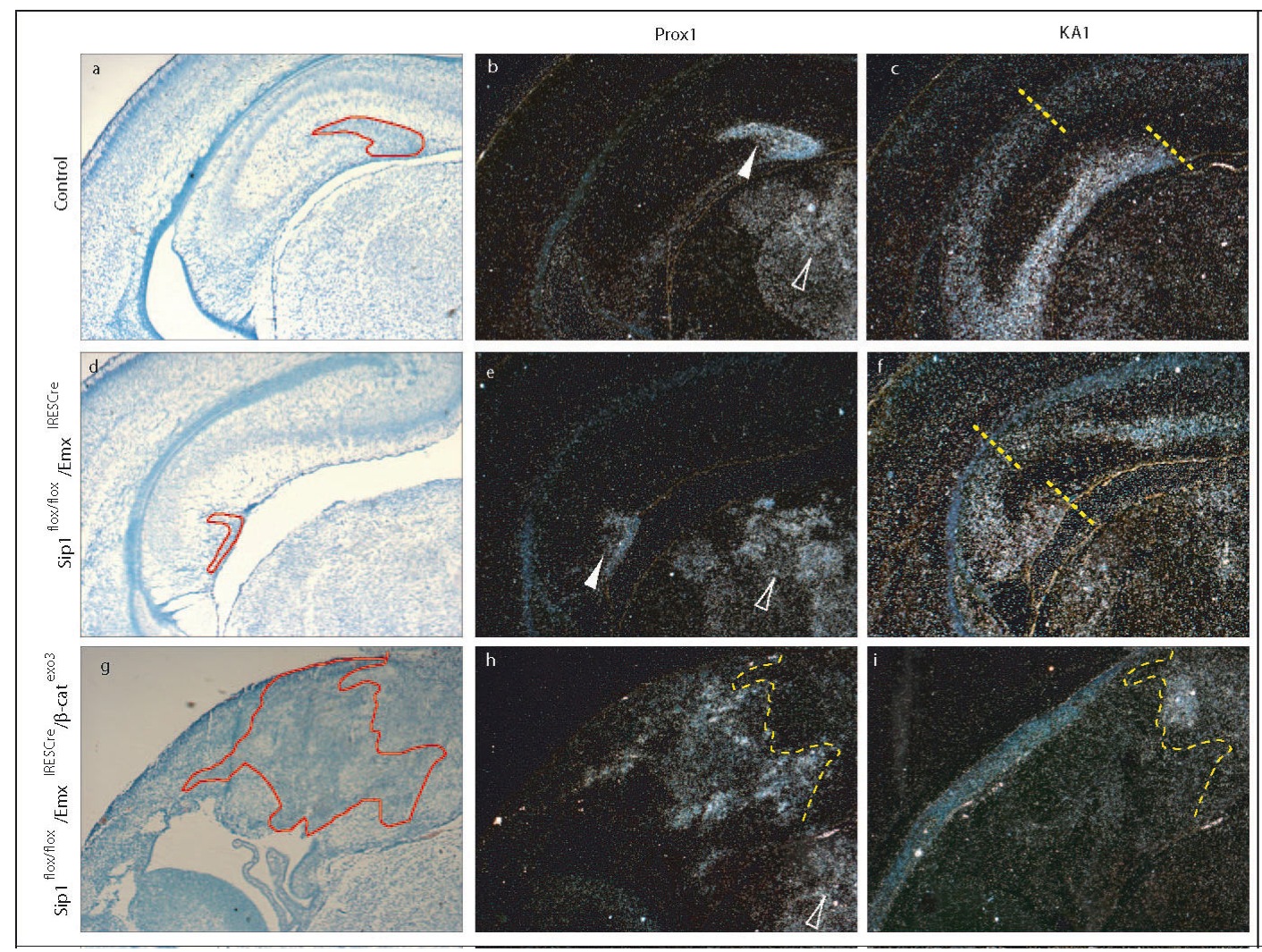

Fig. 16: Genetic stabilization of $\beta$-catenin in Sip1 mutants recovers the deficit of DG cells. (Domains of expression are depicted by filled arrows in the cortex and by empty arrows in noncortical regions for control. Dashed yellow lines demarcate borders of expression. The Prox $1^{+}$ territory is delineated by red lines in a,d,g).

Accordingly, each cell lacking Sip1 in the cortex should now also contain active $\beta$ catenin, and this would in principle rescue, totally or partially, the effects of Sipl ablation.

Double mutant mice $\left(\operatorname{Sip} 1^{\text {flox/flox } / E m x 1^{\text {IRESCre }} / \beta \text {-catenin }}{ }^{\text {exo3 }}\right.$ ) showed a more disorganized cortex than single Sip1 mutants (Fig. 16). The expression of genes specific for the hippocampal formation was analyzed: $K A 1$, to recognize the CA3 field of the hippocampus and Proxl, to specifically label dentate gyrus cells in the cortex. As mentioned before, the dramatic decrease of DG cells production was the strongest morphological feature of the Sip1 mutant phenotype during development (Fig. 16a,d; see also Fig. 9k,1). Although the hippocampus could not be rescued as a structure, the cortical domain expressing the dentate gyrus marker Proxl was significantly increased in the 
double mutants as compared to Sip1 mutants and wild-type littermates at E18.5 (Fig. 16b,e,h).

Furthermore, Prox $1^{+}$cells did not co-express the CA3 marker $K A 1$, but rather these two domains remained adjacent to each other and did not overlap (Fig. 16h,i). On the other hand, the size of the $\mathrm{KA}^{+}$domain in the double mutants did not seem to have changed significantly in comparison to the Sip1 mutants (Fig. 16f,i). Additionally, Axin2 mRNA was up-regulated in the double mutant dorsal telencephalon (data not shown), revealing that indeed the canonical Wnt signaling was enhanced in double mutant mice.

\subsubsection{Canonical Wnt signaling is not significantly impaired in the Sip1 mutant hippocampal CA1-CA3 fields}

As mentioned above, an increase in the number of dentate gyrus cells was observed upon $\beta$-catenin over-expression in Sip1 mutants. However, the effects of $\beta$-catenin in the other hippocampal areas could not be resolved with this genetic approach. Therefore, the canonical Wnt signaling was further investigated in the CA1-CA3 regions of the hippocampus. In order to detect a possible alteration of this pathway in Sip1 mutants, the expression of members of the canonical Wnt signaling was assessed at early stages, when the hippocampus consists mainly of CA1-CA3 cells.

First, the expression of $\beta$-catenin in the hippocampus was analyzed by immunohistochemistry using a pan- $\beta$-catenin antibody (Fig. 17g,h). The distribution of the cytoplasmic and membrane fraction of $\beta$-catenin did not differ significantly between mutant and control. 
In order to be able to quantify subtle differences in the levels of the activated (nonphosphorylated) fraction versus the total $\beta$-catenin in Sip1 mutants, we performed Western blot analysis from E15.5 hippocampal tissue, stage at which most of it consists of CA1-CA3 cells (Fig. 18). For both activated and total $\beta$-catenin, a $\sim 92 \mathrm{kDa}$ band was detected with equal intensity in mutants and controls.

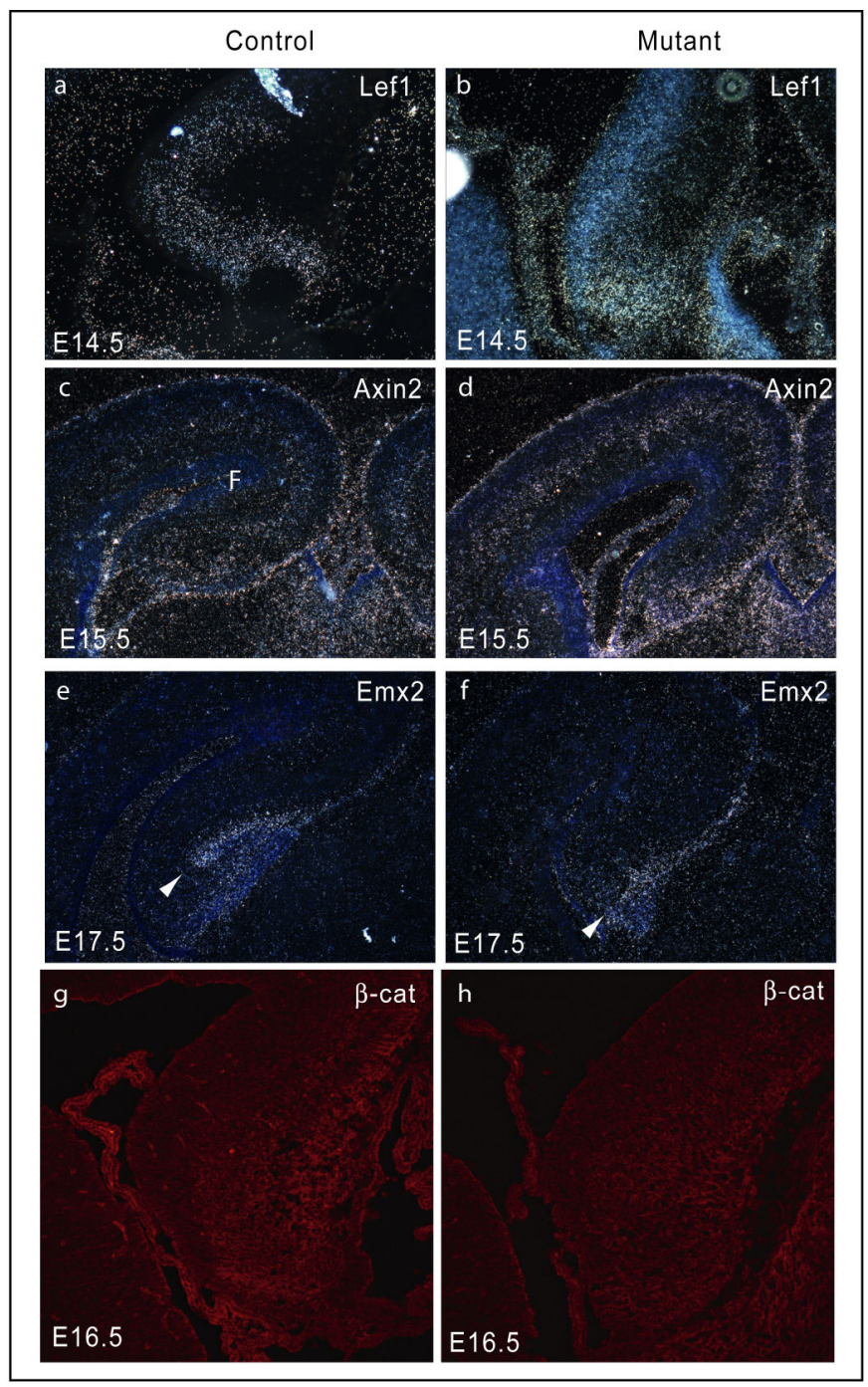

Fig. 17: Canonical Wnt signaling is not impaired in the CA1-CA3 regions of the Sip1 mutant developing hippocampus. In situ hybridization (a-f) and IHC (g,h) analysis of Wnt signaling mediators and effectors and targets. 
In addition, we addressed whether the transcription of members of canonical Wnt signaling was affected in the mutants. At the stages analyzed, neither the expression of the mediator Lef1, nor the expression of Emx2 and Axin2, known down-stream target genes of canonical Wnts (Diep et al., 2004; Lustig et al., 2002), was affected (Fig. 17a-f).

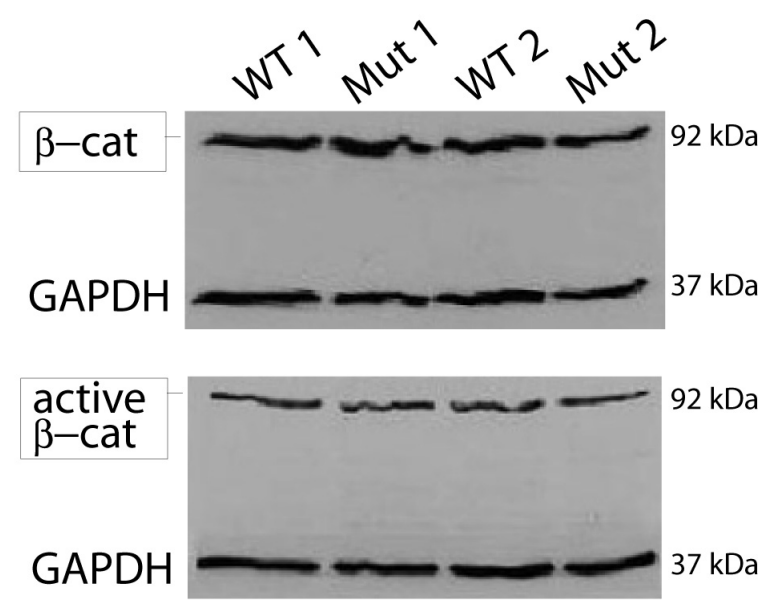

Fig. 18: Canonical Wnt signaling is not impaired in the CA1-CA3 regions of the Sip1 mutant developing hippocampus (2). Western blotting of E15.5 hippocampal total protein extract of two independent pairs of mutant (Mut) and control (WT) brains performed using the pan $\beta$-catenin antibody (upper panel) and an antibody recognizing only its active (non-phosporylated) fraction (lower panel). Anti-GAPDH was used to control the amount of protein loaded.

\subsubsection{The activity of the non-canonical Wnt effector, JNK, is inhibited in the Sip1 mutant hippocampal CA1-CA3 fields}

Non-canonical Wnt signaling (independent of $\beta$-catenin) can occur via the activation of cJun N-terminal kinases (JNK). JNK activation plays important roles during brain development such as cell morphogenetic movements, proliferation, differentiation, axonal growth and dendritic arquitecture (Bjorkblom et al., 2005; Weston and Davis, 2002). In order to assess whether non-canonical Wnt signaling was affected in the hippocampus of Sip1 mutants, western blot analysis from E15.5 hippocampal tissue against the active 
form of JNK was performed. The antibody used specifically recognizes the phosphorylated Thr-183 and Tyr-185 residues of active JNK 1-3. In these experimental conditions, a significant reduction in the levels of active-JNK was observed in the Sip $1^{-/-}$ prospective hippocampus (Fig. 19).

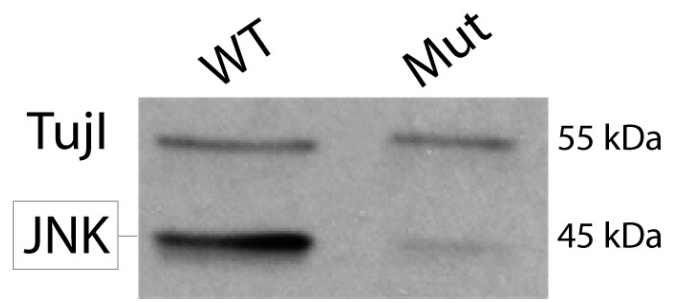

Fig. 19: Non-canonical Wnt signaling is impaired in the CA1-CA3 regions of the Sip1 mutant developing hippocampus. Western blotting of E15.5 hippocampal total protein extract of mutant (Mut) and control (WT) brains against the active form of JNK (1-3). Anti-TujI was used to control the amount of loaded protein.

\subsection{Sip1 in the specification of the neocortex}

\subsubsection{Cell specification defects in the mutant neocortex}

The laminar organization of the neocortex was analyzed perinatally (Fig. 20). At P2, neocortical layers could already be distinguished by their cytoarchitecture in the wildtype brain. Sip1 mutants, on the other hand, did not show proper lamination and the layerspecific cellular compaction appeared disrupted. In addition, the layer 1 or marginal zone that was almost devoid of cells in the wild-type, showed a higher cellular density in the Sip1 mutant. The overall thickness of the Sip $1^{-/-}$neocortex, however, did not significantly differ from the wild-type at this stage.

In order to investigate the lamination defects of Sip1 mutants in a more accurate way, several layer-specific markers were used (Fig. 20). At P2, upper neocortical layers 2-4 
were identified by IHC against the transcription factor Brn2, while deep layers were labeled with Tbr1. A clear expansion of the Brn $2^{+}$domain in the mutant was observed when compared to wild-type (Fig 21). Normally, $\mathrm{Tbr}^{+}$cells are detected in layer 6 although few cells in layer 1 can also be found (Hevner et al., 2003, Gillemot et al., 2006). In Sip1 mutants the thickness of layer 6 was decreased, as shown by the shrinkage of $\mathrm{Tbr}^{+}$expression domain (Fig 21). Therefore, the expansion of upper cortical layers correlates with a decrease in thickness of deep layers in Sip1 mutants.

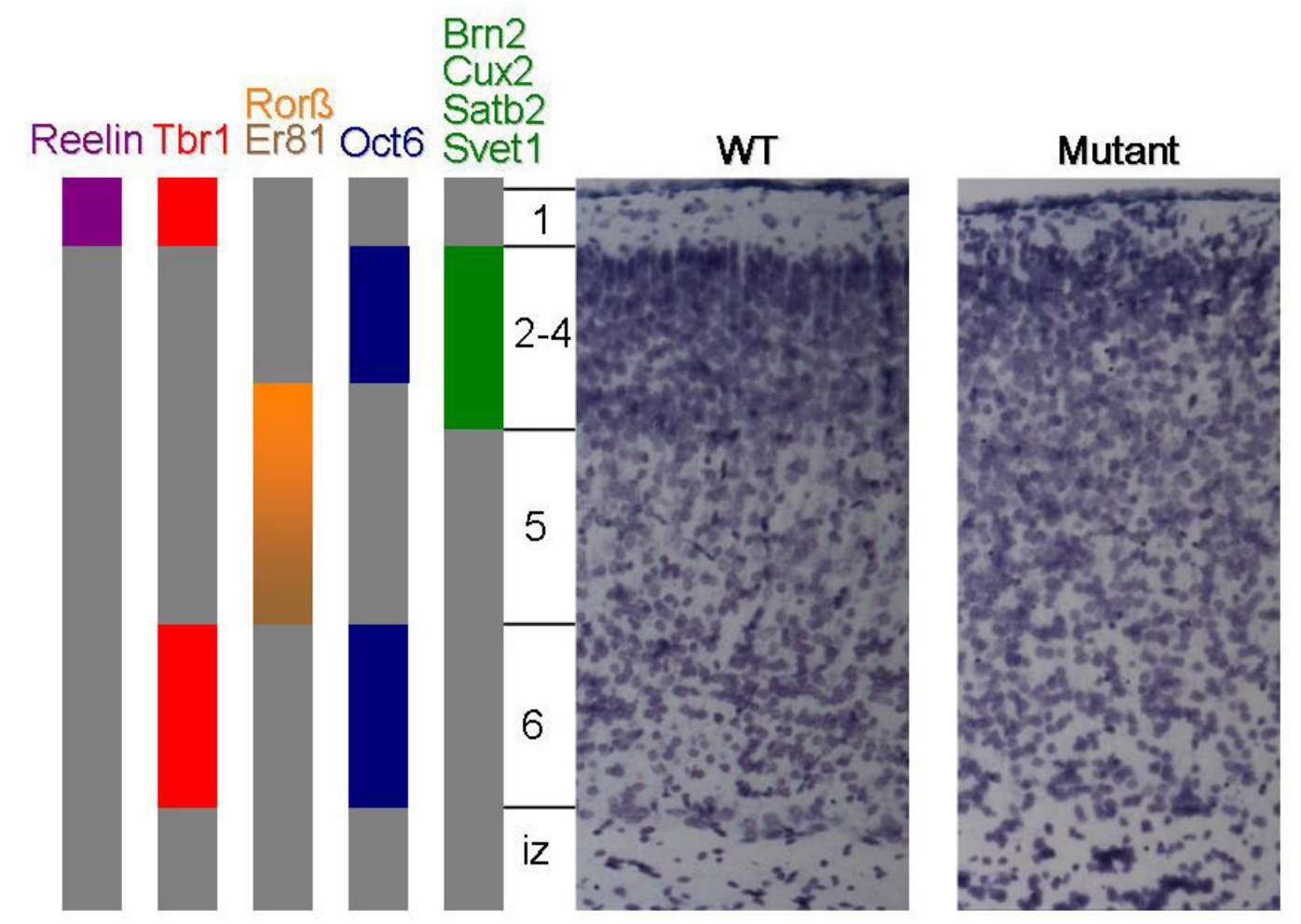

Fig. 20: Cortical lamination in the Sip1 mutant neocortex is disrupted. Corresponding Nisslstained sections of $\mathrm{P} 2$ parietal cortices of mutant and WT littermates. A diagram of layer-specific markers is shown. 


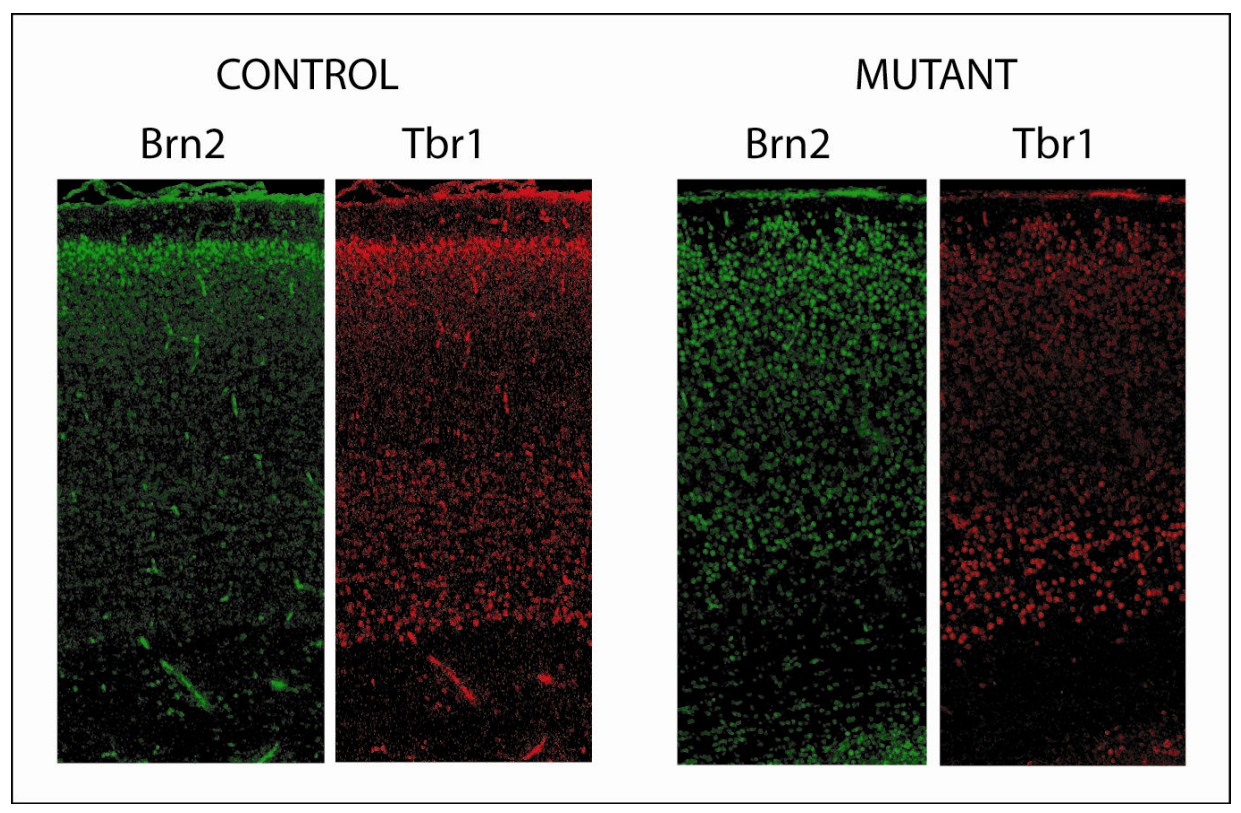

Fig. 21: Layers 2-4 (Brn2+) are expanded while the thickness of Layer $6(\mathrm{Tbr} 1+)$ is reduced in Sip1 mutants. IHC analysis of coronal sections from the P2 parietal cortex of mutant and control littermates.

Lamination was also studied at embryonic developmental stages with the aid of layerspecific markers by in situ hybridization and IHC (Fig. 22). Upper layers (2-4) were labeled by $C u x 2$ (E16.6), Satb2 (E17.6) and Oct6/SCIP (P2). In all the stages analyzed, the relative thickness of upper layers appeared to be expanded in Sip1 mutants as compared to wild-types (Fig. 22).

After birth, Svet1 labels not only cells of the SVZ, but also upper layer cells of the neocortex (Tarabykin et al., 2001). Svet $1^{+}$signals were found in the right location in the wild-type at P2. This is not the case in Sip1 mutants, where Svet 1 expression was located to the subventricular area and was found dispersed within the cortical plate.

Layers 4-5 were in turn labeled by a gradient of expression of $\operatorname{Ror} \beta$ and $\operatorname{Er} 81$ (see diagram in Fig. 22). Less Er81 in situ hybridization signals were detected in Sip1 mutants throughout the neocortex. The thickness of the $\operatorname{Ror} \beta+$ domain did not seem to be altered 
in Sip1 mutants at this stage. Nevertheless, the analysis of Ror $\beta$-expression pattern in the neocortex -dividing the cortical plate into upper and Ror $\beta$-negative layers- supported the observation that upper layers were indeed expanded in the relative increase in upper layers observed in Sip1 mutants (Fig. 22).

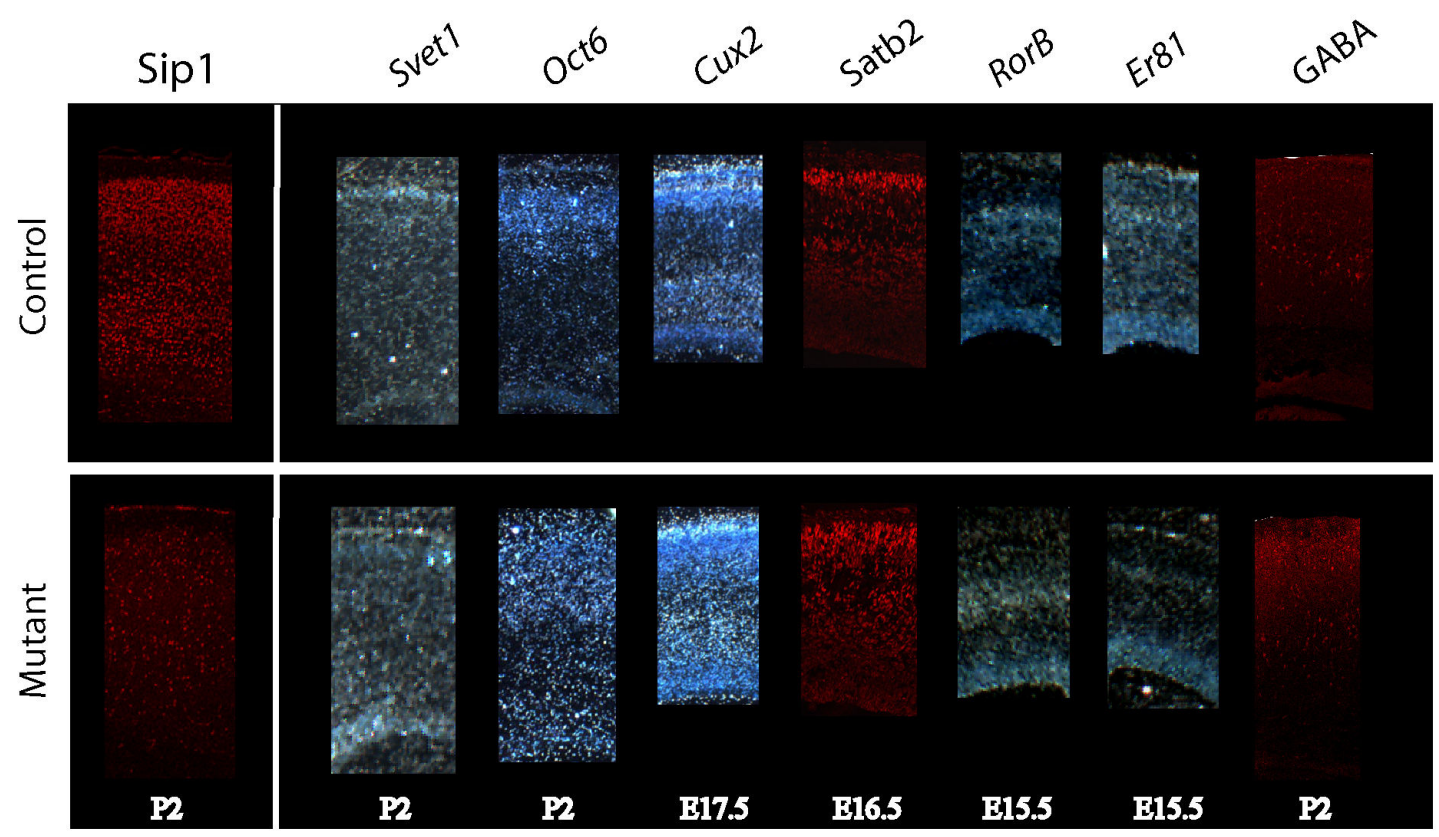

Fig. 22: Analysis of layer-specific markers throughout the development of Sip1 ${ }^{-/-}$neocortex. In situ hybridization and IHC with Sip1 and layer-specific markers performed on corresponding sections at the parietal cortex of mutants (lower panel) and wild-type littermates (upper panel).

GABA was used at P2 as a marker of mature interneurons (Fig. 22). In the wild-type, $\mathrm{GABA}^{+}$cells were located throughout all neocortical layers and were mainly concentrated in layer 5. The amount of GABAergic cells did not differ significantly between mutant and control. Sip1 mutants however, showed a higher dispersion of this cell population within the neocortical thickness and upper layers were stronger labeled when compared to control littermates. 
The layer 1 or marginal zone is located just beneath the pial surface and is characterized by being a cell-sparse zone (Bayer \& Altman, 1991). Cajal-Retzius are large horizontal cells located in layer 1 and are known to express Reelin during development (Hevner et al., 2003). In P2 Sip1 mutants a significant decrease in Cajal-Retzius cells was detected by IHC against Reelin (Fig. 23).

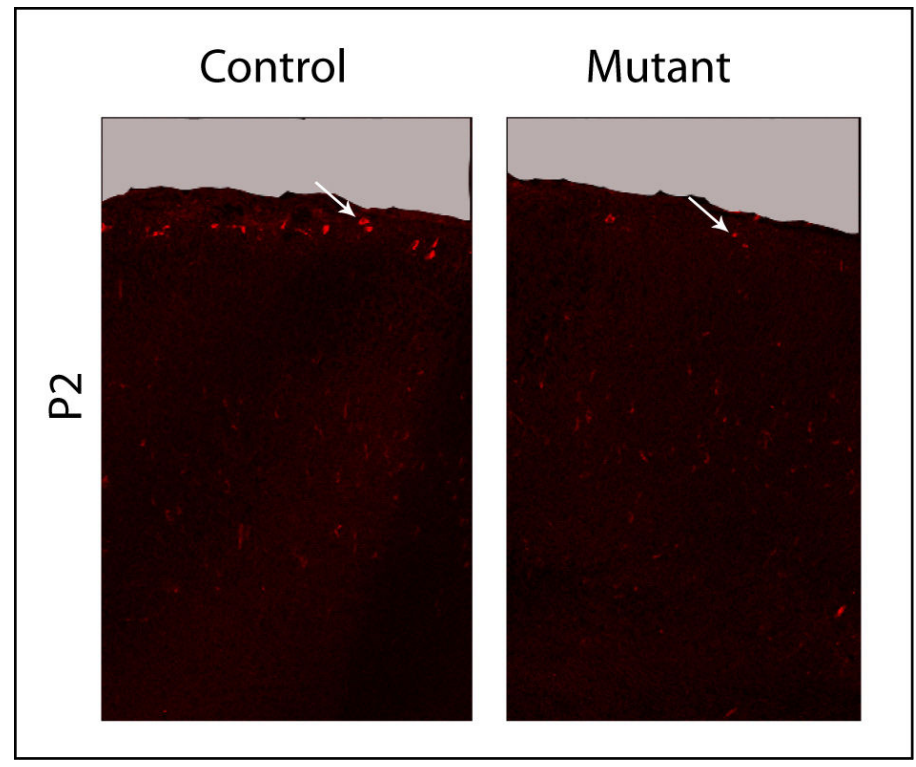

Fig. 23: IHC against Reelin in Sip1 mutant and WT neocortex. Less Reelin+ cells were found in the marginal zone of the mutant neocortex.

\subsubsection{Cell proliferation and apoptosis in the mutant neocortex}

The defects observed in the cortical lamination of Sip1 mutants could be caused by anomalies in the proliferation rate at particular stages and/or by apoptotic cell death within specific layers. In order to investigate whether the changes in cortical lamination in Sip1 mutants arise from defective proliferation, BrdU labeling was performed using a 1.5h pulse (see M\&M). At E15.5, proliferating neocortical cells in mutant and control 
animals were mainly located in the ventricular zone (Fig. 24). Proliferation was quantified at this stage from 3 pairs of mutant and wild-type littermates, in a comparable region comprising the whole neocortical thickness (black boxes in Fig. 24a,b). No significant differences in the amount of proliferating cells were found at this stage between mutants and controls (Fig. 24c).

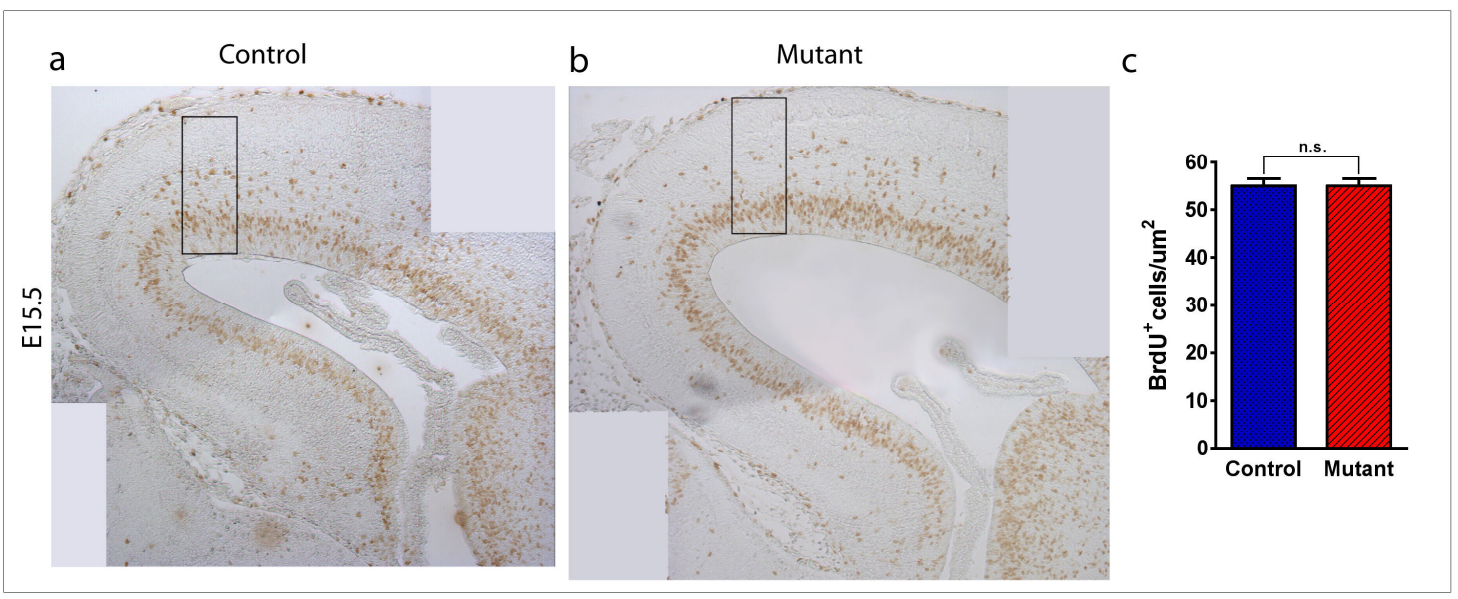

Fig. 24: Proliferation in the Sip1 mutant neocortex at E15.5. Cells that incorporated BrdU after a $1,5 \mathrm{~h}$-pulse were detected by immunohistochemistry in control (a) and mutant (b) mice. The number of proliferating cells (c) quantified in a designated area (black boxes in a,b) did not differ significantly between mutant and control animals (n.s. $P>0.1$ ).

Later in development, however, both the location and amount of proliferating cells were abnormal in Sip1 mutants (Fig. 25). At E17.5, proliferating cells were mainly located in the VZ and SVZ, although few were also found in the IZ of the wild-type neocortex. In the case of Sip1 mutants, proliferating cells were more evenly distributed throughout the thickness of the neocortex. BrdU ${ }^{+}$cells were not only present in larger numbers than in the wild-type but were also found ectopically in the cortical plate. The ectopic proliferation defect in Sip1 mutants seemed to be stronger medially, in the intersection between the developing neocortex and hippocampus. 


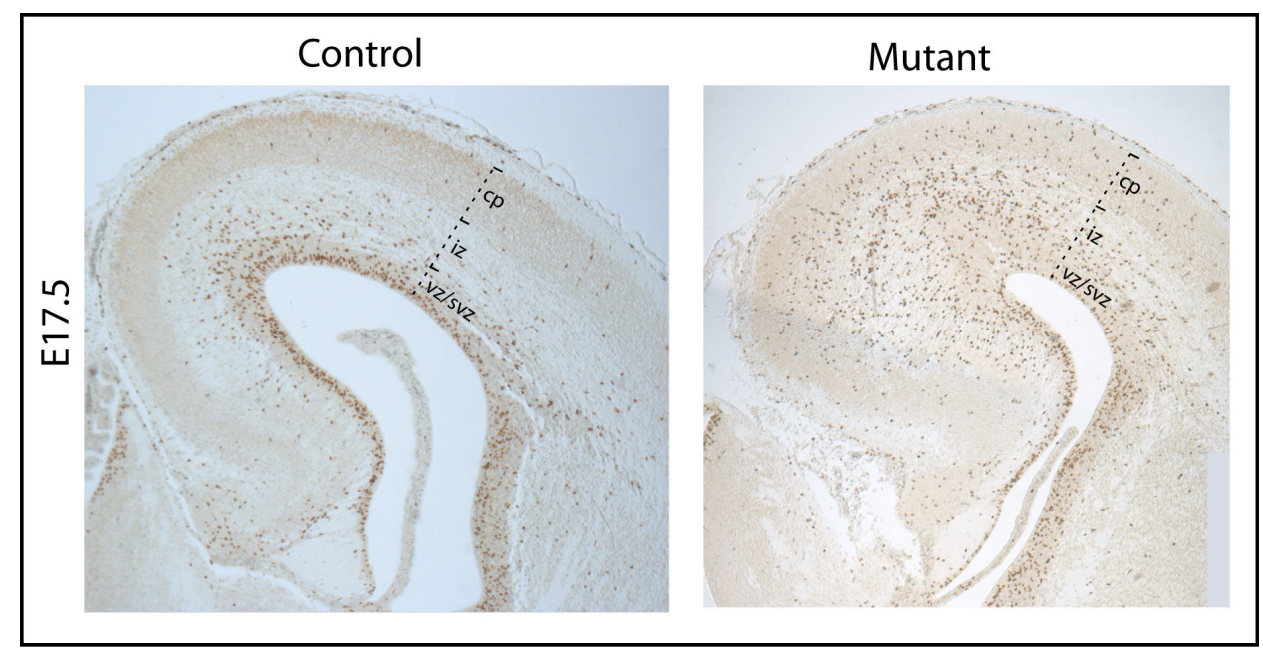

Fig. 25: Proliferation in the Sip1 mutant neocortex at E17.5. Cells that incorporated BrdU after a 1,5h-pulse were detected by immunohistochemistry in corresponding sections of mutant and control mice. Note the increased amount of BrdU ${ }^{+}$cells in the Sip1 mutant neocortex and their ectopic localization in the $\mathrm{CP}$.

Apoptotic cell death, assessed by a direct-TUNEL assay showed cells located in the deep layers of the mutant neocortex that were undergoing apoptosis at P2 (Fig. 26). The region where apoptosis was detected roughly corresponds to the $\operatorname{Tbr} 1^{+}$layer 6 , whose thickness was shown to be reduced in Sip1 mutants (Fig. 26).

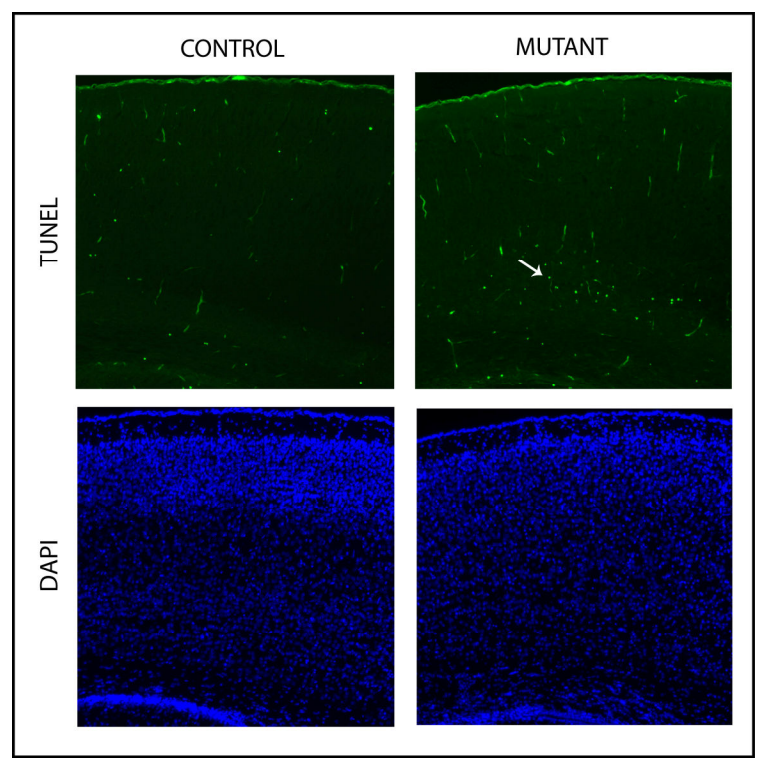

Fig. 26: Apoptotic cell death in the Sip1 mutant necortex. TUNEL shows apoptotic cells in mutant deep layers (arrow) at P2. Sections were counterstained with DAPI (lower panel). 


\subsubsection{Premature gliogenesis in Sip1 mutants}

Differentiated astrocytes, labeled with an antibody against GFAP, are to be found in the murine cortex during the first postnatal week (Chanas-Sacre et al., 2000). At P6, astrocytes were located in the most medial part of the wild-type cortex (Fig. 27, left panel) but they were not present in the parietal region (white box) or in the rest of the neocortex at this stage. A strong phenotipical feature of Sip1 mutants was the presence of GFAP $^{+}$cells not only medially but in deep areas of the neocortex at P6 (Fig. 27, right panel). Already by $\mathrm{P} 2, \mathrm{GFAP}^{+}$cells were detected in the most medial part of the mutant cortex (data not shown).

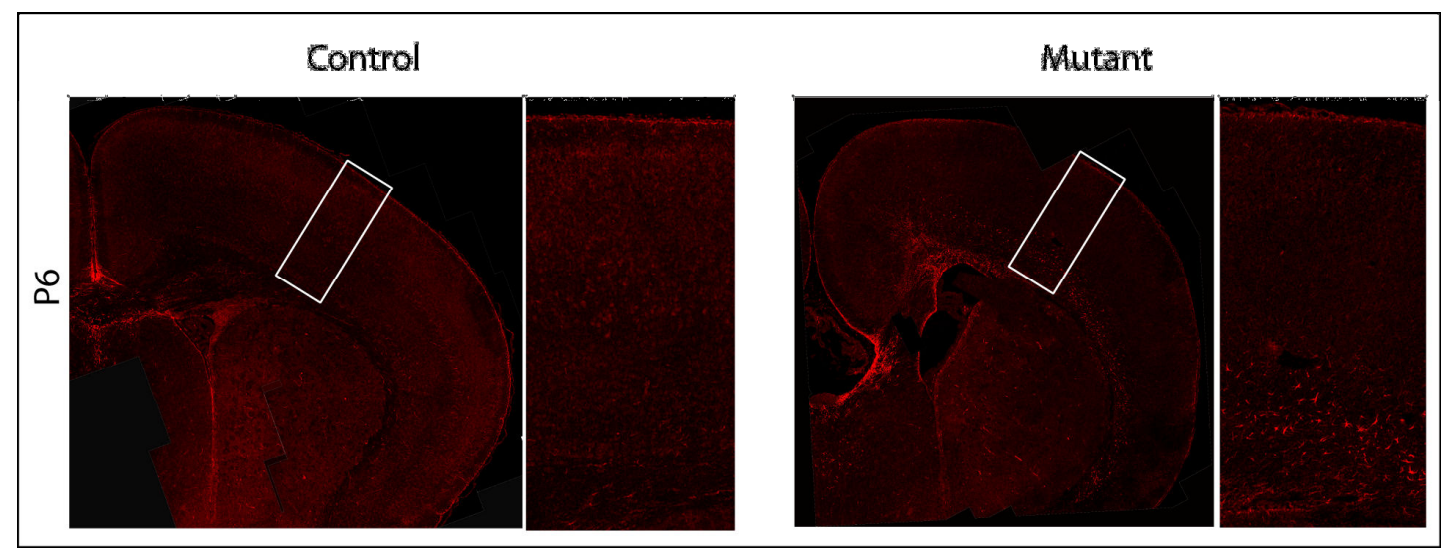

Fig. 27: GFAP $^{+}$cells are found prematurely in the Sip1 mutant neocortex. IHC analysis on corresponding sections of mutant and control littermates at P6. Next to each brain section, an enlarged neocortical column (white boxes) is shown.

\subsubsection{Sfrp1 up-regulation in the Sip1 ${ }^{-/-}$neocortex}

Secreted frizzled-related protein 1 mRNA (Sfrpl) was found in the cortex during most of the embryonic development (Fig. 28, see also Fig. 15c-f). Before birth, Sfrpl transcripts were almost exclusively found in the wild-type VZ, the mitotically active area of the 
neocortex. Perinatally, Sfrpl expression was still detected in the VZ and, additionally, in the cingulate cortex. As shown in Fig. 28, Sfrpl expression pattern in the neocortex appears complementary to that of Sip1.

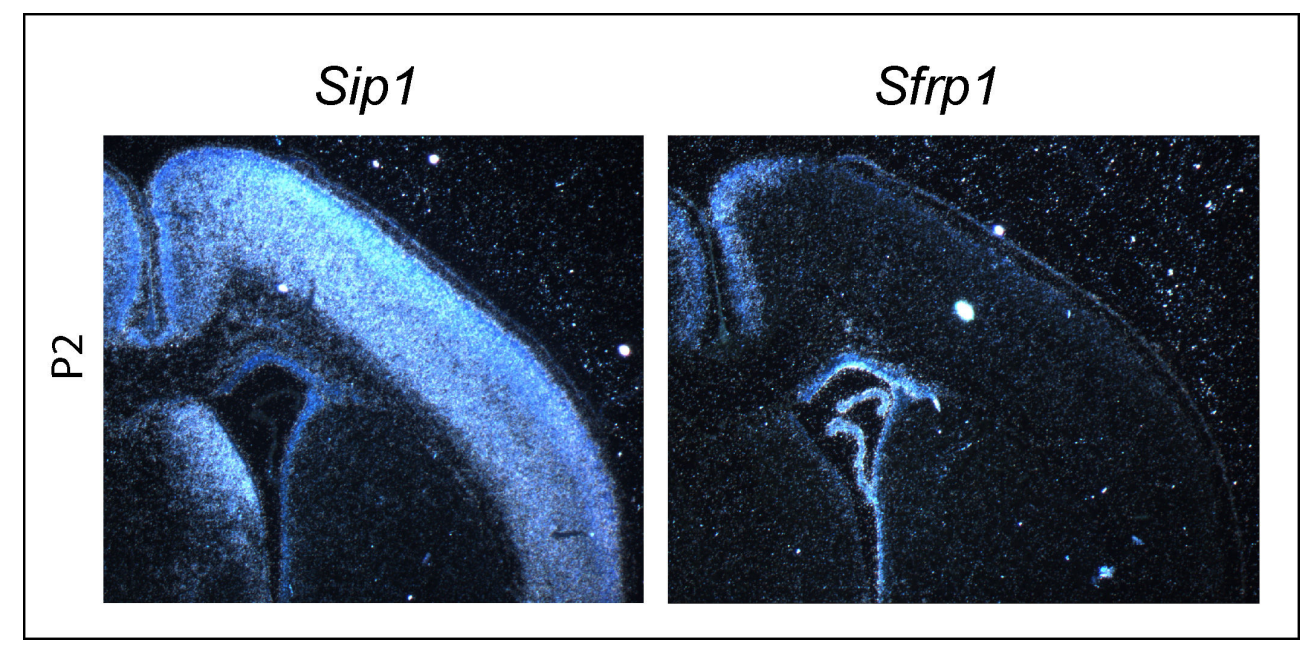

Fig. 28: Complementary expression patterns of Sip1 and Sfrp1 in the P2 WT neocortex.

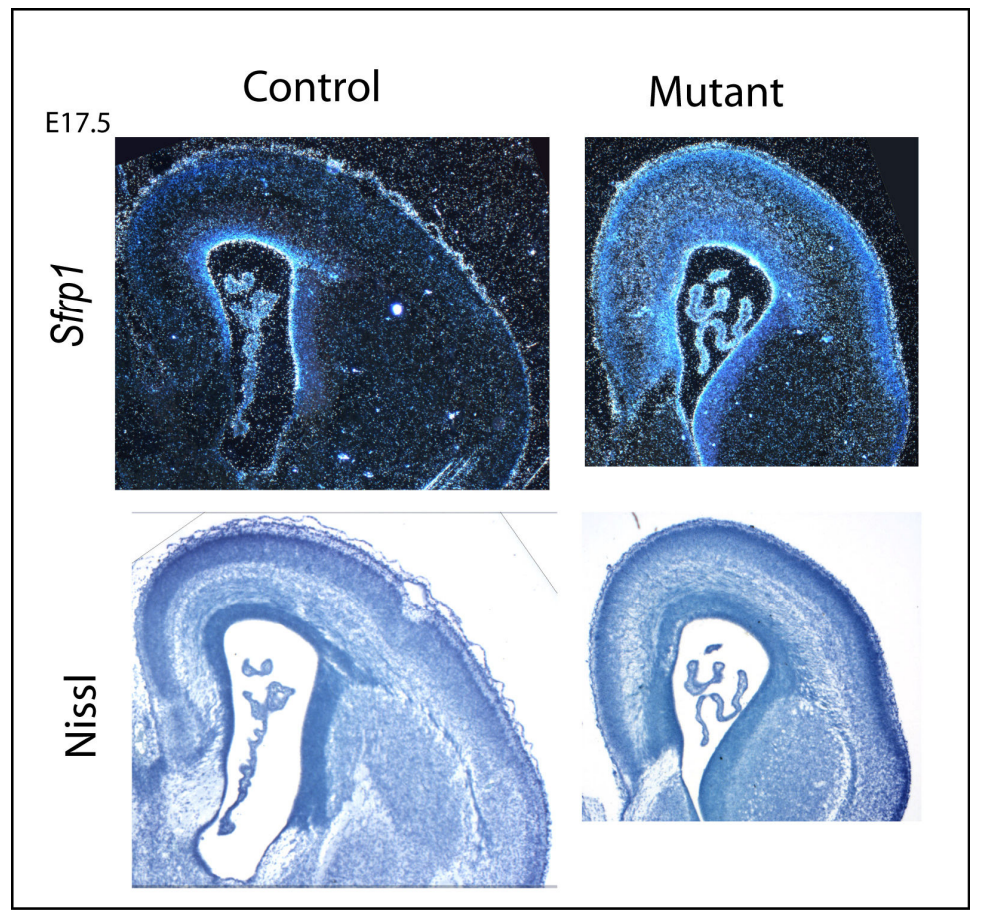

Fig. 29: Sfrp1 up-regulation in the neocortex of Sip1 mutants. In situ hybridization performed on corresponding sections of mutant and control E17.5 brains. 
As mentioned above, Sfrpl was found to be strongly up-regulated in the Sip1 mutant cortex during development. First, at E14.5, Sfrpl was ectopically found in the medial neuroepithelium or VZ (Fig. 15a,b). By E16.5, ectopic Sfrp1 expression was detected within the post-mitotic regions (Fig. 15c,d). The Sfrpl up-regulation in the mutants was more striking at E17.5 (Fig. 28). Whereas in E17.5 control neocortex Sfrpl transcripts were confined to the ventricular region, the overall $\mathrm{Sip}^{-/-}$neocortex showed a dramatic up-regulation of Sfrpl in the post-mitotic fields. 


\section{Discussion}

\subsection{Sip1 expression and gene ablation in the cortex}

The cerebral cortex (dorsal telencephalon) is the most complex brain structure in terms of development, cytoarchitecture and function. The most characteristic feature of cortical development is the inside-out pattern of neuronal migration that generates its typical layered structure. The correct patterning of the six-layered neocortex and the hippocampal formation requires the coordinated function of cortical 'organizers' or signaling centers and transcription factors expressed in particular spatio-temporal domains.

During neural development, Sip1 transcription factor has been detected as early as E8.5 in the mouse neural plate and has been shown to be required for proper neural crest cell development and migration (Nelles et al., 2003). Mice deficient of Sip1 die at E9.5, preventing its functional analysis at later developmental stages.

Throughout cortical development, high expression of Sipl in the cerebral cortex was found to be confined to the post-mitotic areas. Both at the RNA and protein levels, Sip1 could not be detected in the ventricular and subventricular zones at the stages analyzed (Fig. 4; Fig. 5). A similar expression pattern of Sip1 in the developing mouse cortex has been recently reported (Bassez et al. 2004).

In this study, the function of Smad-interacting Protein 1 (Sip1) in the development of the neocortex and the hippocampus was investigated by means of conditional gene inactivation. For this, a mouse line bearing Emxl-promoter driven Cre recombinase

(Gorski et al., 2002) was crossed to another mouse line where Sipl ${ }^{\text {exon7 }}$ was flanked by loxP sequences (Maruhashi et al., 2005). The exon7 of Sipl was specifically deleted in 
the cortex but not in other regions of mice bearing the Cre recombinase together with one or two 'floxed' Sip1 alleles (Fig 6).

Although Sip $1^{\text {exon7 }}$ deletion occurred in almost all cortical areas, a residual expression of Sip1 transcripts in the cortex was still detected at E18.5 (Fig. 4h). The remaining Sip1 expression in the mutants could represent a population of cells that migrated tangentially from other brain structures were Sip1 was not deleted (e.g. basal ganglia interneurons). Alternatively, these cells might represent a subpopulation of locally-born cells that escaped Cre recombination. Indeed, Emx $1^{\text {IRESCre }}$-driven recombination is expected to occur in almost ( $90 \%$ ) but not all of the cortical projection neurons (Gorski et al., 2002).

\subsection{Sip1 in the development of the hippocampus}

Sip1 mutants were born with Mendelian frequency and survived for 3-4 weeks (Fig. 7). The cause of death could not be determined, although it is likely to be related to

$E m x I^{\text {IRESCre }}$-mediated recombination in non-cortical areas (e.g. branchial arches) rather than Sip1 deficiency in the cortex itself. In Sip1 mutant brains, the hippocampus and dentate gyrus were consistently missing (Fig. 8). The corpus callosum was also absent, probably due to defective axonal growing from pyramidal neurons that failed to cross the midline (Fig. 8). The hippocampal morphological defects were traced back in development (Fig. 9). At E15.5 the wild-type hippocampal primordium started already to blend along the longitudinal axis, whereas the hippocampal primordium of Sip1 mutants was smaller than controls and was further decreased perinatally. Accordingly, all hippocampal fields were reduced in size at P2 (Fig. 9). The dentate gyrus (Proxl ${ }^{+}$), being 
probably the most affected structure in Sip1 mutants, was almost undetectable at this stage (Fig. 9).

A combination of decreased proliferation and increased apoptotic cell death accounts for the impaired development of hippocampal structures observed in Sip1 mutants (Fig. 11-13).

At early stages of hippocampal development, the proliferation of hippocampus and dentate gyrus was significantly impaired (Fig. 11). At E15.5, the generation of hippocampal neurons was decreased by $\sim 20 \%$ in Sip1 mutants when compared to wildtype littermates. In addition, the secondary proliferative population (SPP) that gives rise to most of the dentate gyrus cells showed a $75 \%$ reduction in proliferation (Fig 11; Fig 12). As most of the dentate progenitors migrate from the hippocampal $\mathrm{VZ}$ itself (Li and Pleasure, 2005), the decrease in proliferation within the dentate gyrus anlage might be a consequence of the impaired production/migration of hippocampal progenitors. On the other hand, the observation that the relative thickness of the post-mitotic TujI ${ }^{+}$field was not altered in E15.5 mutants (Fig 10) excludes premature differentiation as the main cause for the reduction of the progenitor pool.

Increased apoptotic cell death is also responsible for the hippocampal reduction observed in $\operatorname{Sip}^{-/-}$newborns. Already by E16.5, cells undergoing apoptosis were found in the postmitotic regions of the developing mutant hippocampus but not in controls (Fig. 13a,b). Increased apoptosis was also detected at the end of the neurogenic period (Fig. 13c,d). This suggests that apoptotic cell death largely contributes to the total loss of hippocampus and dentate gyrus observed in adult Sip1 mutant mice.

As Sip1 is known to be able to interact with BMP-Smads (Remacle et al., 1999), the expected phenotype could reflect strong deficiencies in BMP signaling in the dorsal 
telencephalon. However, the expression of Msxl, one of the few well-characterized BMP targets, did not seem to be altered (Fig. 14), suggesting that BMP signaling is not severely affected in the mutant dorsal telencephalic midline.

Although it is still possible that other aspects of BMP signaling are affected, Sip1 mutants did not display any sign of abnormal BMP signaling, like an anticipated characteristic malformation of the choroid plexus (Hebert et al., 2002).

Previous studies have shown that for normal hippocampal development not only BMPs but also Wnt signaling is required. For example, mice deficient for Wnt3a do not develop dentate gyrus while the hippocampal CA1-CA3 fields are specified but do not expand (Gleeson and Walsh, 2000). Like in Sip1 mutants, Wnt3a null mice show a $\sim 20 \%$ decrease in proliferation within the hippocampal VZ. Similarly, the conditional inactivation of the canonical Wnt mediator, $\beta$-catenin, in the embryonic cortex severely impaired the development of hippocampus and dentate gyrus (Machon et al., 2003). In contrast to Sip1 mutants, no substantial cell death was detected in Wnt $3 a$ or in $\beta$-catenin mutant mice. Moreover, deletion of a transcription factor Emx2, known as a target gene of Wnt signaling in the cortex (Theil et al., 2002), leads to an overall reduction of hippocampal fields probably due to a maturation delay (Tole et al., 2000). Like in $E m x 2^{-/-}$ mice, dentate gyrus $\left(\operatorname{Prox}^{+}\right)$cells underproliferate upon disruption of either the Wnt cofactor Lef1 (Galceran et al., 2000), the Wnt co-receptor LRP6 or both (Zhou et al., 2004).

All the aforementioned molecules (Wnt3a, $\beta$-catenin, LRP6, Lef1, Emx2) have been implicated in canonical Wnt signaling (Fig. 2a). The fact that the hippocampus is the most severely affected structure in the canonical Wnt mutants is not surprising, as the medial portion adjacent to the developing hippocampus is an abundant source of Wnt ligands (Fig. 1, Fig. 14). Thus, canonical Wnts emanating from the cortical hem act as mitogenic 
signals required for the expansion of the hippocampal fields and, in particular, for the generation of the dentate gyrus.

Given the resemblance of Sip1 mutants with mice with deficiencies in members of the canonical Wnt pathway, the possible role of Sip1 in canonical Wnt signaling was investigated. As Sip1 is known to act mainly as a transcriptional repressor (Postigo, 2003; Remacle et al., 1999), it is likely that Sip1 imposes negative regulation on certain inhibitors of Wnt signaling. This was investigated by looking at the expression of those extracellular Wnt antagonists from the Sfrp family known to be expressed in the dorsal telencepalon (Kim et al., 2001). Although Sfrp2 expression was not altered (data not shown), the expression of Sfrpl was dramatically up-regulated (Fig. 15).

Interestingly, the up-regulation of the secreted Frizzled-related protein 1 (Sfrpl) precedes the morphological abnormalities in the hippocampus of Sip1 mutants (Fig. 15, Fig. 9). In the wild-type developing telencephalon, Sfrpl is expressed in the VZ of the neocortex but is normally excluded from the hippocampal VZ. This pattern of expression corresponds to what has been reported elsewhere (Augustine et al., 2001; Kim et al., 2001). In Sip1 mutants, however, Sfrpl is ectopically expressed in the hippocampal VZ at E14.5 and is also up-regulated in post-mitotic areas at later stages (Fig. 15). Being a secreted molecule, Sfrp1 could antagonize Wnt signaling by sequestering Wnt ligands or by blocking Fzd receptors in the vicinity.

The correct positioning and function of the cortical hem was first confirmed in Sip1 mutants by the expression of the hem-specific $W n t 3 a$ and Wnt5a (Fig. 14). Thus, Sip1 is not required for the specification of the cortical hem itself, at least after the onset of Emx 1 expression. It is also suggested by the fact that Sipl is expressed in the dorsal ventricular zone at a relatively low level (Fig. 4c). Rather, Sip1 might be involved in the proper 
responsiveness to Wnt signals in the adjacent hippocampus by repressing, either directly or indirectly, the expression of Sfrpl.

In order to overcome a possible Sfrp1-mediated inhibition on the canonical Wnt pathway in the $\operatorname{Sip} 1^{-/-}$hippocampus, a genetic rescue was attempted by crossing Sip 1 mutants to a mouse line where $\beta$-catenin in the cortex can be artificially stabilized (see Results for details). Although the hippocampus could not be rescued as a structure, the expression of the dentate gyrus-cell marker Proxl was increased in the double mutants (Sip1 ${ }^{\text {flox/flox }}$ $/ \mathrm{Emx} 1^{\text {IRESCre }} / \beta$-cat ${ }^{\mathrm{exo} / \mathrm{wt}}$ ) as compared to Sip1 mutants (Fig 16). Furthermore, the Prox ${ }^{+}$ and $\mathrm{KAl}^{+}$domains did not overlap, suggesting that hippocampal boundaries between DG and CA3 are somewhat maintained in double mutants and, more importantly, that the effects of $\beta$-catenin stabilization have a strong impact in the generation of dentate gyrus cells.

To further investigate the role of canonical Wnt signaling in the hippocampal areas -other than the dentate gyrus- during development, several components of this pathway were analyzed at early developmental stages, when the hippocampus consists mainly of CA1CA3. The expression of the canonical Wnt mediators: $\beta$-catenin, Lef1, Axin2 and Emx2, was maintained in the Sip $1^{-/}$developing hippocampus (Fig. 17). Moreover, the amount of both the activated (non-phosphorylated) fraction of $\beta$-catenin and the total amount of $\beta$-catenin in the CA1-CA3 hippocampal regions in Sip1 mutants did not differ from controls (Fig. 18).

One possible explanation is that canonical Wnt signaling is impaired in Sip1 mutants at earlier stages than the ones analyzed here. In this respect, it was recently proposed that the canonical Wnt pathway is dynamically regulated throughout corticogenesis in a stagedependent manner (Hirabayashi and Gotoh, 2005). Indeed, during the expansion phase of 
the cortex (E10.5-E12.5) $\beta$-catenin seems to act as a mitogenic signal (Chenn and Walsh, 2002) while promoting differentiation and specification at later embryonic stages, during the neurogenic period (Backman et al., 2005; Hirabayashi and Gotoh, 2005). As suggested by Hirabashi et al. (2005), at earlier stages of cortical development $\beta$-catenin might regulate cellular proliferation, and therefore cortical growth. Concordantly, the hippocampal defects of Wnt3a mouse mutants (Gleeson and Walsh, 2000) and mice deficient of $\beta$-catenin (Backman et al., 2005; Machon et al., 2003) are related to impaired proliferation and progenitor migration. The possibility that canonical Wnt signaling is affected in Sip1 mutants during the 'expansion period' (E10.5-E13.5) cannot be ruled out. Because Emx $1^{\text {IREScre }}$ is active from E10.5 and Sip1 could be expressed before E12.5, Sfrpl could in principle be also up-regulated in the mutant medial cortex before E14.5.

Another possible explanation is that non-canonical rather than canonical Wnt signaling is affected in Sip1 mutant CA1-CA3 hippocampal fields. Indeed, the activation of the noncanonical mediator of the planar cell polarity (PCP) Wnt pathway, c-Jun N-terminal Kinase (JNK), was inhibited in the developing hippocampus of E15.5 Sip1 mutants (Fig. 19). The role of the PCP/JNK Wnt pathway in cortical development is not yet known. The $J n k 1$ and $J n k 2$ compound knock-out mouse display severe apoptosis in the forebrain and die too early, probably due to the multiple roles of JNKs in various tissues (Kuan et al., 1999). Although increased apoptosis in the dentate gyrus was detected in Frizzled-9 ${ }^{-/}$ mice, it was not determined whether this effect was caused by alterations in canonical or non-canonical Wnt signaling (Zhao et al., 2005). Whether the lack of JNK activity is the direct cause of the apoptotic cell death observed in the hippocampus of Sip1 mutants (Fig. 13) remains unclear. However, experiments with hippocampal cultures recently showed that Wnt signaling through Dishevelled, Rac and JNK is required for dendritogenesis. 
Moreover, in those experiments, the exposure to Sfrp1 was able to decrease both dendritic development and endogenous JNK activity to below control levels (Rosso et al., 2005).

The generation of the latest-formed structure in the hippocampus, the dentate gyrus, seems to be mainly dependent on canonical Wnt signaling, as both LRP6 and Lef1 mutant mice show decreased proliferation in this area. The observations that dentate gyrus cells underproliferate by $\sim 75 \%$ in Sip 1 mutants (Fig. 11; Fig. 12) and that only the dentate gyrus cells could be rescued upon $\beta$-catenin stabilization in a Sip $1^{-/-}$background (Fig. 16), support this hypothesis. Whether the dentate gyrus responds preferentially to one particular Wnt pathway during development is difficult to address in detail, primarily because most of the dentate gyrus progenitors derive from the hippocampal VZ but also because of technical limitations. The development of techniques that allow the isolation and manipulation of the dentate gyrus would be therefore extremely useful for the study of its molecular determinants during development.

The Wnt antagonist Sfrp1 could inhibit both canonical and non-canonical pathways (Kawano and Kypta, 2003). Thus, it is likely that the hippocampal phenotype observed in Sip1 mutants is caused by a combined impairment of canonical and non-canonical Wnt signaling upon Sfrp1 up-regulation.

\subsection{Sip1 in the specification of the neocortex}

As mentioned above, Sip1 was found to be expressed in the cerebral cortex during corticogenesis. Throughout development, the expression of Sip1 in the neocortex was mainly confined to the post-mitotic fields (Fig. 4; Fig. 5). Despite of the fact that Sip1 
could not detected in the proliferating ventricular and subventricular zones, complex abnormalities were found in the neocortex of Sip1 mutants.

Although the overall thickness of the neocortex was not affected in Sip1 mutants, the analysis of the neocortical cytoarchitecture (Fig. 20) showed a defective lamination accompanied by cellular invasion into the superficial layer 1 , a layer normally devoid of cells. The cellular density that characterizes upper (2-4) and deeper (5-6) layers in the wild-type already at P2, was not maintained in the Sip $1^{-/-}$neocortex. Instead, Sip1 mutants showed a higher cellular dispersion and poor layer compaction.

Analysis of layer-specific markers revealed an expansion of upper layers at the expense of deep layers in Sip1 mutants (Fig. 21). The increase in the relative thickness of upper layers was already detected by E16.5 onwards (Fig. 22)

Interneurons $\left(\mathrm{GABA}^{+}\right)$were found in the neocortex of Sip1 mutant and control littermates in roughly the same numbers (Fig. 22). In agreement with other studies, GABAergic cells were present throughout the wild-type neocortex and were more abundant in layer 5 (Hevner et al., 2003). In P2 Sip1 $1^{-/}$littermates, however, GABA ${ }^{+}$cells were found in the entire neocortical thickness but were mainly allocated to upper layers instead of layer 5 (Fig. 22). Previous studies have demonstrated that interneurons and projection neurons have similar inside-out relations between cell birthday and laminar fate (Hevner et al., 2004). Because interneurons are born outside the Emxl lineage (Gorski et al., 2002) and most of the cortical interneurons migrating from the basal ganglia probably use projection neurons as guidance cues (Hevner et al., 2004), it seems reasonable that the distribution of GABAergic cells would reflect the lamination defects observed in Sip1 mutants. In this respect, the expansion of upper layers in the mutant correlates with the increased GABA 
staining in corresponding locations. Similarly, the decreased number of interneurons in layer 5 reflects the overall reduction of deep layers detected in Sip1 mutants.

Birth-dating studies have shown that deeper layers 5 and 6 are formed by neurons generated at earlier stages (E12.5-E14.5) while cells specified to become part of upper layers (2-4) are born later, between E15.5 and E17.5. (Bayer and Altman, 1991; Hevner et al., 2003). It is well accepted that neuronal fate is specified by the time of birth and before neurons start to migrate out from the ventricular zone into the cortical plate, a process that normally takes 2-3 days (Bayer and Altman, 1991; Tole et al., 2000). Thus, it is likely that the abnormal lamination observed in Sip1 mutants results from defective cellular specification in the proliferating areas and perhaps from impaired neuronal migration.

The number of proliferating $\left(\mathrm{BrdU}^{+}\right)$cells and their location in the $\mathrm{VZ}$ and $\mathrm{SVZ}$ was not significantly altered in the $\operatorname{Sip}^{-/-}$neocortex at E15.5 (Fig. 24). However, later in development at E17.5 (Fig. 25), an increased number of progenitors was detected. Surprisingly, most of these progenitors were not located in the proliferating areas (VZ, SVZ) but were found within the differentiated fields (IZ, CP). At this stage, the cortical plate should contain only few proliferating cells (Bayer and Altman, 1991). Thus, both ectopic and increased proliferation takes place in the Sip $1^{-/-}$neocortex by the end of the neurogenic period (E17.5). As most of the neurons generated at this stage would normally form part of upper layers, it is likely that these proliferating cells contribute to the expansion of layers 2-4. Birth-dating experiments would be required to follow the precise fate of progenitors at different developmental stages.

It has been suggested that apoptotic cell death is not a frequent process in the early postnatal cortex (Hevner et al., 2004). By using similar detection methods, this could be confirmed in the wild-type at P2 (Fig. 26). In Sip1 mutant littermates however, an 
increased number of cells undergoing apoptosis was detected within the neocortex. Notably, these cells were located in areas corresponding to the deep layers, which were found to be shrunken in the mutant (Fig. 26; Fig. 21). Thus, apoptotic cell death could account, at least partially, for the reduction of deep layers in the Sip1 mutant neocortex. On the other hand, deep layers are affected in the mutant earlier than $\mathrm{P} 2$, as suggested by the decreased expression of $\operatorname{Er} 81$ and the relative reduction of the Ror $\beta$-negative lower domain at E15.5 (Fig. 22). Because apoptosis was not detected in the Sip $1^{-/-}$neocortex at this stage (data not shown), it is likely that cortical specification is particularly affected at early stages.

As shown in Fig. 23, a significant decrease in Reelin ${ }^{+}$cells was detected in Sip1 mutants. Reelin is an extracelullar protein expressed in the cortex exclusively by Cajal-Retzius (CR) cells (Soriano et al., 1997). CR cells are one of the first cortical neurons to be generated and represent a transient population of cells. They are normally located in the outermost layer 1 during corticogenesis (Fig. 20) and disappear during the early postnatal days. In the wild-type P2 neocortex, Reelin ${ }^{+}$cells were correctly placed within layer 1 but were almost absent in the neocortex of Sip1 mutants (Fig. 23). Whether the decrease in CR cells in Sip1 mutants is caused by underproliferation, cell death or premature differentiation at earlier stages remains to be clarified. In Sip1 mutants, possible alterations of Reelin signaling at early stages could be responsible for the abnormalities in neuronal migration and specification. For instance, mice with deficiencies in either the extracellular protein Reelin (reeler mouse), the Reelin receptors Apoer2 and Vldlr, or the adaptor molecule Disabled-1 (Dab1) display an inverted lamination of the cortex due to defects in neuronal migration (Gleeson and Walsh, 2000). It has been proposed that young neurons are attracted to a Reelin source in the outermost layer 1 or marginal zone (Hammond et al., 2001). Newly generated neurons migrate on radial glia and bypass older 
neurons in their way to their final position. Once neurons approach the marginal zone, the increased activation of the Reelin pathway via Dab1 activation is followed by Dab degradation. At this point, neurons are no longer responsive to the Reelin pathway and detach from radial glia (Caviness et al., 2000; Hammond et al., 2001). Thus, in Sip1 mutants, a partial deficiency in the Reelin signaling pathway could be responsible for the poor laminar compaction and the diffuse expression pattern of various layer-specific markers.

It has been recently shown that Reelin prevents projection neurons from entering the marginal zone (Hammond et al., 2001). The marginal zone of Sip1 mutants did not only have less CR cells but was also found to be invaded by projection neurons at P2 (Fig. 23, Fig. 20). Because Cajal-Retzius cells derive from the Emxl lineage (Gorski et al., 2002)and Sip1 is expressed in most of the post-mitotic cells in the cortex (Fig. 4), one possibility is that Sip1 is required for the correct generation/survival of the Reelin ${ }^{+} \mathrm{CR}$ cells. Alternatively, the reduction of CR cells could be related to a secondary effect.

Interestingly, the postnatal reduction in the $\mathrm{CR}$ cell population has been shown to correlate in time with the transformation of radial glia into astrocytes (Soriano et al., 1997). Although both neurons and glia originate mainly from radial glial cells within the neocortex, the development of astrocytes begins during the early postnatal days, once the neurogenic period is completed (Bayer and Altman, 1991; He et al., 2005). It has been shown that diffusible factors secreted by Cajal-Retzius (CR) cells promote the radial glia phenotype and its proper scaffolding (Hunter-Schaedle, 1997; Soriano et al., 1997). Accordingly, in Reeler mutant mice, the radial glia form a misaligned fiber scaffold and differentiate prematurely into astrocytes (Hunter-Schaedle, 1997). Although radial glia filaments $\left(\right.$ nestin $^{+)}$could be stained in Sip1 mutants (Fig. 10), their proper scaffolding and 
function has not yet been analyzed. In Sip1 mutants, an increased number of GFAP ${ }^{+}$ astrocytes was detected within the deep layers of the neocortex as compared to controls (Fig 27). Because the location where $\mathrm{GFAP}^{+}$cells were found in the mutant roughly correspond to the regions where apoptotic cells were also found (Fig. 26), one could argue that those $\mathrm{GFAP}^{+}$cells are reactive astrocytes that respond to cell death. However, astrocytes generated prematurely in reeler were not shown to be activated upon brain injury (Hunter-Schaedle, 1997), a response that is mostly seen in damaged adult brains. Another possibility is that, as in reeler, astrocytes are generated prematurely in the Sip1 mutant neocortex due to the abnormal differentiation of radial glia.

Time-lapse studies have shown that in the ventricular zone (VZ), radial glial cells divide symmetrically to expand the progenitor pool and asymmetrically, to generate either one or two neurons. Some progenitors migrate out into the subventricular zone (SVZ) where they either undergo symmetrical terminal or symmetric progenitor divisions divisions (Noctor et al., 2004). The proportion of assymetrical divisions increases as neurogenesis progresses. It has been suggested that intermediate progenitors that sojourn in the SVZ give mainly rise to neurons that migrate into upper cortical layers (Tarabykin et al., 2001; Nieto et al., 2004; Noctor et al., 2004;). Thus, it is likely that the expansion of upper layers observed in Sip1 mutants, (Fig. 21; Fig. 22) is caused, at least partially, from abnormalities in the intermediate progenitors of the SVZ.

The transition of VZ to SVZ progenitors largely depends on the cell cycle and the expression of transcription factors such as Pax6 and Ngn2 (Estivill-Torrus et al., 2002; He et al., 2005; Hirabayashi and Gotoh, 2005). The morphological changes occurring during this transition are starting to be elucidated. It has been suggested that the integrity of the neuroepithelium is required for the normal functioning of the proliferating fields 
(Junghans et al., 2005). In this respect, the loss of adherens junctions in the cortical lumen of $\beta$-catenin conditional mutants correlates with a higher dispersion of proliferating cells towards the pial surface (Machon et al., 2003). Moreover, these mice showed severe defects in the development of upper cortical layers, a situation that is similar to Sip1 mutants. Thus, it is tempting to think that possible abnormalities within the SVZ of Sip1 mutants could account for the expansion of the SVZ-derived upper cortical layers, for the abnormal number and position of progenitors late in the neurogenic period and also for the premature differentiation of SVZ progenitors into astrocytes.

As mentioned earlier, Sfrpl was found to be strongly up-regulated in the dorsal telencephalon of Sip1 mutants. During corticogenesis, Sfrpl expression is confined to the ventricular zone (Kim et al., 2001). From E16.5 onwards, Sfrp1 was dramatically upregulated in the post-mitotic fields (Fig. 29; Fig. 15). Thus, Sip1 inhibits, either directly or indirectly, the expression the Wnt antagonist Sfrpl in both the neocortex and hippocampus. It is likely that Sip1 exerts transcriptional regulation directly on the Sfrp1 gene, as several binding sites for Sip1 were found in the $10 \mathrm{~kb}$-upstream regulatory region (data not shown).

The role of Wnt signaling in the specification of the neocortex is still not known. However, several Wnt ligands, receptors and antagonists have been found to be expressed in the neocortex, from development until adulthood, in overlapping and sometimes complementary manners (Kim et al., 2001; Shimogori et al., 2004).

The mediator of the PCP/JNK Wnt pathway, c-Jun terminal kinase, has been shown to be predominantly expressed in the subventricular and intermediate zones of the developing mouse neocortex. In the intermediate zone, young neurons change their migration rate and direction and undergo characteristic morphological changes (Bayer and Altman, 
1991; Noctor et al., 2004). Interestingly, the exogenous activation of the JNK pathway in cortical progenitors in vivo, arrests the migration of immature neurons to the IZ/SVZ. The opposite situation is also true: cells with disrupted JNK activity do not sojourn in the IZ/SVZ but migrate instead ectopically into the cortical plate (Hirai et al., 2002). If the activation of JNK in Sip1 mutants was affected in the developing neocortex in a similar way as in the hippocampus (Fig. 19), one could speculate that some of the specification and migration defects in Sip1 mutants are caused by defective PCP/JNK Wnt signaling within the neocortex.

Thus, it is likely that also in the in the neocortex, Sip1 mediates the responsiveness to Wnt signaling through the regulation of Sfrpl expression. Such regulation would allow Wnt factors to be freely available for interaction with the cognate receptor and its activation cascade. In Sip1 mutants, Sfrpl is no longer subject to this negative regulation and can in fact become up-regulated, interfering in this way with the normal Wnt signaling. Rescue experiments in progress will be useful for dissecting those phenotypical features of Sip1 mutants that are mediated by the up-regulation of Sfrpl.

Notably, the normal expression patterns of Sipl and Sfrpl in the neocortex are mutually exclusive (Fig. 28). Similar to the inverse correlation of Sip1 and E-cadherin expression in various models (see Introduction), high levels of Sipl expression in carcinoma cells and tumor cell lines correlate with tumor invasion (Comijn et al., 2001; Vandewalle et al., 2005), whereas Sfrpl expression has been rather linked to tumor suppression (Kawano and Kypta, 2003; Suzuki et al., 2004). In the developing hindbrain, however, both Sip1 and Sfrpl have been found to be expressed in all rhombomeres except r3 and r5 (Hoang et al., 1998; Maruhashi et al., 2005). Thus, it seems plausible that Sip1 differentially regulates the expression of Sfrpl depending on the cellular context. 
Sip1 could play important roles also at postnatal stages. In adult mice, Sip1 has been found in the cerebral cortex with highest levels in the hippocampus and dentate gyrus (Bassez et al., 2004). Recent studies have reported on the expression of Sfrpl in the adult cerebral cortex, including the inner surface of the dentate gyrus (Shimogori et al., 2004). In particular, Sfrpl expression in the lateral wall of the ventricle and the olfactory bulb correlates with the location of the rostral migratory stream (RMS). This could have major implications in the adult brain as both the dentate gyrus and the RMS are the selective areas where adult neurogenesis and migration take place.

\subsection{Implications to the Mowat-Wilson syndrome}

In humans, heterozygous mutations in SIP1 lead to the Mowat-Wilson (MW) syndrome. Non-sense and frameshift mutations are responsible for SIP1 happloinsufficiency and the broad phenotypical spectrum observed in MW patients. Most of the congenital brain abnormalities in MW, such as microcephaly, corpus callosum agenesis and poor hippocampal formation were recapitulated in Sip1 mutant mice (Fig. 8). This is not very surprising, as both human SIP1 and mouse Sip1 show strong homologies at the aminoacid level ( $\sim 97 \%)$ with conserved organization of domains (Cacheux et al., 2001).

As discussed here, Sip1 mutants also showed severe malformations in the neocortex. Thus, it is likely that MW patients additionally display lamination defects, possibly caused by misspecification and abnormal migration during corticogenesis.

Given the small numbers $(<100)$ of MW patients described to date (Zweier et al., 2005), no recognizable genotype-phenotype correlation has been identified. It is therefore not clear to what extent the different functional domains of Sip1 contribute to its function. 
Several studies suggest that the integrity of Sip1 terminal zinc-fingers is necessary for the transcriptional regulation of certain genes even independently of Smad and CtBP binding domains (Comijn et al., 2001; Eisaki et al., 2000; Remacle et al., 1999).

Alternative splicing of Sip1 RNA has been recently reported to occur in the mouse (Nelles et al., 2003). In humans, at least four SIP1 transcripts were found with a complex distribution in various tissues (Bassez et al., 2004). Interestingly, the adult human brain expressed most of the splice variants identified and the longest splice variant was found exclusively in the brain. Moreover, a study with MW patients revealed that, from the two splice variants between SIP1 exons 6-9, only the small one was present in MW patients. Mutations in regulatory sequences of SIPI could potentially lead to an aberrant expression of the different variants and, as a consequence, to partial loss-of function effects.

\section{Conclusions}

The role of the transcription factor Sip1 was investigated by conditional gene inactivation in the cerebral cortex. In the developing hippocampus and dentate gyrus, Sip1 regulates Wnt signaling by inhibiting the expression of Sfrp1. In Sip1 mutants, the misregulation of Wnt signaling affected neuronal proliferation and survival, leading to the total absence of these structures in the adult. In the neocortex, Sip1 controls cell specification and is required for correct lamination. This work provides the first mouse model of the brainrelated abnormalities in Mowat-Wilson syndrome and is potentially useful for understanding the molecular and cellular mechanisms underlying the disease. 


\section{References}

Amiel, J., and Lyonnet, S. (2001). Hirschsprung disease, associated syndromes, and genetics: a review. J Med Genet 38, 729-739.

Attisano, L., and Wrana, J. L. (2000). Smads as transcriptional co-modulators. Curr Opin Cell Biol 12, 235-243.

Augustine, C., Gunnersen, J., Spirkoska, V., and Tan, S. S. (2001). Place- and timedependent expression of mouse sFRP-1 during development of the cerebral neocortex. Mech Dev 109, 395-397.

Backman, M., Machon, O., Mygland, L., van den Bout, C. J., Zhong, W., Taketo, M. M., and Krauss, S. (2005). Effects of canonical Wnt signaling on dorso-ventral specification of the mouse telencephalon. Dev Biol 279, 155-168.

Bassez, G., Camand, O. J., Cacheux, V., Kobetz, A., Dastot-Le Moal, F., Marchant, D., Catala, M., Abitbol, M., and Goossens, M. (2004). Pleiotropic and diverse expression of ZFHX1B gene transcripts during mouse and human development supports the various clinical manifestations of the "Mowat-Wilson" syndrome. Neurobiol Dis 15, 240-250.

Bayer, S. A., and Altman, J. (1991). Neocortical development, Raven Press).

Bjorkblom, B., Ostman, N., Hongisto, V., Komarovski, V., Filen, J. J., Nyman, T. A., Kallunki, T., Courtney, M. J., and Coffey, E. T. (2005). Constitutively active cytoplasmic c-Jun N-terminal kinase 1 is a dominant regulator of dendritic architecture: role of microtubule-associated protein 2 as an effector. J Neurosci 25, 6350-6361.

Bodine, P. V., Zhao, W., Kharode, Y. P., Bex, F. J., Lambert, A. J., Goad, M. B., Gaur, T., Stein, G. S., Lian, J. B., and Komm, B. S. (2004). The Wnt antagonist secreted frizzled-related protein-1 is a negative regulator of trabecular bone formation in adult mice. Mol Endocrinol 18, 1222-1237.

Burden, S. J. (2000). Wnts as retrograde signals for axon and growth cone differentiation. Cell 100, 495-497.

Cacheux, V., Dastot-Le Moal, F., Kaariainen, H., Bondurand, N., Rintala, R., Boissier, B., Wilson, M., Mowat, D., and Goossens, M. (2001). Loss-of-function mutations in SIP1 Smad interacting protein 1 result in a syndromic Hirschsprung disease. Hum Mol Genet 10, 1503-1510.

Caviness, V. S., Jr., Takahashi, T., and Nowakowski, R. S. (2000). Neuronogenesis and the early events of neocortical histogenesis. Results Probl Cell Differ 30, 107-143.

Chanas-Sacre, G., Rogister, B., Moonen, G., and Leprince, P. (2000). Radial glia phenotype: origin, regulation, and transdifferentiation. J Neurosci Res 61, 357363.

Chenn, A., and Walsh, C. A. (2002). Regulation of cerebral cortical size by control of cell cycle exit in neural precursors. Science 297, 365-369.

Clark, S. G., and Chiu, C. (2003). C. elegans ZAG-1, a Zn-finger-homeodomain protein, regulates axonal development and neuronal differentiation. Development 130, 3781-3794.

Comijn, J., Berx, G., Vermassen, P., Verschueren, K., van Grunsven, L., Bruyneel, E., Mareel, M., Huylebroeck, D., and van Roy, F. (2001). The two-handed E box binding zinc finger protein SIP1 downregulates E-cadherin and induces invasion. Mol Cell 7, 1267-1278.

Diep, D. B., Hoen, N., Backman, M., Machon, O., and Krauss, S. (2004). Characterisation of the Wnt antagonists and their response to conditionally 
activated Wnt signalling in the developing mouse forebrain. Brain Res Dev Brain Res 153, 261-270.

Eisaki, A., Kuroda, H., Fukui, A., and Asashima, M. (2000). XSIP1, a member of twohanded zinc finger proteins, induced anterior neural markers in Xenopus laevis animal cap. Biochem Biophys Res Commun 271, 151-157.

Espinosa-Parrilla, Y., Amiel, J., Auge, J., Encha-Razavi, F., Munnich, A., Lyonnet, S., Vekemans, M., and Attie-Bitach, T. (2002). Expression of the SMADIP1 gene during early human development. Mech Dev 114, 187-191.

Estivill-Torrus, G., Pearson, H., van Heyningen, V., Price, D. J., and Rashbass, P. (2002). Pax6 is required to regulate the cell cycle and the rate of progression from symmetrical to asymmetrical division in mammalian cortical progenitors. Development 129, 455-466.

Frantz, G. D., Bohner, A. P., Akers, R. M., and McConnell, S. K. (1994). Regulation of the POU domain gene SCIP during cerebral cortical development. J Neurosci 14, 472-485.

Fukuchi-Shimogori, T., and Grove, E. A. (2003). Emx2 patterns the neocortex by regulating FGF positional signaling. Nat Neurosci 6, 825-831.

Galceran, J., Miyashita-Lin, E. M., Devaney, E., Rubenstein, J. L., and Grosschedl, R. (2000). Hippocampus development and generation of dentate gyrus granule cells is regulated by LEF1. Development 127, 469-482.

Gehring, W. J., Affolter, M., and Burglin, T. (1994). Homeodomain proteins. Annu Rev Biochem 63, 487-526.

Gleeson, J. G., and Walsh, C. A. (2000). Neuronal migration disorders: from genetic diseases to developmental mechanisms. Trends Neurosci 23, 352-359.

Gorski, J. A., Talley, T., Qiu, M., Puelles, L., Rubenstein, J. L., and Jones, K. R. (2002). Cortical excitatory neurons and glia, but not GABAergic neurons, are produced in the Emx1-expressing lineage. J Neurosci 22, 6309-6314.

Grove, E. A., and Tole, S. (1999). Patterning events and specification signals in the developing hippocampus. Cereb Cortex 9, 551-561.

Grove, E. A., Tole, S., Limon, J., Yip, L., and Ragsdale, C. W. (1998). The hem of the embryonic cerebral cortex is defined by the expression of multiple Wnt genes and is compromised in Gli3-deficient mice. Development 125, 2315-2325.

Hammond, V., Howell, B., Godinho, L., and Tan, S. S. (2001). disabled-1 functions cell autonomously during radial migration and cortical layering of pyramidal neurons. J Neurosci 21, 8798-8808.

Harada, N., Tamai, Y., Ishikawa, T., Sauer, B., Takaku, K., Oshima, M., and Taketo, M. M. (1999). Intestinal polyposis in mice with a dominant stable mutation of the beta-catenin gene. Embo J 18, 5931-5942.

He, F., Ge, W., Martinowich, K., Becker-Catania, S., Coskun, V., Zhu, W., Wu, H., Castro, D., Guillemot, F., Fan, G., et al. (2005). A positive autoregulatory loop of Jak-STAT signaling controls the onset of astrogliogenesis. Nat Neurosci 8, 616625.

Hebert, J. M., Mishina, Y., and McConnell, S. K. (2002). BMP signaling is required locally to pattern the dorsal telencephalic midline. Neuron 35, 1029-1041.

Hevner, R. F., Daza, R. A., Englund, C., Kohtz, J., and Fink, A. (2004). Postnatal shifts of interneuron position in the neocortex of normal and reeler mice: evidence for inward radial migration. Neuroscience 124, 605-618.

Hevner, R. F., Daza, R. A., Rubenstein, J. L., Stunnenberg, H., Olavarria, J. F., and Englund, C. (2003). Beyond laminar fate: toward a molecular classification of cortical projection/pyramidal neurons. Dev Neurosci 25, 139-151. 
Hirabayashi, Y., and Gotoh, Y. (2005). Stage-dependent fate determination of neural precursor cells in mouse forebrain. Neurosci Res 51, 331-336.

Hirai, S., Kawaguchi, A., Hirasawa, R., Baba, M., Ohnishi, T., and Ohno, S. (2002). MAPK-upstream protein kinase (MUK) regulates the radial migration of immature neurons in telencephalon of mouse embryo. Development 129, 44834495.

Hoang, B. H., Thomas, J. T., Abdul-Karim, F. W., Correia, K. M., Conlon, R. A., Luyten, F. P., and Ballock, R. T. (1998). Expression pattern of two Frizzled-related genes, Frzb-1 and Sfrp-1, during mouse embryogenesis suggests a role for modulating action of Wnt family members. Dev Dyn 212, 364-372.

Hunter-Schaedle, K. E. (1997). Radial glial cell development and transformation are disturbed in reeler forebrain. J Neurobiol 33, 459-472.

Job, C., and Tan, S. S. (2003). Constructing the mammalian neocortex: the role of intrinsic factors. Dev Biol 257, 221-232.

Jones, S. E., and Jomary, C. (2002). Secreted Frizzled-related proteins: searching for relationships and patterns. Bioessays 24, 811-820.

Junghans, D., Hack, I., Frotscher, M., Taylor, V., and Kemler, R. (2005). Beta-cateninmediated cell-adhesion is vital for embryonic forebrain development. Dev Dyn 233, 528-539.

Kawano, Y., and Kypta, R. (2003). Secreted antagonists of the Wnt signalling pathway. J Cell Sci 116, 2627-2634.

Kim, A. S., Lowenstein, D. H., and Pleasure, S. J. (2001). Wnt receptors and Wnt inhibitors are expressed in gradients in the developing telencephalon. Mech Dev 103, 167-172.

Kohn, A. D., and Moon, R. T. (2005). Wnt and calcium signaling: beta-cateninindependent pathways. Cell Calcium 38, 439-446.

Kuan, C. Y., Yang, D. D., Samanta Roy, D. R., Davis, R. J., Rakic, P., and Flavell, R. A. (1999). The Jnk1 and Jnk2 protein kinases are required for regional specific apoptosis during early brain development. Neuron 22, 667-676.

Li, G., and Pleasure, S. J. (2005). Morphogenesis of the dentate gyrus: what we are learning from mouse mutants. Dev Neurosci 27, 93-99.

Long, J., Zuo, D., and Park, M. (2005). Pc2-mediated sumoylation of Smad-interacting protein 1 attenuates transcriptional repression of E-cadherin. J Biol Chem 280, 35477-35489.

Lustig, B., Jerchow, B., Sachs, M., Weiler, S., Pietsch, T., Karsten, U., van de Wetering, M., Clevers, H., Schlag, P. M., Birchmeier, W., and Behrens, J. (2002). Negative feedback loop of Wnt signaling through upregulation of conductin/axin2 in colorectal and liver tumors. Mol Cell Biol 22, 1184-1193.

Machon, O., van den Bout, C. J., Backman, M., Kemler, R., and Krauss, S. (2003). Role of beta-catenin in the developing cortical and hippocampal neuroepithelium. Neuroscience 122, 129-143.

Malatesta, P., Hartfuss, E., and Gotz, M. (2000). Isolation of radial glial cells by fluorescent-activated cell sorting reveals a neuronal lineage. Development 127 , 5253-5263.

Maruhashi, M., Van De Putte, T., Huylebroeck, D., Kondoh, H., and Higashi, Y. (2005). Involvement of SIP1 in positioning of somite boundaries in the mouse embryo. Dev Dyn 234, 332-338.

Monuki, E. S., and Walsh, C. A. (2001). Mechanisms of cerebral cortical patterning in mice and humans. Nat Neurosci 4 Suppl, 1199-1206. 
Nelles, L., Van de Putte, T., van Grunsven, L., Huylebroeck, D., and Verschueren, K. (2003). Organization of the mouse Zfhx lb gene encoding the two-handed zinc finger repressor Smad-interacting protein-1. Genomics 82, 460-469.

Nelson, W. J., and Nusse, R. (2004). Convergence of Wnt, beta-catenin, and cadherin pathways. Science 303, 1483-1487.

Niehrs, C. (2001). Developmental biology. Solving a sticky problem. Nature 413, 787788.

Nieto, M., Monuki, E. S., Tang, H., Imitola, J., Haubst, N., Khoury, S. J., Cunningham, J., Gotz, M., and Walsh, C. A. (2004). Expression of Cux-1 and Cux-2 in the subventricular zone and upper layers II-IV of the cerebral cortex. J Comp Neurol 479, 168-180.

Noctor, S. C., Martinez-Cerdeno, V., Ivic, L., and Kriegstein, A. R. (2004). Cortical neurons arise in symmetric and asymmetric division zones and migrate through specific phases. Nat Neurosci 7, 136-144.

O'Leary, D. D., and Nakagawa, Y. (2002). Patterning centers, regulatory genes and extrinsic mechanisms controlling arealization of the neocortex. Curr Opin Neurobiol 12, 14-25.

Oliver, G., Sosa-Pineda, B., Geisendorf, S., Spana, E. P., Doe, C. Q., and Gruss, P. (1993). Prox 1, a prospero-related homeobox gene expressed during mouse development. Mech Dev 44, 3-16.

Patapoutian, A., and Reichardt, L. F. (2000). Roles of Wnt proteins in neural development and maintenance. Curr Opin Neurobiol 10, 392-399.

Pellegrini, M., Mansouri, A., Simeone, A., Boncinelli, E., and Gruss, P. (1996). Dentate gyrus formation requires Emx2. Development 122, 3893-3898.

Postigo, A. A. (2003). Opposing functions of ZEB proteins in the regulation of the TGFbeta/BMP signaling pathway. Embo J 22, 2443-2452.

Ragsdale, C. W., and Grove, E. A. (2001). Patterning the mammalian cerebral cortex. Curr Opin Neurobiol 11, 50-58.

Remacle, J. E., Kraft, H., Lerchner, W., Wuytens, G., Collart, C., Verschueren, K., Smith, J. C., and Huylebroeck, D. (1999). New mode of DNA binding of multi-zinc finger transcription factors: deltaEF1 family members bind with two hands to two target sites. Embo J 18, 5073-5084.

Rosso, S. B., Sussman, D., Wynshaw-Boris, A., and Salinas, P. C. (2005). Wnt signaling through Dishevelled, Rac and JNK regulates dendritic development. Nat Neurosci $8,34-42$.

Shimamura, K., and Rubenstein, J. L. (1997). Inductive interactions direct early regionalization of the mouse forebrain. Development 124, 2709-2718.

Shimogori, T., VanSant, J., Paik, E., and Grove, E. A. (2004). Members of the Wnt, Fz, and Frp gene families expressed in postnatal mouse cerebral cortex. J Comp Neurol 473, 496-510.

Soriano, E., Alvarado-Mallart, R. M., Dumesnil, N., Del Rio, J. A., and Sotelo, C. (1997). Cajal-Retzius cells regulate the radial glia phenotype in the adult and developing cerebellum and alter granule cell migration. Neuron 18, 563-577.

Super, H., Soriano, E., and Uylings, H. B. (1998). The functions of the preplate in development and evolution of the neocortex and hippocampus. Brain Res Brain Res Rev 27, 40-64.

Suzuki, H., Watkins, D. N., Jair, K. W., Schuebel, K. E., Markowitz, S. D., Chen, W. D., Pretlow, T. P., Yang, B., Akiyama, Y., Van Engeland, M., et al. (2004). Epigenetic inactivation of SFRP genes allows constitutive WNT signaling in colorectal cancer. Nat Genet 36, 417-422. 
Tarabykin, V., Stoykova, A., Usman, N., and Gruss, P. (2001). Cortical upper layer neurons derive from the subventricular zone as indicated by Svet1 gene expression. Development 128, 1983-1993.

Theil, T., Aydin, S., Koch, S., Grotewold, L., and Ruther, U. (2002). Wnt and Bmp signalling cooperatively regulate graded Emx2 expression in the dorsal telencephalon. Development 129, 3045-3054.

Tole, S., Goudreau, G., Assimacopoulos, S., and Grove, E. A. (2000). Emx2 is required for growth of the hippocampus but not for hippocampal field specification. $\mathrm{J}$ Neurosci 20, 2618-2625.

Tole, S., and Grove, E. A. (2001). Detailed field pattern is intrinsic to the embryonic mouse hippocampus early in neurogenesis. J Neurosci 21, 1580-1589.

Trainor, P. A., Manzanares, M., and Krumlauf, R. (2000). Genetic interactions during hindbrain segmentation in the mouse embryo. Results Probl Cell Differ 30, 51-89.

van Grunsven, L. A., Michiels, C., Van de Putte, T., Nelles, L., Wuytens, G., Verschueren, K., and Huylebroeck, D. (2003). Interaction between Smadinteracting protein-1 and the corepressor C-terminal binding protein is dispensable for transcriptional repression of E-cadherin. J Biol Chem 278, 26135-26145.

Vandewalle, C., Comijn, J., De Craene, B., Vermassen, P., Bruyneel, E., Andersen, H., Tulchinsky, E., Van Roy, F., and Berx, G. (2005). SIP1/ZEB2 induces EMT by repressing genes of different epithelial cell-cell junctions. Nucleic Acids Res 33, 6566-6578.

Wakamatsu, N., Yamada, Y., Yamada, K., Ono, T., Nomura, N., Taniguchi, H., Kitoh, H., Mutoh, N., Yamanaka, T., Mushiake, K., et al. (2001). Mutations in SIP1, encoding Smad interacting protein-1, cause a form of Hirschsprung disease. Nat Genet 27, 369-370.

Wang, H. Y., and Malbon, C. C. (2004). Wnt-frizzled signaling to G-protein-coupled effectors. Cell Mol Life Sci 61, 69-75.

Weston, C. R., and Davis, R. J. (2002). The JNK signal transduction pathway. Curr Opin Genet Dev 12, 14-21.

Wilson, M., Mowat, D., Dastot-Le Moal, F., Cacheux, V., Kaariainen, H., Cass, D., Donnai, D., Clayton-Smith, J., Townshend, S., Curry, C., et al. (2003). Further delineation of the phenotype associated with heterozygous mutations in ZFHX1B. Am J Med Genet A 119, 257-265.

Wisden, W., and Seeburg, P. H. (1993). A complex mosaic of high-affinity kainate receptors in rat brain. J Neurosci 13, 3582-3598.

Wrana, J. L. (2000). Crossing Smads. Sci STKE 2000, RE1.

Zhao, C., Aviles, C., Abel, R. A., Almli, C. R., McQuillen, P., and Pleasure, S. J. (2005). Hippocampal and visuospatial learning defects in mice with a deletion of frizzled 9, a gene in the Williams syndrome deletion interval. Development 132, 29172927.

Zhou, C. J., Zhao, C., and Pleasure, S. J. (2004). Wnt signaling mutants have decreased dentate granule cell production and radial glial scaffolding abnormalities. J Neurosci 24, 121-126.

Zweier, C., Thiel, C. T., Dufke, A., Crow, Y. J., Meinecke, P., Suri, M., Ala-Mello, S., Beemer, F., Bernasconi, S., Bianchi, P., et al. (2005). Clinical and mutational spectrum of Mowat-Wilson syndrome. Eur J Med Genet 48, 97-111. 


\section{Acknowledgements}

I would like to thank my supervisor Dr. Victor Tarabykin for offering me this project and for his continuous guidance. I would also like to thank Prof. Walter Stühmer for inviting me to work in his department in the MPIem and for unconditional support. I am also indebted to Prof. Nils Brose and Prof. Hebert Jäckle for helpful suggestions and support as members of my thesis committee.

I would also like to thank our collaborators from the Flanders Interuniversity Institute of Biotechnology (VIB) in Leuven, Belgium: Prof. Danny Huylebroeck, Dr. Tom Van de Putte and Dr. Eve Seuntjens, for providing the Sip1 ${ }^{\text {flox }}$ mouse line and the Sip1 ${ }^{\text {exon7 }}$ probe and for very useful feedback; to Dr, Makoto Taketo for providing the $\beta$-catenin ${ }^{\text {exo3 }}$ mouse; to Dr. Kevin Jones for the Emx $1^{\text {IRESCre }}$ mouse line; to Dr. Antonello Mallamaci and Dr. Rudi Grosschedl for sharing their probes and to Dr. Anton Karabinos for making a fantastic Sip1 antibody.

I am very grateful to everyone in the MBNS Department for sharing everything and making such a good environment. I would like to particularly thank Ute Rust for helping me in administrative -and non-administrative- matters, and to Manu Schwark for keeping the lab always organized.

Special thanks are due to the organizers of the Neuroscience Program for providing such a good learning environment and for assisting me in multiple matters.

Last but not least, I would like to thank my family and friends for their love and support during all these years. 


\section{Curriculum Vitae}

Personal Details

Name: $\quad$ Amaya Miquelajáuregui Graf

Date of birth: $\quad 04.12 .1977$

Place of birth: $\quad$ Mexico City

Nationality: Mexican

\section{Education}

Aug 1996-Sept2001

BSc. equivalent in Biology

Faculty of Sciences

UNAM, Mexico City, Mexico

Jan 1999-June 2000 Academic exchange

Biology Faculty

McGill University, Montreal, Canada

Oct 2000-Sept 2001 DEA in Neuroscience

Université Claude-Bernard Lyon I

Lyon, France

Sept 2001-present $\quad \mathrm{MSc} / \mathrm{PhD}$ Program in Neuroscience

Georg-August Universität

Göttingen, Germany

\section{Scientific projects}

Oct 2000-Sept 2001 Dopamine and noradrenaline in the nucleus accumbens during amphetamine sensitisation in freely moving rats.

Laboratoire de Neuropharmacologie et Neurochimie INSERM U.512, Faculté de Pharmacie. Lyon,France.

Supervisors: Dr. Laura Lambas-Señas and Dr. Julio Morán.

Oct 2002-May 2006 Role of Smad-interacting Protein 1 (Sip1) in the development of the cerebral cortex.

Max Planck Institute for experimental medicine.

MBNS Dept. Prof. Walter Stühmer. Supervisor: Dr. Victor Tarabykin 


\section{Honours/Awards}

1997

Special Mention, UNAM.

$1998-2001$

Telmex Foundation Award.

$1999-2000$

Award for academic exchange. UNAM/McGill University.

$2000-2001$

SEP scholarship

$2001-2002$

Stipend International Max Planck Research School

\section{Employment}

$1996-1998$

Museo Interactivo Infantil Papalote, Mexico City.

Scientific assistance in Biodiversity and Neuroscience.

\section{$\underline{\text { Scientific courses/ Poster presentations }}$}

Jan 2003

Jul-Aug 2003

Oct 2003

Jul 2004

Nov 2004

Feb 2005

May 2005
Scientific communication course

Summer school 2003. "Nurturing the brain"

Riken Brain Science Institute

Saitama, Tokio, Japan

IBRO-UNAM School of Neuroscience 2003

"Development and regeneration"

UNAM, Mexico City, Mexico

\section{FENS}

Lisbon, Portugal

International PhD Symposium "Neurizons".

MPIem, Göttingen, Germany

$30^{\text {th }}$ Göttingen Neurobiology Conference

Göttingen, Germany

Cortical Development Meeting

"From neural stem cells to neural circuits"

Santorini, Greece

\section{Extracurricular activities}

Aug 1998

Organization of the First Scientific Colloquium of the Telmex Foundation, Mexico City. 

world. $\mathrm{MSc} / \mathrm{PhD}$ meeting at Heidelberg University, Germany. Member of the Organization Committee of Neurizons 2004 Neuroscience conference arranged by $\mathrm{PhD}$ students of Göttingen $\mathrm{MSc} / \mathrm{PhD}$ Neuroscience Program

\section{$\underline{\text { Publications }}$}

Amaya Miquelajauregui, Tom Van de Putte, Alexander Polyakov, Eve Seuntjens, Makoto M. Taketo, Yujiro Higashi, Danny Huylebroeck and Victor Tarabykin. "Smad-interacting protein-1 (Sip1/Zfhx1b) acts upstream of Wnt signaling in the control of hippocampus formation in the mouse" (Neuron in review). 
Cause and effect, means and ends, seed and fruit, cannot be severed; for the effect already blooms in the cause, the end preexists in the means, the fruit in the seed.

Ralph Waldo Emerson

“Compensation"(1841) 